\title{
Fitogeografía de Galicia (NW Ibérico): análisis histórico y nueva propuesta corológica
}

\author{
Recibido: 12 Xullo 2008 / Aceptado: 16 Outubro 2008 \\ (C) IBADER- Universidade de Santiago de Compostela 2008
}

\begin{abstract}
Resumen Se revisan las diversas propuestas corológicas que se han ido sucediendo a lo largo del último siglo para el SW Europeo en general y el territorio gallego en particular, así como los fundamentos teóricos sobre los que éstas se sustentan. Teniendo en cuenta el estado actual de los conocimientos sobre flora y vegetación en el extremo NW Ibérico y los efectos que la dinámica paleoambiental reciente (Pleistoceno-Holoceno) y la actividad humana han tenido en este territorio, se propone una nueva sectorización biogeográfica enmarcada en la propuesta más reciente de Rivas-Martínez para la Península Ibérica. Como aportación más novedosa de esta nueva sectorización destaca la inclusión de la totalidad del territorio gallego dentro de la Región Eurosiberiana, desestimándose la existencia de territorios biogeográficamente mediterráneos, tal y como había sido sostenido hasta el momento por numerosos autores.
\end{abstract}

Palabras clave Fitogeografía - unidades biogeográficas . corología $\cdot$ Galicia

Summary The diverse chorological schemes proposed for Galicia (NW Spain) through the last century and the theorical basis on they were founded are re-assesed. For this, we take into account both the present-day state of floristic and vegetation knowledge and the palaeoenviromental reconstructions and the impact of human actvity on vegetation in the NW Iberian area. As a result, a new phytogeographical map fitted into the most recent published by Rivas-Martínez for the Iberian Peninsula is proposed for Galicia. On the contrary of many previous authors, we

\footnotetext{
M.A. Rodríguez Guitián

Dpto. de Produción Vexetal. EPS. USC.

Campus Universitario s/n. Lugo (Galicia)

e-mail: manuelantonio.rodriguez@usc.es

P. Ramil-Rego

Laboratorio de Botánica \& Bioxeografía. USC. IBADER

Campus Universitario s/n. Lugo (Galicia)
}

conclude that all Galician territory must be included into the Eurosiberian Region, although the vegetation of some valleys in the SE area have a strong influence of mediterranean flora.

Key words: Phytogeography · biogeographical units chorology · Galicia

\section{Introducción y objetivos}

La distribución de los taxones vegetales a lo largo de la superficie terrestre permite sectorizar las tierras continentales en áreas geográficas con afinidades florísticas que se organizan en la geobotánica clásica en un sistema jerárquico de unidades (Reino, Región, Provincia, Sector, Distrito, etc.)(Takhtajan 1988). De manera general se admite que los reinos se caracterizan por contener familias, subfamilias y tribus florísticas endémicas, mientras que las regiones se establecen básicamente a partir de la distribución de géneros y especies propios de determinados ámbitos geográficos. A su vez, las provincias se fundamentan en la distribución de determinados géneros poco diversificados (con frecuencia monoespecíficos) así como en combinaciones florísticas específicas que las hacen diferentes de sus territorios vecinos. En la mayor parte de los casos, la delimitación de unidades de rango inferior (sectores, subsectores, distritos) se realiza a partir de la distribución de endemismos infraespecíficos (subespecies, variedades o formas) de distribución restringida o en el dominio geográfico de determinados tipos de comunidades vegetales.

El estudio de las áreas de distribución de los vegetales ha preocupado a los científicos desde los inicios de la propia disciplina botánica, incluso cuando ésta era considerada en algunas escuelas como una rama de la geografía. En consecuencia, a lo largo de la historia de la geobotánica se han realizado un gran número de propuestas de división de las áreas continentales fundamentadas en unidades cuyo número y extensión geográfica ha ido variando en función del grado de conocimiento que en cada momento se tenía 
de la distribución de las estirpes vegetales (cf. Ozenda 1994). Si en los primeros momentos los trabajos corológicos estaban principalmente basados en el conocimiento de la distribución de conjuntos florísticos, en las últimas décadas se ha ido produciendo una progresiva integración de este tipo de información con la procedente de reconstrucciones paleoambientales y la determinación de las repercusiones que la generalización de la actividad humana ha tenido sobre la cubierta vegetal en los diferentes territorios del Planeta. Así, aunque puedan existir deficiencias en el conocimiento detallado de la distribución de las especies que han venido constituyendo la flora de los diferentes territorios, dichas carencias pueden suplirse, hasta cierto nivel de detalle, por la informacion proporcionada por trabajos de basados en técnicas polínicas, antracológicas o, incluso, arqueológicas. No obstante, la propuesta de división corológica que se presenta en este trabajo estará sujeta a cambios y modificaciones, como no podría ser de otra manera, al tratarse de una plasmación gráfica del conocimento científico que se posee en un determinado momento actual. Los avances derivados del tratamiento informático de las bases de datos florísticas y el estudio estadístico de los modelos de distribución de especies, como ya se está realizando en otras partes de España, contribuirán de manera efectiva a su mejora.

Partiendo de este planteamiento, se realiza en el presente trabajo una revisión de las diversas propuestas de sectorización corológica que se han ido sucediendo desde principios del pasado siglo para el territorio europeo en general y el gallego en particular. En dicho análisis se discuten tanto las unidades definidas como los fundamentos sobre los que descansa cada una de las propuestas. Finalmente, teniendo en cuenta el estado actual de conocimentos sobre la distribución de diversos elementos florísticos presentes en Galicia y las tendencias que las reconstrucciones paleoambientales establecen para el territorio noroccidental ibérico a lo largo del último ciclo glaciar, se propone una nueva división fitogeográfica de
Galicia enmarcada en la más recientemente publicada por Rivas-Martínez (2007).

\section{Propuestas corológicas a escala europea}

A pesar de las aportaciones realizadas por un ingente número de botánicos y naturalistas a lo largo del último siglo $y$, en contra de lo que pudiera pensarse, las lagunas de conocimientos sobre la distribución real de las especies vegetales alcanza nuestros días, careciéndose aún de una base de datos completa y actualizada de la distribución de los más de 8.000 taxones que conforman la flora española, lo que dificulta el establecimiento de una sectorización corológica fiable y detallada. Ello no ha impedido, como se verá a continuación, que los botánicos hayan planteado divisiones corológicas de los diferentes territorios de manera sucesiva, desde los albores de la ciencia botáncia hasta la actualidad.

En las primeras sectorizaciones corológicas de Europa ya se establece dentro de su área meridional una división en dos grandes unidades, una de carácter atlánticocentroeuropeo y otra mediterránea, ambas presentes en la Península Ibérica. Tanto para Braun-Blanquet (1923) como para Huguet del Villar (1927) la franja cantábrica, junto a las áreas atlántica gallega y norportuguesa, conforman una unidad caracterizada por el dominio de la flora adaptada al clima oceánico que se plasma, desde el punto de vista fisionómico, en la constitución de bosques planocaducifolios, matorrales de ericáceas y leguminosas y una abundante presencia de turberas en el paisaje (Figura 1). Hacia el Sur, las formaciones arboladas de carácter esclerófilo y los matorrales dominados por cistáceas y labiadas se adueñarían de la cubierta vegetal.

Como aportación novedosa a este planteamiento dual, Meusel (1964) añade en la segunda mitad del siglo XX la propuesta de una tercera unidad de carácter transicional (submediterránea), intercalada entre las dos anteriores y de

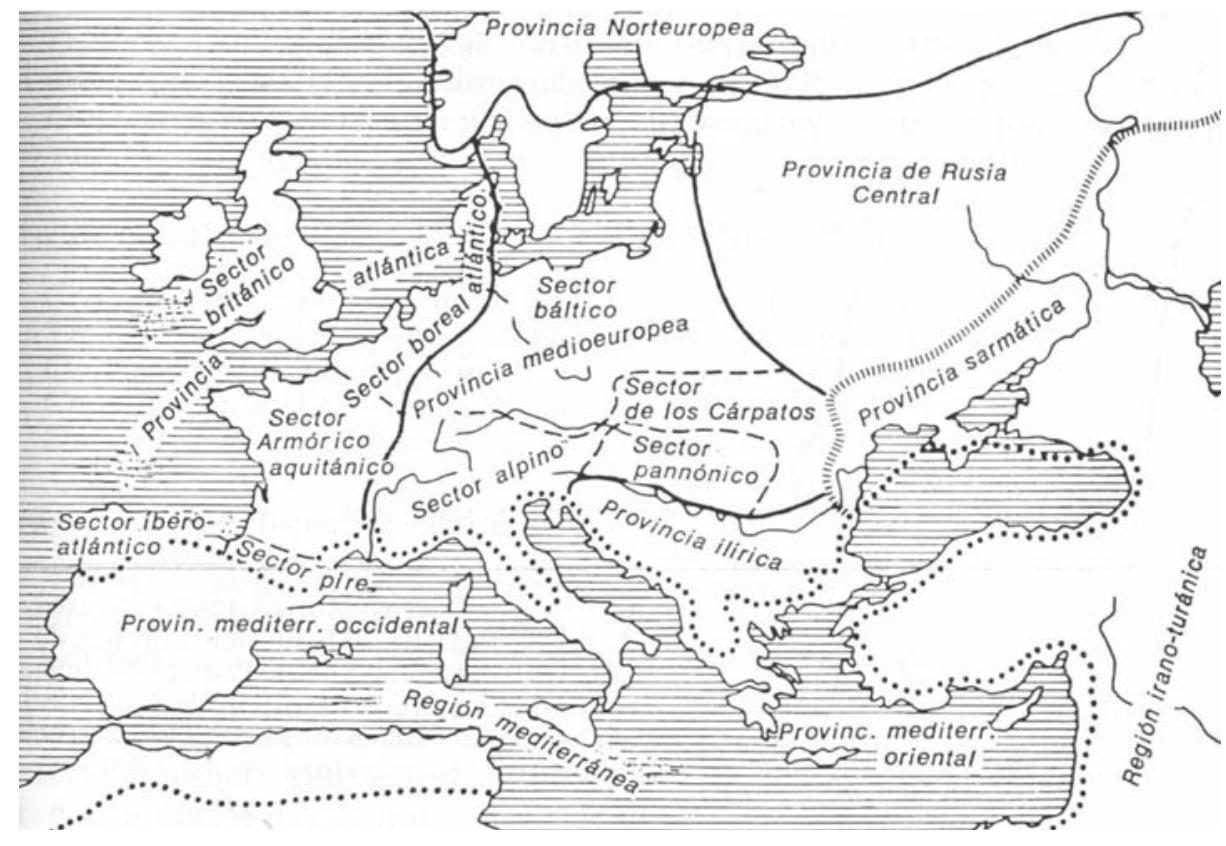

Figura 1.- Delimitación de territorios florísticos y de vegetación de Europa según Braun-Blanquet (1923) 
distribución latitudinal europea, caracterizada por la mezcla de taxones mediterráneos con otros de carácter atlántico en la parte occidental, con especies centroeuropeas en su porción media y con otras pónticas e irano-turánicas en su extremo oriental (Figura 2). Dicha unidad comprendería una parte sustancial de los territorios ibéricos considerados por autores precedentes como de carácter atlántico, así como diversos macizos montañosos cubiertos por grandes masas de bosques caducifolios, tales como la Cordillera Cantábrica o los Pirineos. Esta propuesta se mantuvo con ligeras modificaciones en obras posteriores (cf. Meusel et al. 1965, Figura 3) y ha influido en las interpretaciones de otros autores europeos e ibéricos (cf. Figuras 9 y10).

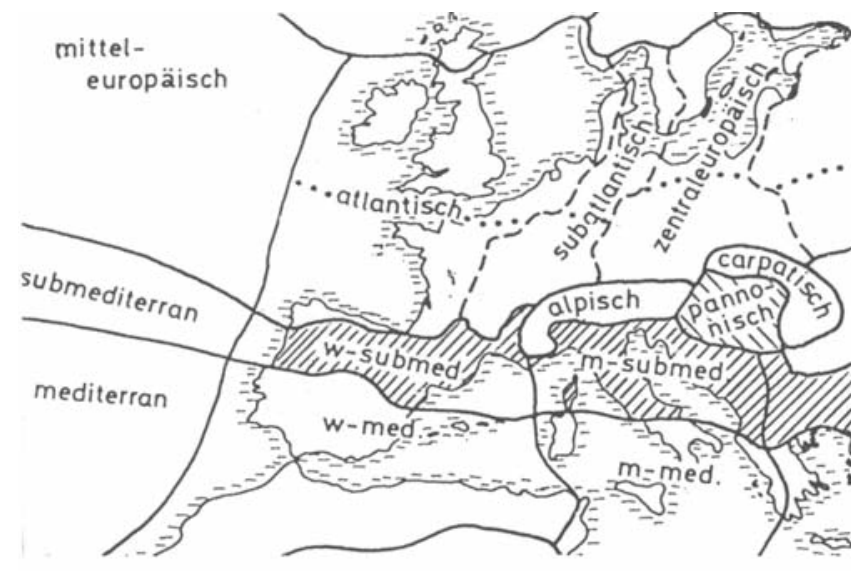

Figura 2.- División florística de Europa según Meusel (1964), en la que se individualiza una cintura "submediterránea" que se extiende de manera contínua desde las costas del $\mathrm{N}$ de Portugal hasta el margen occidental del Mar Negro

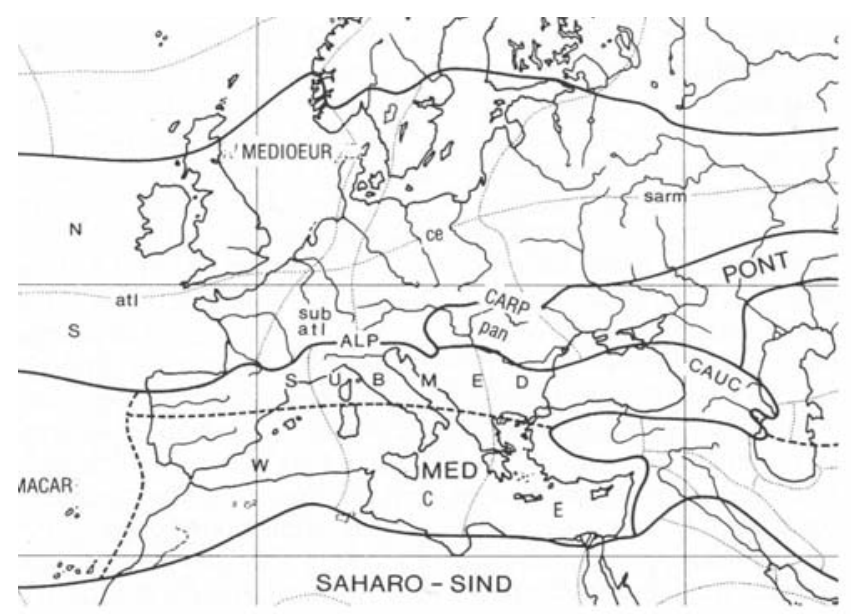

Figura 3.- Regiones florísticas de Europa y África del $\mathrm{N}$ según Meusel et al. (1965)

Un trabajo que ha tenido gran trascendencia en los estudio geobotánicos modernos del $\mathrm{W}$ europeo ha sido el estudio monográfico del elemento florístico que define la Provincia o Dominio Atlántico publicado por Dupont (1962). Según este autor, esta unidad geobotánica estaría caracterizada por albergar los principales núcleos poblacionales de diversos taxones poco o nada tolerantes a los climas centroeuropeos, con inviernos rigurosos, pero también incompatibles con los prolongados períodos de sequía estival que caracterizan el área mediterránea (Tabla 1). Dupont hace hincapié, además, en la necesidad de profundizar en el estudio de las áreas de distribución de otros muchos vegetales de corología insuficientemente conocida que podrían ayudar a perfilar con mayor exactitud esta provincia, a la vez que plantea sus dudas sobre la condición atlántica de un tercer grupo de especies.

A partir de este análisis, Dupont propone una delimitación del Dominio Atlántico coincidente, en su mayor parte, con la opinión mostrada por autores precedentes. Sin embargo, plantea una reducción apreciable de este territorio en el ámbito noroccidental ibérico (Figura 4), excluyendo gran parte del centro de Portugal y las sierras galaicozamoranas, a la vez que perfila una penetración mediterránea en Galicia a través de las cuencas bajas de los rios Sil y Miño.

Años más tarde, en contra de lo planteado por Dupont y autores anteriores, Mayer (1984) establece una división forestal de Europa en la que los territorios peninsulares de la cuenca del Duero serían afines a los del resto de Europa occidental, mientras que la mayor parte de los Pirineos se ubicarían en la región sureuropea, junto a otras áreas perimediterráneas y gran parte de las costas de África del Norte (Figura 5). En este contexto, Rivas-Martínez (1987) propone en su sectorización del SW de Europa un esquema en el que se conjugan criterios seguidos por Dupont en la delimitación de los territorios atlánticos y mediterráneos en el cuadrante NW ibérico con la independización de la cadena pirenaica, junto con el Macizo Central francés y los Alpes, entre otros territorios, dentro de una unidad de carácter centroeuropeo (Figura 6). Según este esquema, Galicia quedaría compartimentada en tres provincias corológicas, dos de clara influencia oceánica (CántabroAtlántica y Orocantábrica) y la tercera (Carpetano-lbéricoLeonesa) de tendencia mediterránea.

Volviendo a los autores no españoles, las representaciones cartográficas del continente que se sucedieron en los últimos años del pasado siglo muestran la persistencia de divergencias en los criterios aplicados para la delimitación de grandes unidades, en especial en los paises del entorno mediterráneo y en concreto para el caso del NW Ibérico. Mientras que Takhtajan (1988) mantiene posiciones restrictivas próximas a las ya comentadas de Dupont (1962) en la delimitación de su provincia Atlántico-Europea (Figura 7), Polunin \& Walters (1989) van más allá de lo opinado por Mayer (1984) e incorporan al dominio de los bosques caducifolios de influencia oceánica (Provincia Altlántica) las áreas montañosas del Sistema Central y sector culminante del Ibérico (Macizo del Moncayo), además de la totalidad del territorio gallego, $\mathrm{N}$ de Portugal y arco montañoso galaico-zamorano-leonés (Sanabria, Cabrera, Teleno, Montes de León), dentro de los que, a modo de isleo, se encontraría el área del Bajo Sil dominada por vegetación esclerófila mediterránea (Figura 8).

Una tercera fórmula es la adoptada años más tarde por Ozenda (1994), que podría considerarse como una continuación de la "cintura submediterránea" sostenida por 


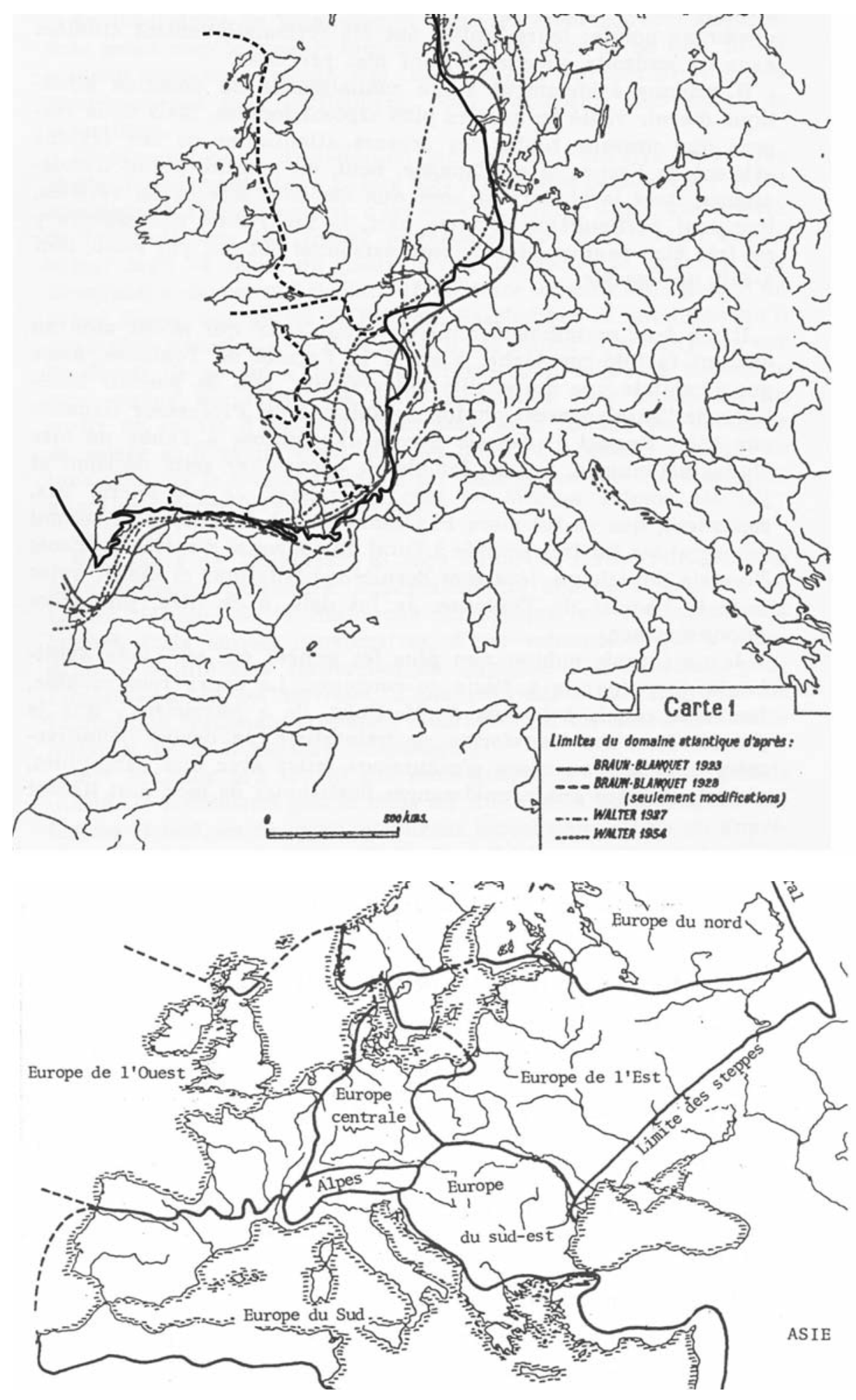

Figura 4.- Delimitación del "Dominio Atlántico Europeo" según diversos autores y propuesta de Dupont (adaptado de Dupont 1962). En trazo negro grueso, límite y divisiones internas de esta unidad biogeográfica propuestas por este autor
Meusel (1964) y Meusel et al. (1965), aunque con ciertos matices, ya que para este autor estas áreas transicionales deberían incluirse dentro de unidades biogeográficas de carácter mediterráneo (Figura 9).

La discrepancia entre los autores europeos e ibéricos sobre la delimitación e interpretación corológica de determinados territorios del centro y sur de Europa se mantiene hasta fechas recientes, tal y como pone de manifiesto la cartografia de provincias realizada por Rivas-Martínez \& Penas (1996), para quienes gran parte de las áreas continentales ribereñas del Mar del Norte serían centroeuropeas, a pesar de haber sido contempladas como integrantes del dominio atlántico de manera reiterada por numerosos autores más norteños (Figura 10). Por otra parte, se incorporan a esta última unidad corológica las 


\begin{abstract}
Taxones euatlánticos.
Allium ericetorum, Angelica pachycarpa, Angelica razulii, Anthirrhinum meonanthum, Anthoxanthum amarum, Armeria pubigera, Armeria pubinervis, Asparagus prostratus, Baldellia alpestris, Brassica olerace, Cardamine raphanifolia, Carex durieui, Carex trinervis, Caropsis verticillato-inundata, Centaurium chloodes, Centaurium scilloides, Ceratocapnos claviculata, Cirsium filipendulum, Crepis lampsanoides, Crocus salzmannii, Cytisus cantabricus, Cytisus commutatus, Daboecia cantabrica, Deschampsia setacea, Dianthus hyssopifolius, Dryopteris aemula, Erica mackaiana, Erica vagans, Eryngium viviparum, Euphorbia hyberna, Genista berberidea, Genista florida, Genista occidentalis, Halimium alyssoides, Hyacinthoides non-scripta, Iris latifolia, Koeleria glauca, Lasepitium dufourianum, Linaria arenaria, Meconopsis cambrica, Narcissus asturiensis, Narcissus cyclamineus, Omphalodes littoralis, Omphalodes nitida, Pentaglottis sempervirens, Petrocoptis viscosa, Peucedanum gallicum, Peucedanum lancifolium, Potentilla montana, Pritzelago auerswaldii, Ranunculus omyophyllus, Rumex biformis, Rumex rupestris, Sagina merinoi, Saxifraga hirsuta, Saxifraga lepismigena, Saxifraga spathularis, Saxifraga trifurcata, Scilla verna, Senecio legionensis, Senecio nemorensis, Serratula seoanei, Spergularia rupicola, Thymelaea coridifolia, Thymus caespititius, Ulex micranthus, Ulex minor, Valeriana pyrenaica, Vicia orobus, Viola lactea
\end{abstract}

\section{Taxones subatlánticos.}

Agrostis curtisii, Agrostis durieui, Anarrhinum duriminum, Arabis scabra, Arenaria montana, Avenula sulcata, Carduus carpetanus, Carex binervis, Carex laevigata, Carum verticillatum, Centaurea limbata, Chamamelum nobile, Cistus psilosepalus, Cochlearia danica, Conopodium majus, Cytisus striatus, Digitalis purpurea, Erica ciliaris, Erica cinerea, Erica erigena, Erica tetralix, Erica umbellata, Euphorbia portlandica, Genista anglica, Genista micrantha, Helleborus occidentalis, Hypericum elodes, Hypericum linarifolium, Hypericum pulchrum, Iberis procumbens, Lathrea clandestina, Lepidium heterophyllum, Lepidophorum repandum, Linaria elegans, Linaria triornithophora, Lithodora diffusa, Lithodora prostrata, Lobelia urens, Narthecium ossifragum, Pinguicula grandiflora, Pinguicula lusitanica, Polygala serpyllifolia, Prunela hastifolia, Pseudoarrhenatherum longifolium, Pterospartum tridentatum, Scirpus germanicus, Scrophularia scorodonia, Scutellaria minor, Selinum broteri, Senecio adonidifolius, Senecio aquaticus, Succisa pinnatifida, Teucrium pyrenaicum, Tuberaria globularifolia, Ulex gallii, Wahlenbergia hederacea

\section{Taxones insuficientemente conocidos (probablemente subatlánticos).}

Aira caryophyllea subsp. multiculmis, Aira praecox, Ammophilla arenaria subsp. arenaria, Aquilegia vulgaris subsp. dichroa, Carex arenaria, Centaurea nigra subsp. nigra, Chrysosplenium oppositifolium, Fumaria muralis, Galium saxatile, Jasione laevis, Narcissus pseudonarcissus subsp. pseudo narcissus, Ornithopus sativus, Phyteuma orbiculare subsp. tenerum, Ranunculus bulbosus var. gallaecicus, Ranunculus ololeucos, Ribes rubrum, Salix repens, Silene uniflora subsp. uniflora, Tamarix gallica, Tragapogon pratensis subsp. minor, Ulex europaeus subsp latebracteatus, Ulex europaeus subsp. europaeus, Valeriana repens

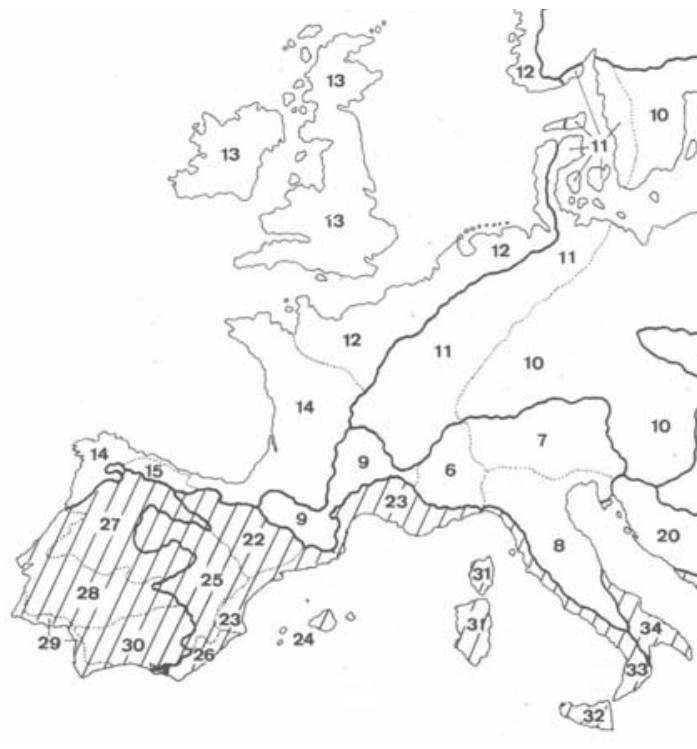

Figura 7.- Provincias florísticas de Europa, Asia Menor y Cáucaso según Takhtajan (1988). 1: Ártica; 2: Atlántico-Europea; 3: Centroeuropea; 4: llírica (Balcánica): 5: Euxínica; 6: Caucásica; 7: Oriental Europea; 8: Norteeuropea; 9: Siberiana Occidental; 10: Mediterránea Suroccidental; 11: Ibérica; 12: Baleárica; 13: Liguro-Tirrénica; 14: Adriática; 15: Mediterránea Oriental; 16: Crimeano-Novorossiyskánica; 17: Hyrcánica; 20: Turánica (Aralo-Cáspica); 21: Mesopotámica
Figura 6.- Unidades biogeográficas del SW

Europeo según Rivas-Martínez (1987)
Tabla 1.-

Clasificación corológica de taxones de distribución atlántica según Dupont (1962)

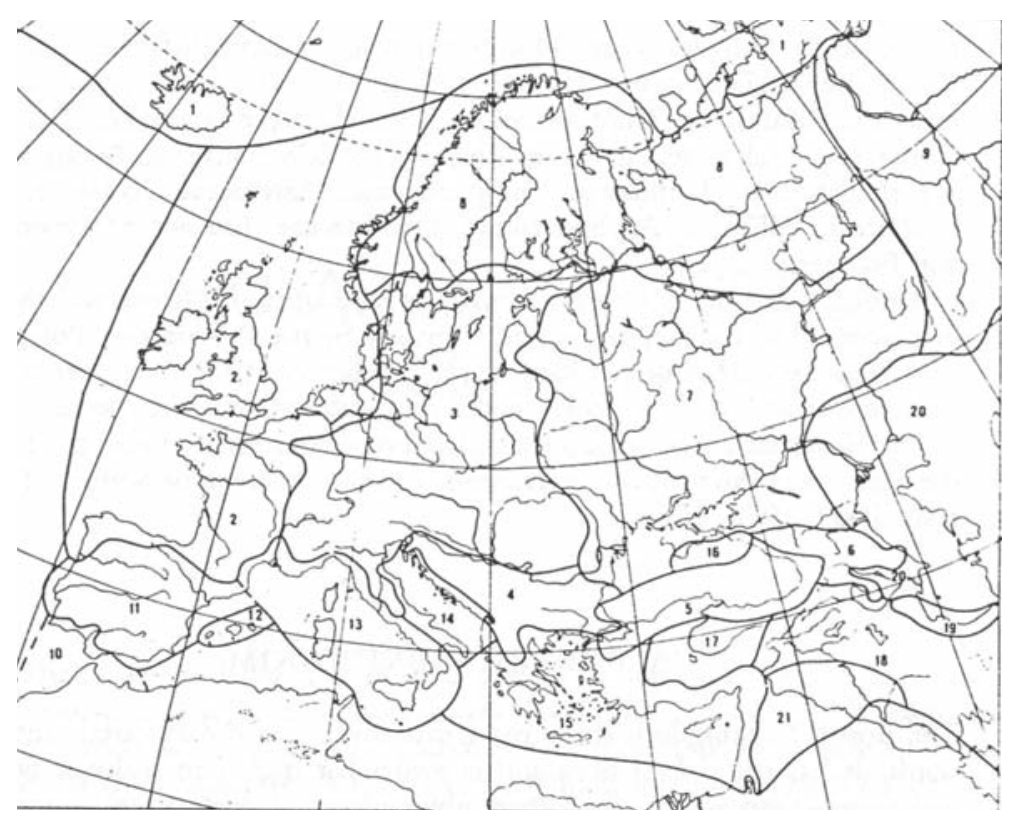




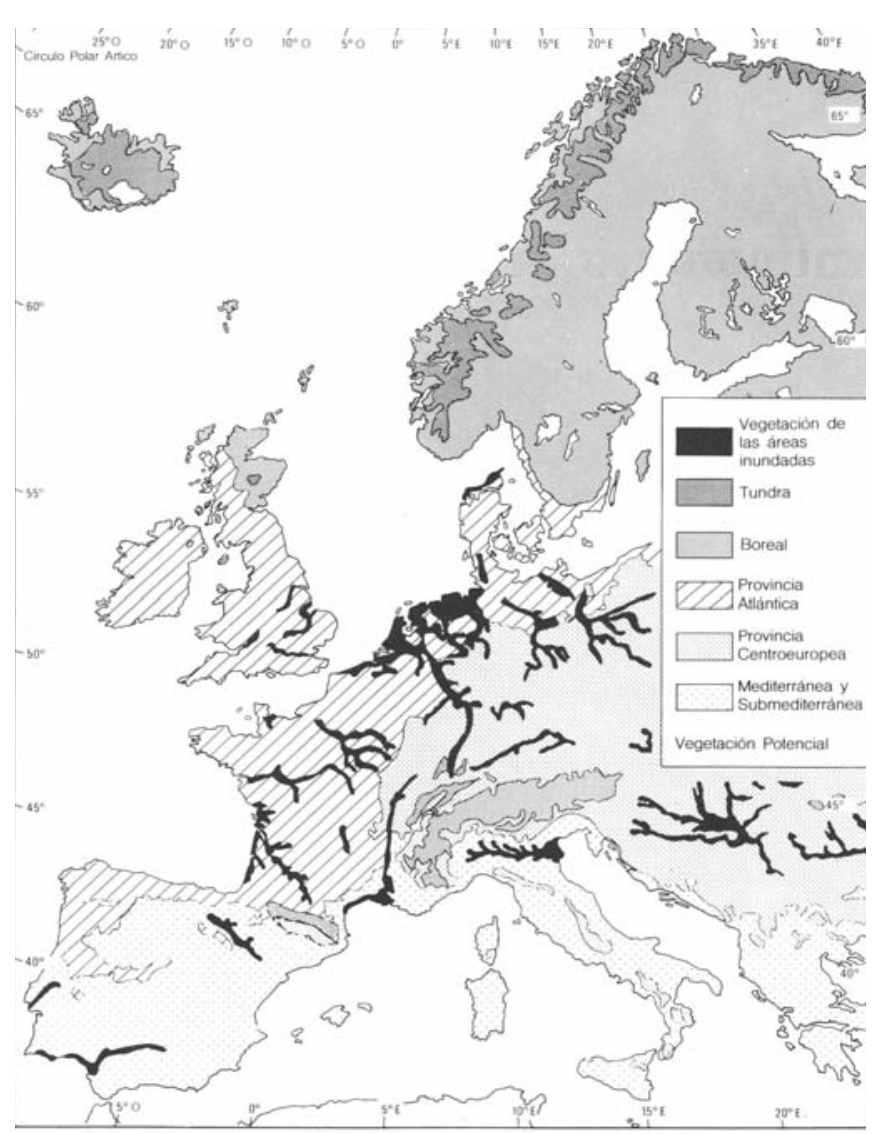

Figura 8.- Mapa de vegetación natural de Europa basado en regiones climáticas (Polunin \& Walters 1989)

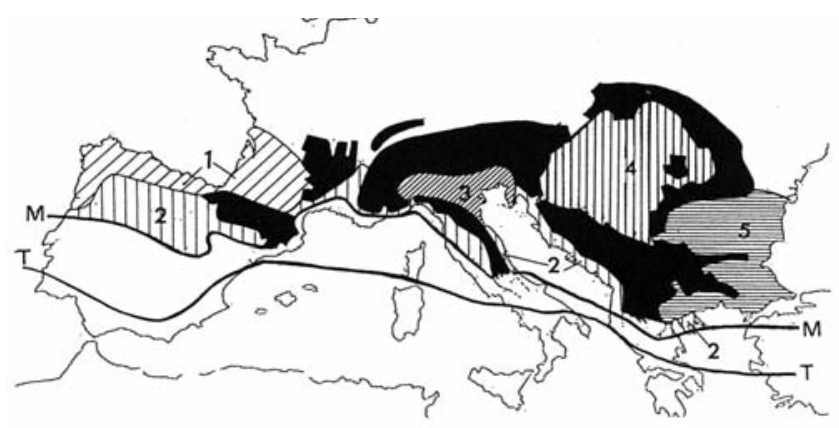

Figura 9.- Divisiones geobiológicas de Europa Meridional de Ozenda (1994). En negro, cadenas del sistema alpino; T: límite norte de la cintura termomediterránea, M: límite norte de la cintura mesomediterránea; 1: Sector Termoatlántico; 2: Dominio submediterráneo; Dominio termonemoral: 3: Llanura del Po; 4: Depresión Panónica; 5: Cuenca baja del Danubio y llanura Búlgara

montañas de Sanabria, tradicionalmente incluidas por Rivas-Martínez en territorios mediterráneos ibéricos.

Esta última interpretación se refuerza en las últimas versiones de la tipología corológica publicada por este último autor (Figura 11), llegando al punto de admitir como áreas bajo clima templado la totalidad del arco montañoso que rodea por el E la hoya berciana así como la totalidad de las áreas montañosas del interior ibérico situadas en la mitad septentrional de la Península Ibérica (sierras de

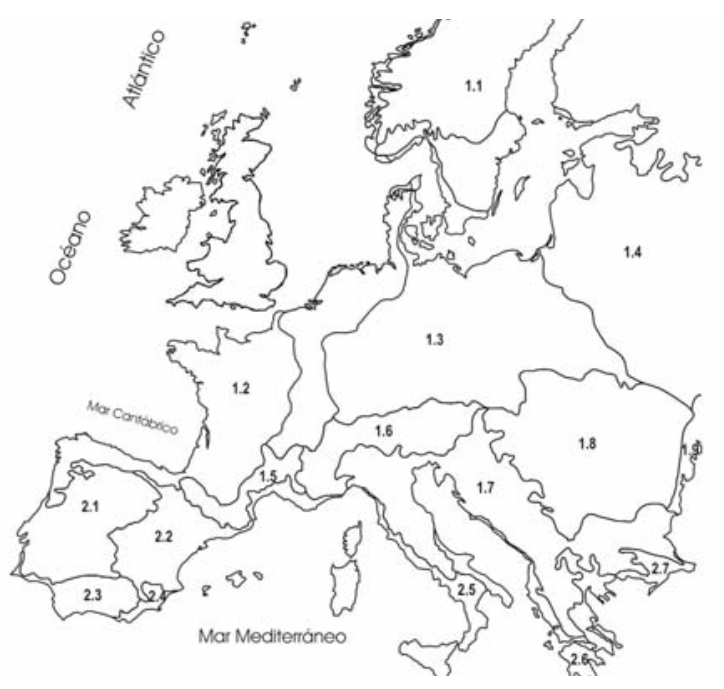

Figura 10.- Tipología biogeográfica de Europa (provincias) según Rivas-Martínez \& Penas (1996). Unidades: 1: Región Eurosiberiana. 1.1.: Provincia Boreal Europea; 1.2; Provincia Atlántica Europea; 1.3: Provincia Medioeuropea; 1.4: Provincia Sarmática; 1.5: Provincia Pirenaico-Cevenennse; 1.6: Provincia Alpina; 1.7: Apenino-Balcánica; 1.8: Provincia Panónico-Carpática; 1.9: Provincia Escítica; 2.1: Provincia Ibero-atlántica; 2.2.: Provincia Ibero-Levantina; 2.3: Provincia Bética; 2.4: Provincia Murciano-Almeriense; 2.5: Provincia Italo-Tirrénica; 2.6: Provincia Adriática; 2.7: Provincia Greco-Aegéica

Estrela, Gata, Gredos, Guadarrama, Ayllón, Moncayo, Cuenca, Javalambre y Gúdar).

A efectos de la constitución y puesta en práctica de la Red Ecológica Europea Natura 2000, la Comisión Europea ha tomado como referencia para la elaboración de los listados de hábitats y especies de interés la cartografía de grandes unidades biogeográficas que se muestra en la Figura 12. Dicho mapa ha sido elaborado por la Agencia Ambiental Europea, dependiente del Centro Temático Europeo, a partir de diversas fuentes cartográficas publicadas previamente, tanto por administraciones estatales como por organismos comunitarios. Dicha división territorial se utiliza para, entre otras finalidades, el establecimiento de las cuotas (\% sobre el total) que cada país debe aportar para garantizar la conservación de cada uno de los hábitats considerados de interés en función de la representatividad espacial que alcanzan en los diferentes estados miembros. Aunque a lo largo del proceso de puesta en marcha de dicha red de espacios naturales, iniciado en 1992, se ha ido produciendo una adaptación de la delimitación de las unidades biogeográficas citadas en diversas áreas de Europa, en el caso de España ha permanecido inalterada desde la propuesta inicial, en la que se tomó como referencia para la delimitación de las regiones biogeográficas Atlántica, Mediterránea y Alpina los límites establecidos por RivasMartínez en su Mapa de Series de Vegetación de España (Rivas-Martínez 1987). Esto ha provocado un desajuste con respecto a las últimas versiones corológicas publicadas por este autor y plantea problemas relativos a la consideración que deben tener (atlánticos o mediterráneos) un cierto número de Lugares de Importancia Comunitaria (LIC) y Zonas de Especial Protección para las Aves (ZEPA) 


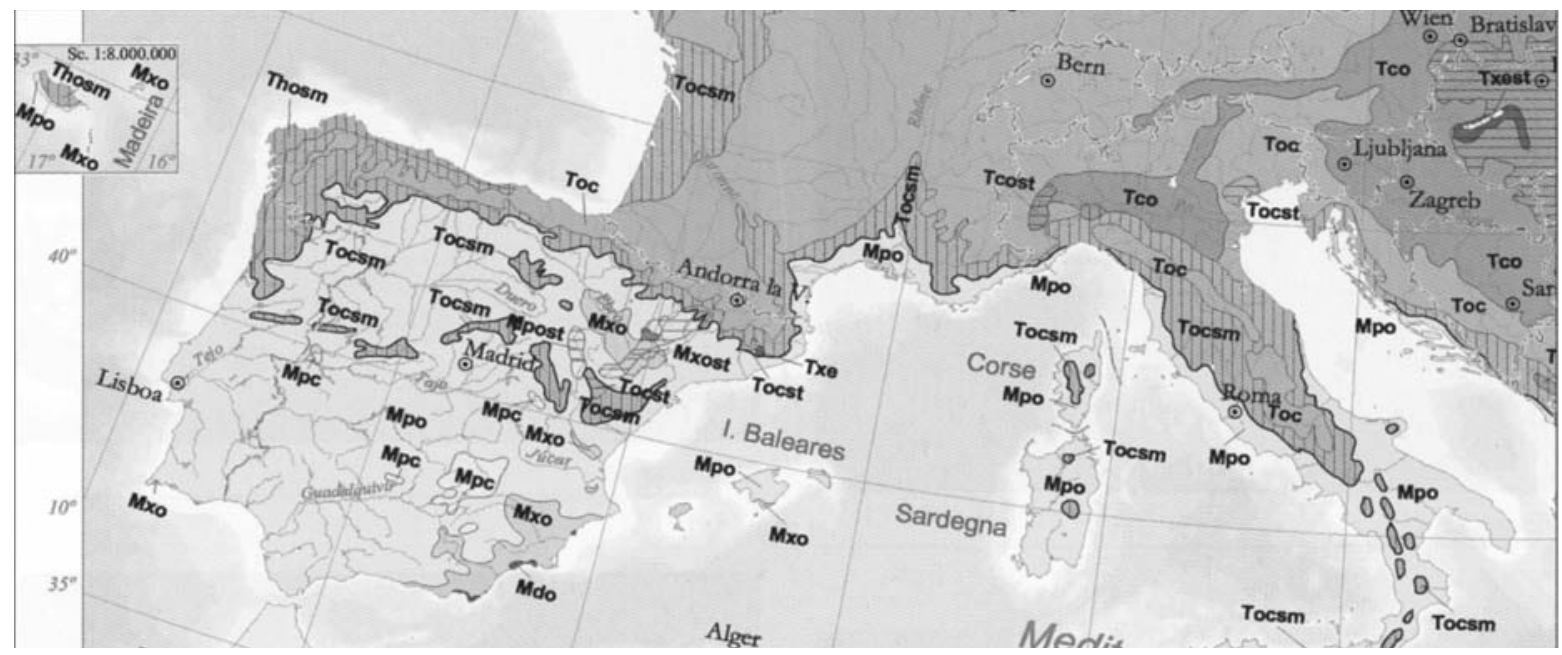

Figura 11.-Macroclimas, bioclimas y variantes del centro-oeste de Europa (Rivas-Martínez 2001). M: macrobioclima mediterráneo; C: continental; D: desértico; P: pluviestacional; St: estépico; X: xérico. T: macrobioclima templado; Co: continental; Ho: hiperoceánico; Oc: oceánico; Sm: submediterráneo; St: estépico; Xe: xérico

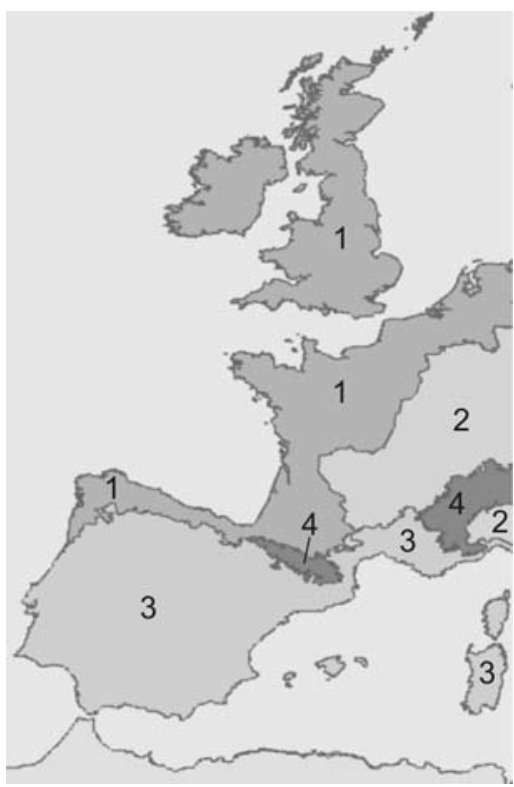

Figura 12.-Vista parcial de la versión 2001 del Mapa de Regiones Biogeográficas adoptado por la Agencia Ambiental Euroea (EEA) utilizada en la puesta en marcha y gestión de la Red Natura 2000

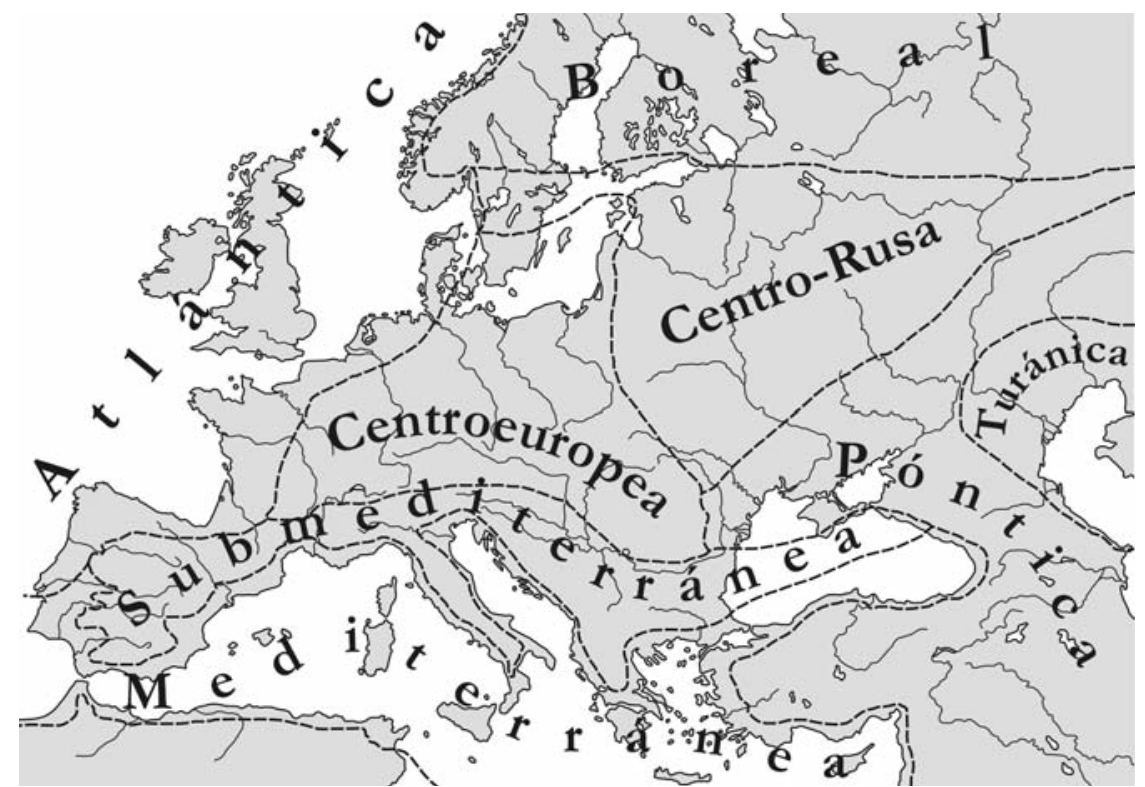

Figura 13.-Regiones florísticas de Europa según Frey \& Lösch (2004)

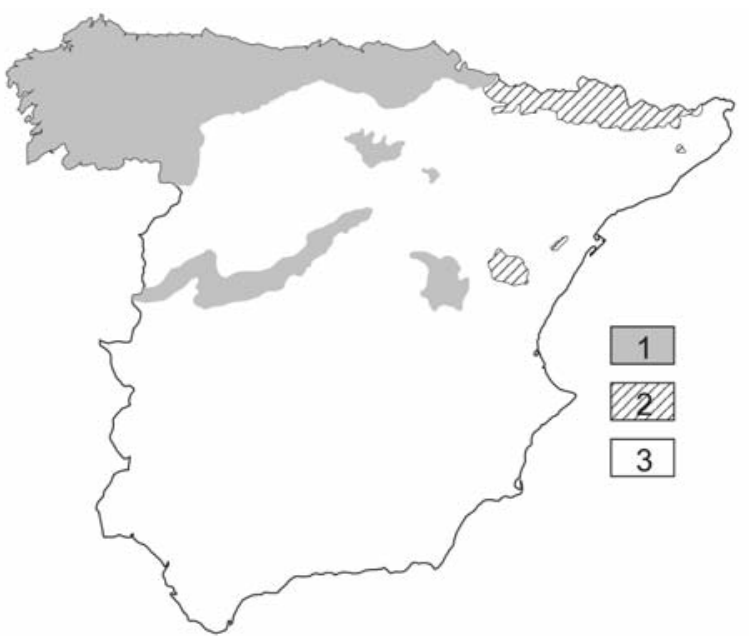

Figura 14.-Regiones y dominios florales de la España peninsular según Lacoste \& Salanon (1973). 1: dominio atlántico-europeo; 2: dominio submediterráneo; 3: Región Mediterránea 
localizados en territorios que han registrado un cambio de adscripción corológica en los últimos años.

La sectorización utilizada por la Comisión Europea tampoco es compartida por autores de otros países europeos, que proponen unidades sensiblemente diferentes a las utilizadas por esta institución. Para ilustrar esta situación sirva la cartografía de regiones florísticas publicada recientemente por Frey \& Lösch (2004), en la que se mantiene la propuesta ya comentada de Meusel de considerar una Región Submediterránea interpuesta entre las regiones Atlántica y Centroeuropea y la propiamente Mediterránea (Figura 13). Según dichos autores, esta unidad transicional se extendería ininterrumpidamente en Europa por las áreas ribereñas del Mar Mediterráneo de España, Francia, Italia, Croacia, Bosnia-Herzegovina, Serbia, Montenegro, Albania y Grecia. Además, esta unidad biogeográfica comprendería territorios bajos próximos a las costas atlánticas del $\mathrm{S}$ de Portugal, del Mar Negro en Ucrania, Rusia y Georgia, y ribereños del Mediterráneo de países norsaharianos como Marruecos, Argelia, Túnez, Libia y Egipto.

\section{Contextualización a escala ibérica}

El establecimiento de las unidades corológicas presentes en la Península Ibérica ha recorrido un camino tortuoso parejo al comentado para el continente europeo, en gran medida agravado por la inexistencia de información detallada sobra la distribución de taxones con valor diagnóstico desde el punto de vista corológico. A lo largo del siglo XX se han ido sucediendo algunas propuestas realizadas por autores europeos, cuyo limitado conocimiento de la geobotánica peninsular se deja traslucir en la delimitación de los dominios propuestos. Es el caso de Lacoste \& Salanon (1973), quienes proponen, en la línea de lo comentado en apartados anteriores, la existencia de dos dominios florísticos (atlántico-europeo y submediterráneo) dentro de las áreas eurosiberianas de la Península Ibérica junto al predominio de los territorios asignables a la Región Mediterránea (Figura 14).

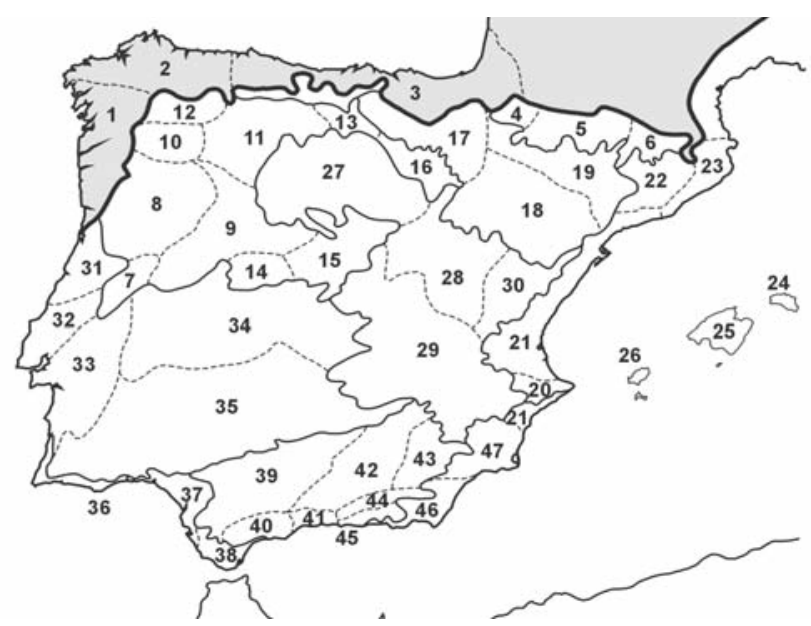

Figura 15.- Sectores corológicos de la Península Ibérica y Baleares según Rivas-Martínez (1973). En sombreado gris, unidades eurosiberianas
Dejando a un lado las interpretaciones realizadas a lo largo del siglo XX por autores no ibéricos y las descripciones biogeográficas de carácter general de algunos botánicos españoles, los primeros esbozos corológicos de detalle se realizaron bien entrada la segunda mitad de este período, correspondiendo la primera delimitación de provincias y sectores florísticos a Rivas-Martínez (1973). Llama la atención, tanto en esta propuesta (Figura 15) como en otras publicadas en trabajos posteriores (Rivas-Martínez et al. 1977; Rivas-Martínez 1979), la exclusión de las áreas eurosiberianas de todo el conjunto de elevaciones montañosas que conforman las Montañas GalaicoZamorano-Leonesas, Cordillera Cantábrica y Pirineos y la tendencia que se registra a restringir progresivamente los territorios eurosiberianos, que estarían integrados exclusivamente en la delimitación de 1979 por los territorios litorales y sublitorales de las costas cántabro-atlánticas españolas y una pequeña porción del $\mathrm{N}$ de Portugal. En esta última propuesta, alrededor de $1 / 3$ de la superficie de Galicia se adscribe a unidades de carácter mediterráneo (Figura 16, unidades num. 26, 27 y 28), quedando repartido el resto entre los sectores 2 , al $\mathrm{N}$, y 1 , hacia el SW.

En el año 1978 Bellot publica una revisión de la vegetación de la Península Ibérica acompañada de un mapa fitogeográfico (Figura 17) en el que llama la atención el criterio "cuasi-administrativo" aplicado para la delimitación de algunas unidades, como las denominadas "AsturLeonesa", "Galicia y Norte de Portugal" o "LusoExtremadurense". Según este autor, existirian notables diferencias entre la segunda de las unidades citadas, que incluiría Galicia, y sus vecinas "Submeseta Norte" y "LusoExtemadurense" centradas en la ausencia de estas últimas de los robledales de Quercus robur característicos de la primera y el dominio de los bosques de $Q$. pyrenaica y $Q$.ilex subsp. ballota.

Entrada ya la década de los ‘80, Rivas-Martínez (1982) propone una modificación de la división territorial publicada unos años atrás, especialmente en lo concerniente a la delimitación y sectorización de las áreas eurosiberianas (Figura 18). El autor comentado adopta un cambio de

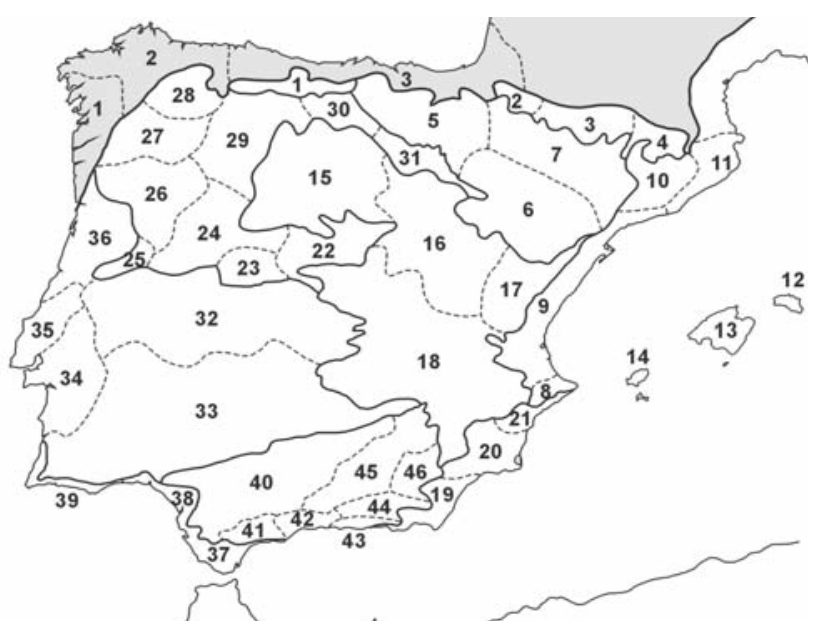

Figura 16.- Sectorización biogeográfica de la Península Ibérica y áreas limítrofes según Rivas-Martínez (1979). En sombreado gris, unidades eurosiberianas 


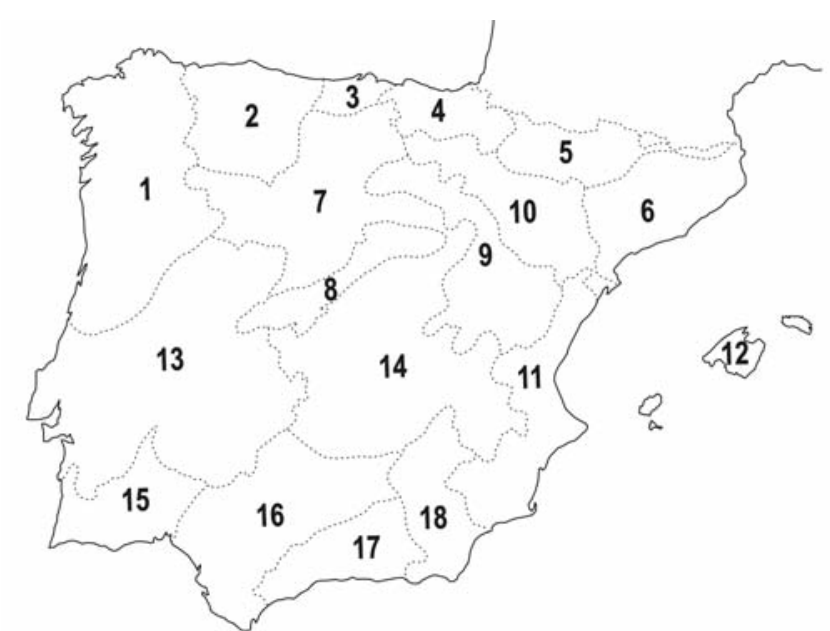

Figura 17.- Sectorización fitogeográfica de la Península Ibérica y Baleares seguida por Bellot (1978). 1: Galicia y Norte de Portugal; 2: Astur-Leonesa; 3: Cantabria; 4: Pais Vasco-Navarra; 5: Pirineos; 6: Cataluña; 7: Submeseta Norte; 8: Cordillera Central; 9: Cordillera Ibérica; 10: Valle del Ebro; 11: Valencia y Murcia; 12: Baleares; 13: Luso-Extremeña; 14: Submeseta Sur; 15: Valle del Guadiana; 16: valle del guadalquivir; 17: Granada y Málaga; 18: Sierra de Segura y Almeria

criterio que se va a mantener en sus sucesivas "aproximaciones" corológicas de la Península Ibérica y engloba la mayor parte de las montañas galaico-cantábricas y pirenaicas en sendas unidades particulares incluidas en la Región Eurosiberiana (Figura 19). Para el caso del territorio gallego, esta modificación supone que las montañas de $\mathrm{A}$ Fonsagrada, Ancares y O Courel, junto con las sierras que conforman la cabecera de las cuencas de los ríos Sil y Narcea (Muniellos, Degaña, Laciana, Omañas), pasan a formar parte de la unidad denominada Sector LacianoAncarense.

A partir de esta fecha y hasta nuestros días, Rivas-Martínez ha ido actualizando progresivamente los límites de las unidades corológicas, principalmente de aquellas que configuran el límite de las regiones Eurosiberiana y Mediterránea, entre las que se encuentran varias que incluyen territorios de Galicia. Dentro de éstas, quizás la que se ha mantenido durante un tiempo más prolongado y ha tenido una mayor repercusión en el ámbito de la gestión forestal y la divulgación y docencia de la disciplina botánica en España haya sido la sectorización corológica peninsular contenida en la Memoria del Mapa de Series de Vegetación de España E 1:400.000 (Rivas-Martínez 1987) (Figura 20). Como se ha comentado anteriormente, dicha cartografía ha tenido una trascendencia particular en lo relativo a la confección de Mapa de Regiones ecológicas de la Unión Europea, dado que ha sido utilizado como referencia en cuanto a la delimitación de las areas eurosiberianas en la Península Ibérica.

El proceso de delimitación y jerarquización de las unidades corológicas del SW Europeo por parte de Rivas-Martínez ha ido paralelo al desarrollo de su "Clasificación Bioclimática Mundial", de la que se han publicado numerosas "aproximaciones". En la actualmente vigente (RivasMartínez 2007) se ha verificado un cambio en la

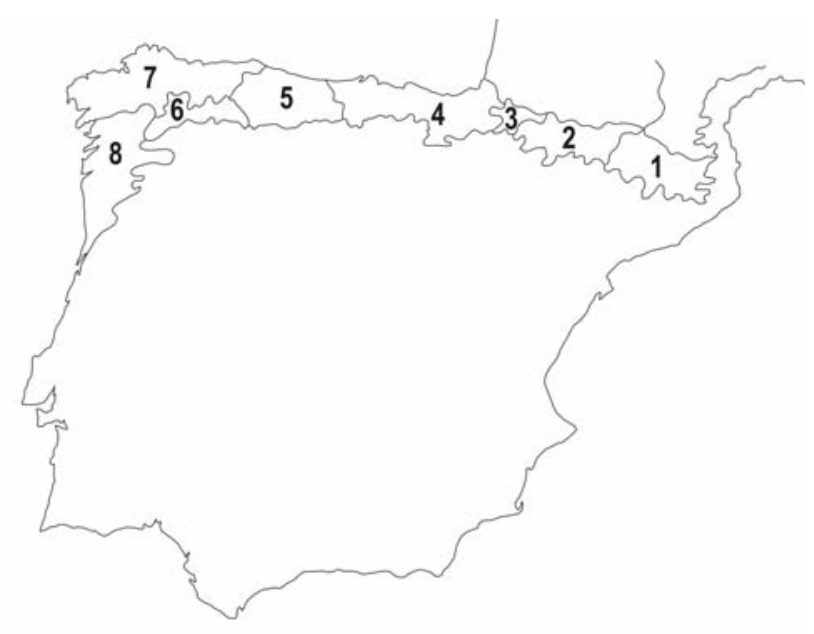

Figura 18.- Redelimitación de las unidades biogeográficas eurosiberianas ibéricas propuesta Rivas-Martínez (1982, redibujado)

interpretación de la condicion bioclimática de gran parte de las áreas de montaña del interior septentrional español, que han pasado en los últimos años a considerarse como "islas" sometidas a la variante "submediterránea" del bioclima templado, en el seno de áreas de bioclima mediterráneo (cf. Rivas-Martínez et al. 2002), planteamiento que recuerda criterios utilizados con anterioridad por autores centroeuropeos, como Braun-Blanquet (1923) o Polunin \& Walters (1989). Sin embargo, este hecho no ha encontrado una correspondencia desde el punto de vista corológico, ya que en la mayor parte de los casos no se otorga un tratamiento especial a estas áreas que, en general se acomodan al esquema de unidades previamente establecido (cf. Rivas-Martínez et al. 2002)(Figura 21).

Simultáneamente a las propuestas corológicas de RivasMartínez, fundamentadas principalmente en la distribución de tipos de comunidades vegetales y de series de vegetación, otros autotes han analizado las peculiaridades florísticas de la Península Ibérica a través del estudio de la distribución de grupos de vegetales concretos. Así, a partir del examen del reparto geográfico de los helechos peninsulares, Salvo Tierra (1990) establece la existencia de siete sectores pteridogeográficos cuya delimitación aparece reflejada en la Figura 22. Según los criterios de este autor, la Península Ibérica estaría repartida fundamentalmente en dos grandes unidades, los sectores Ibero-Submediterráneo e Ibero-Eumediterráneo, alrededor de los cuales se dispondrían las cinco unidades restantes: Cornisa Cantábrica, Cordillera Cantábrica y Cordillera Pirenaica, al N, Sierras de Sintra y Mafra al W y Sierras de Algeciras en el extremo meridional.

Otros botánicos se han centrado en la distribución de las angiospermas endémicas de la Península Ibérica. Partiendo de un estudio centrado en las dicotiledóneas, Sáinz Ollero \& Hernández Bermejo (1981) proponen una sectorización ibérica (Figura 23) que, años más tarde ha servido a estos autores para justificar sus resultados en un nuevo trabajo (Sáinz Ollero \& Hernández Bermejo 1985), en este caso realizado sobre las monocotiledóneas endémicas (Figura 24). En dicha división corológica, se establecen seis 


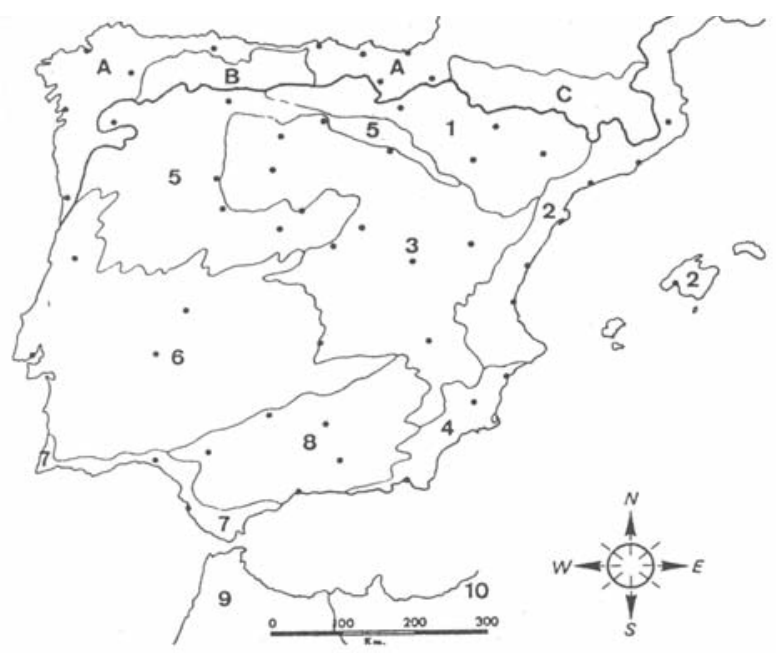

Figura 19.- Redelimitación de las unidades biogeográficas eurosiberianas ibéricas propuesta Rivas-Martínez en 1985

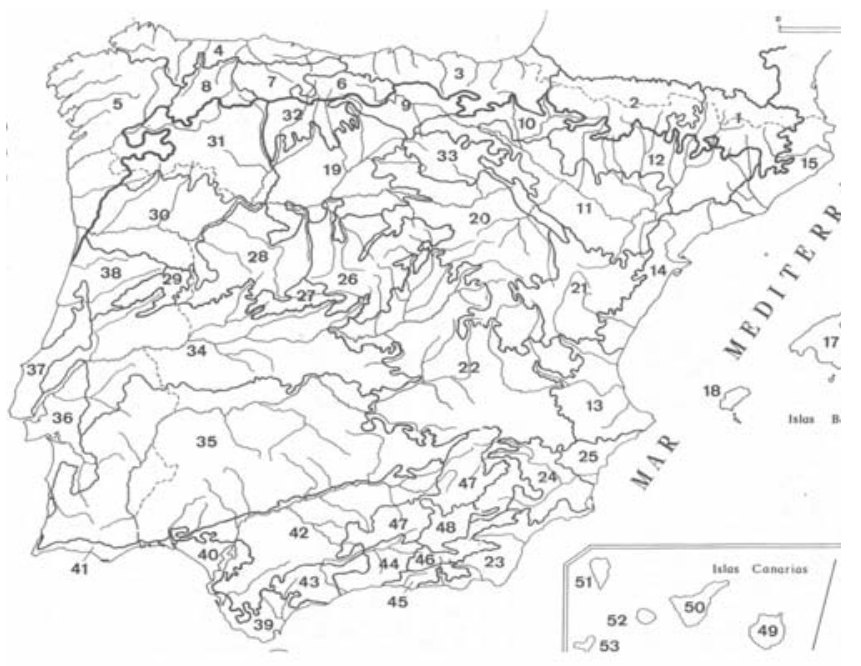

Figura 20.- Sectores biogeográficos de la Península Ibérica, Baleares y Canarias según Rivas-Martínez (1987)

grandes unidades (provincias) dentro de las que se pueden diferenciar otras de rango inferior (subprovincias, sectores, subsectores). Su distribución ha resultado coincidente, en gran medida, con algunas de las propuestas más reciente de sectores corológicos realizada por Rivas-Martínez et al. (2002), especialmente en la mitad meridional de este territorio, poniendo de manifiesto la importancia que tienen los estudios corológicos de la flora endémica peninsular en el establecimiento de su tipología corológica. Con respecto al NW Ibérico, Galicia junto a una porción del occidente asturiano, la hoya de El Bierzo, las montañas galaicozamoranas, el tercio septentrional portugués y la Serra da Estrela conforman una provincia con carácter transicional entre la Cántabro-Pirenaica y la Occidental Hercínica, denominada Galaico-Sanabriense. Sin embargo, un nuevo análisis de la información sobre monocotiledóneas endémicas realizado por Moreno Sáiz \& Sáinz Ollero (1992) finaliza con una cartografía de unidades que difiere en gran medida de la publicada a mediados de los '80 (cf. Figuras 24 y 25$)$.

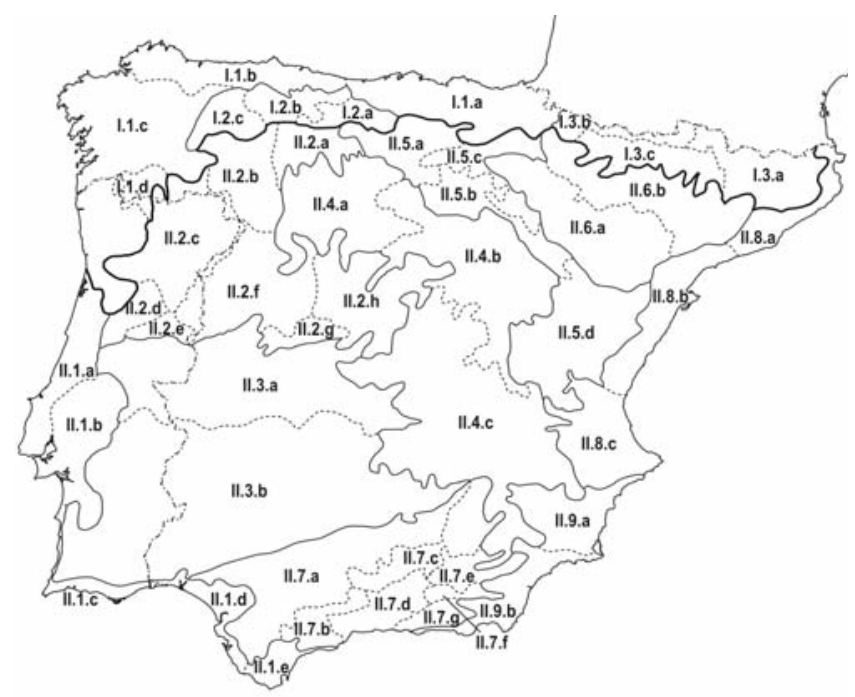

Figura 21.- Sectorización biogeográfica (sectores) de la Península Ibérica según Rivas-Martínez et al. (2002). I.1.a: CántabroEuskaldún; I.1.b: Galaico-Asturiano; I.1.c: Galaico-Portugués; I.1.d: Juresiano; I.2.a: Campurriano-Carrionés; I.2.b: UbiñensePicoeuropeano; I.2.c: Laciano-Ancarense; II.I.a: Divisorio Portugués; II.1.b: Ribatagano-Sadense; II.1.c: Algarviense; II.1.d: Gaditano-Onubense; II.1.e: Aljíbico; II.2.a: Leonés; II.2.b: BercianoSanabriense; II.2.c: Lusitano-Duriense; II.2.d: Bajo Beirense; II.2.e: Estrelense; II.2.f: Salmantino; II.2.g: Bejarano-Gredense; II.2.h: Guadarrámico; II.3.a: Toledano-Tagano; II.3.b: MariánicoMonchiquense; II.4.a: Castellano-Duriense; II.4.b: CeltibéricoAlcarreño; II.4.c: Alcarreño; II.5.a: Castellano-Cantábrico; II.5.b: Oroibérico-Soriano; II.5.c: Riojano; II.5.d: Maestracense; II.6.a: Bardenas y Monegros; II.6.b: Somontano Aragonés; II.7.a: Hispalense; II.7.b: Rondense; II.7.c: Subbético; II.7.d: MalacitanoAlmijarense; III.7.e: Guadijeño-Baztetano; II.7.f: Nevadense; II.7.g: Alpujarreño-Gadorense; II.8.a: Vallesano-Empordanés; II.8.b: Valenciano-Tarraconense; II.8.c: Setabense; II.9.a: AlicantinoMurciano; II.9.b: Almeriense

En conjunto, las divisiones corológicas propuestas tomando como base los diversos grupos de flora comentados (pteridofitas, dicotiledóneas y monocotiledóneas endémicas) ofrecen un nivel de discriminación territorial que, en la mayor parte de los casos, no alcanza un grado de precisión superior al alcanzado en las delimitaciones de unidades sectoriales realizadas por Rivas-Martínez, por lo que su aplicación en áreas geográficas reducidas (escala regional) encuentra grandes limitaciones. No obstante, la aplicabilidad de estas aproximaciones corológicas podría mejorar si se conociese con mayor precisión la distribución de los conjuntos florísticos manejados, por lo que sería deseable la intensificación de los trabajos de campo orientados a cubrir estas lagunas de conocimiento.

Todo lo hasta aquí expuesto pone de manifiesto que, a pesar de la existencia de un considerable volumen de información sobre distribución de flora y tipología de la vegetación ibéricas, generado fundamentalmente durante los últimos veinticinco años, todavía no se ha planteado un 


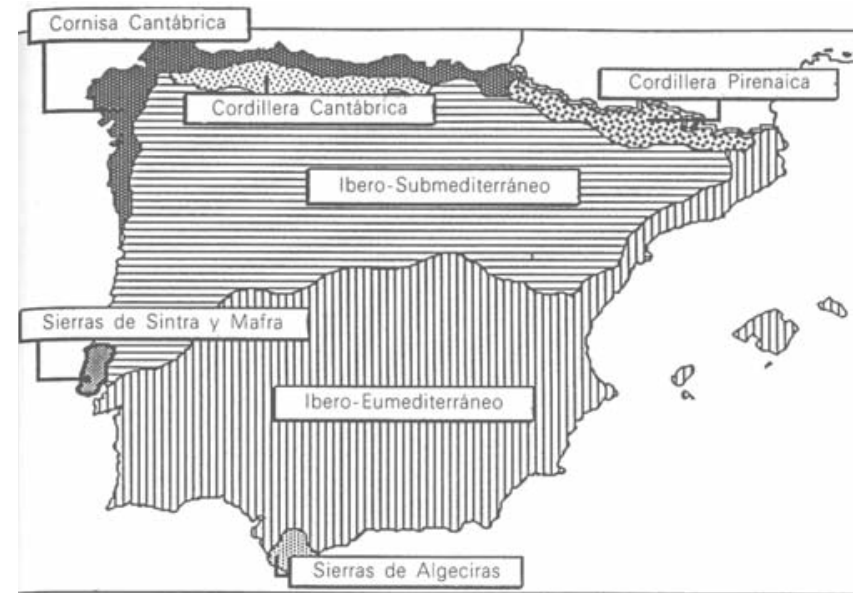

Figura 22.- Sectores pteridogeográficos de la Península Ibérica y Baleares (Salvo Tierra 1990)

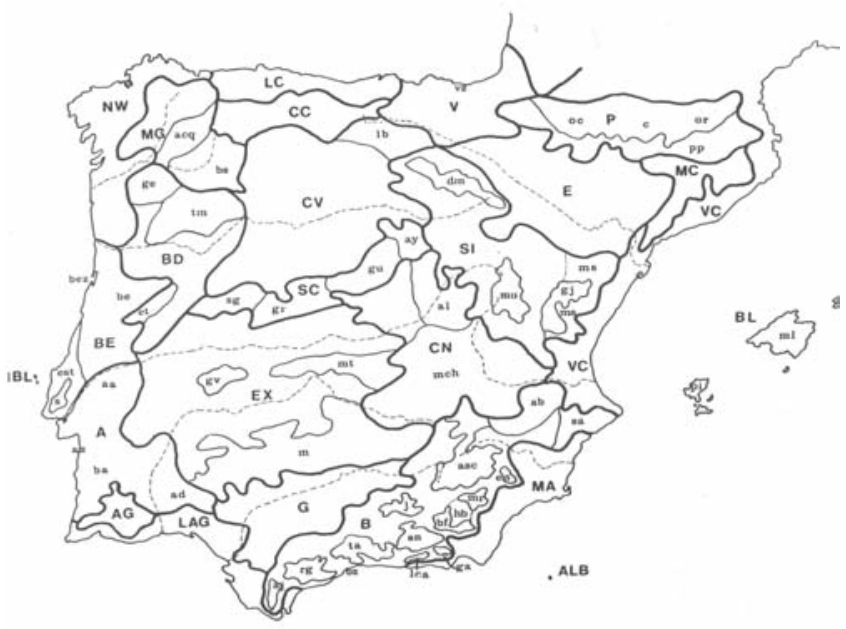

Figura 23.- Sectorización de la Península Ibérica y Baleares en función de la distribución de dicotiledóneas endémicas peninsulares propuesta por Sáinz Ollero \& Hernández Bermejo (1981)

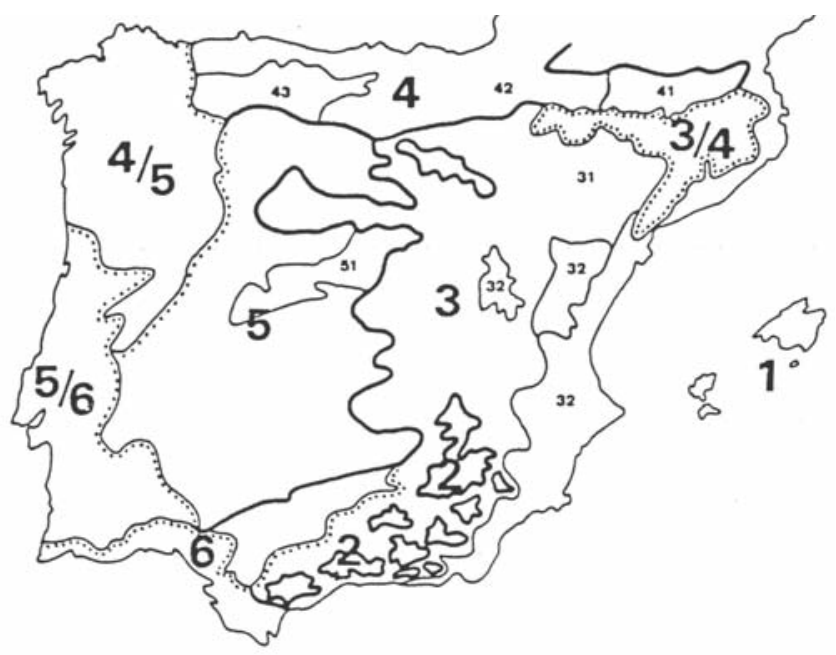

Figura 24.- Sectorización de la Península lbérica y Baleares en función de la distribución de monocotiledóneas endémicas peninsulares propuesta por Sáinz Ollero \& Hernández Bermejo (1985)

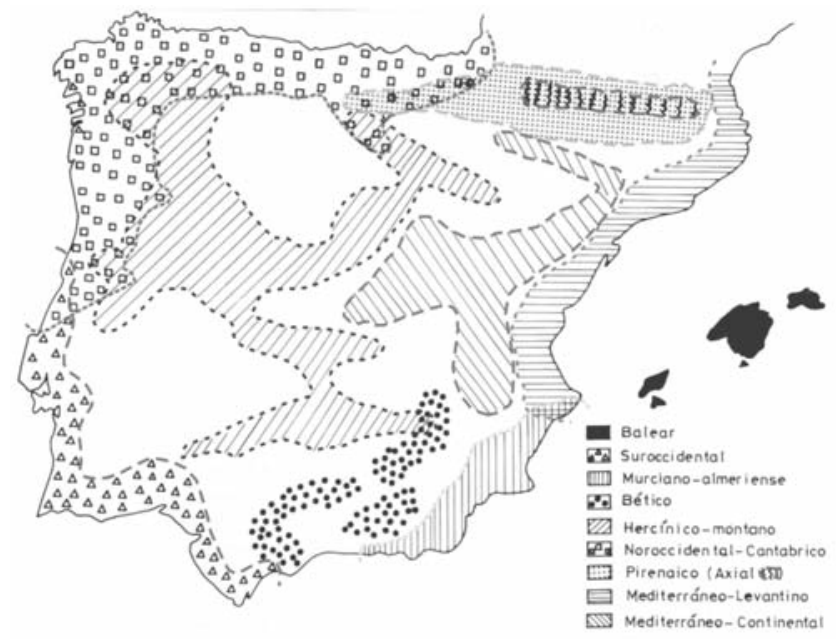

Figura 25.- Sectorización de la Península Ibérica y Baleares en función de elementos corológicos endémicos de la flora de monocotiledóneas (Moreno Sáiz \& Sáinz Ollero 1992)

trabajo de síntesis en el que se unifiquen criterios para la propuesta de un modelo corológico único y de aplicación general en el territorio.

\section{Modelos corológicos de Galicia}

Aunque existen diveras descripciones geográficas previas en las que se advierte un intento de diferenciar áreas en función de elementos del paisaje, quizás, la primera sectorización de Galicia y territorios limítrofes con una base corológica se encuentre en los capítulos tercero y cuarto del "Ensayo de una flora fanerogámica gallega" de Planellas (1852). En dicha obra se establecen para Galicia cuatro unidades fitogeográficas o "distritos" (Marítimo, Miñiano, Compostelano y Coureliano), cuya distribución aproximada sigue patrones correlacionados con la altitud asociados, obviamente, con limitantes de tipo bioclimático. Para cada una de estas unidades, Planellas propone una serie de especies o géneros característicos, cuya distribución permitiría delimitarlas con cierta precisión, aunque en algunos de dichos grupos se incluyen plantas que hoy en día se consideran ajenas a la flora autóctona de Galicia (tabla 2). No obstante, estas pequeñas imprecisiones no invalidan el análisis territorial planteado por este autor y los fundamentos en los que se asienta, en gran medida plenamente vigentes a dia de hoy.

Según Planellas, el Distrito Marítimo comprendería todo el área litoral gallego internándose, a través de las rías, hacia aquellos territorios próximos que registran alguna influencia del agua marina. El Distrito Miñiano se extendería desde A Guardia hacia el interior siguendo el Baixo Miño y abarcando el área pontevedresa limítrofe con Portugal y la mayor parte de la provincia de Ourense, englobando igualmente la comarca leonesa del El Bierzo. Además de con una serie de especies silvestres muy características (tabla 2), este autor identifica esta unidad como la óptima para la vid, el olivo y árboles frutales, entre ellos el almendro, en Galicia y el extremo occidental leonés. El Distrito Compostelano sería el más ampliamente distribuído 


\author{
Distrito Marítimo \\ Honkenya peploides , Anthyllis vulneraria , Artemisia \\ crithmifolia, Asparagus stipularis*, Beta maritima, Carex \\ arenaria, Cakile maritima, Carlina corymbosa, Centranthus \\ calcitrapae, Crithmum maritimum, Crucianella maritima, \\ Otanthus maritimus, Eryngium maritimum, Glaucium \\ flavuum, Glaux maritima, Heliotropium europaeum, \\ Matthiola sinuata, Medicago maritima, Pancratium \\ maritimum, Physospermum cornubiense, Phytolacca \\ americana*, Plantago maritima, Salicornia ramosissima \\ Salsola kali, Salsola soda* \\ Distrito Compostelano \\ Ajuga reptans, Ajuga pyramidalis, Aquilegia vulgaris, Arnica \\ montana, Asphodelus lusitanicus, Buxus sempervirens *, \\ Caltha palustris, Carex spp., Digitalis purpurea, Erica spp., \\ Eriophorum angustifolium, Gentiana pneumonanthe, \\ Helianthemum spp., Euphorbia amygdaloides, Heracleum \\ sphondylium, Lonicera periclymenum, Daboecia cantabrica, \\ Narcisus spp., Pedicularis sylvatica, Polygala vulgaris,
Potentilla tormentilla, Primula acaulis, Ranunculus spp., \\ Ruscus aculeatus, Solanum dulcamara, Ulex europaeus, \\ Valeriana officinalis
}

\section{Distrito Miñiano}

Ammi majus, Anarrhinum duriminum, Arbutus unedo, Chenopodium botrys, Chondrilla juncea, Cucubalus baccifer, Delphinium halteratum subsp. verdunense, Eryngium campestre, Eryngium tenue, Euphrasia officinalis*, Gratiola officinalis, Lavandula stoechas, Mentha cervina, Nymphoides peltata, Ononis spinosa, Polygonum amphibium, Potamogeton perfoliatus, Potentilla reptans, Quercus pyrenaica, Reseda luteola, Ruta montana, Solidago virgaurea, Thymus mastichina

\section{Distrito Coureliano}

Aconitum napellus ${ }^{*}, \quad$ Allium carinatum ${ }^{*}, \quad$ Anemone nemorosa, Hypericum androsaemum*, Astrantia major, Polygonatum odoratum, Cratageus oxyacantha *, Genista hispanica*, Gentiana lutea, Hellebous foetidus, Helleborus viridis subsp. occidentalis, Iris foetidissima, Ligustrum vulgare, Melampyrum pratense, Ornithogalum pyrenaicum, Trifolium glomeratum

Tabla 2.- Grupos de especies diagnósticas de los cuatro distritos fitogeográficos definidos por Planellas (1851) en Galicia. Se han substituído las denominaciones originales por las consideradas correctas actualmente siguiendo el criterio de Romero (2008) y se han marcado con un asterisco $\left({ }^{*}\right)$ las especies consideradas ajenas a la flora autóctona de Galicia

por el territorio y llevaría como especies asociadas un conjunto de plantas con amplia presencia en el NW ibérico, entre ellas algunas que denotan un cierto carácter térmico y escasamente contrastado del clima (Ruscus aculeatus, Solanum dulcamara, Ulex europaeus). Por último, el Distrito Coureliano comprende los principales alineamientos montañosos del norte y oriente de Galicia, entendidos por este autor como las ramificaciones más occidentales de los "Pirineos astúricos" y que ponen en relación la flora gallega con la de áreas europeas de climas fríos.

Ya a primeros del pasado siglo, Merino (1905-1909) retoma el planteamiento de Planellas en su tercer tomo de la "Flora Descriptiva e llustrada de Galicia", profundizando en la caracterización de los territorios gallegos en función de su flora. Propone, así, la existencia de cuatro pisos o "tramos" de vegetación distribuidos altitudinalmente desde el litoral hacia el interior caracterizados paisajísticamente por el dominio de Pinus pinaster, Castanea sativa, Quercus robur y el enebro rastrero (tramos "del pino marítimo", "del castaño", "del roble" y "del enebro"), junto a una quinta unidad de tendencia mediterránea restringida a un estrecho sector ubicado entre la comarca de Valdeorras y los montes de Casaio. Como en el caso anterior, Merino propone una serie de grupos de especies vegetales con carácter diagnóstico para cada una de las unidades comentadas (tabla 3) muchas de las cuáles coinciden con las empleadas por Planellas.

Al igual que este autor, Merino entiende que la distribución geográfica de estos pisos de vegetación no se establece mediante límites netos, sinó que se dispondrían imbricados, con áreas más o menos amplias de intersección, en las que sería posible encontrar de manera conjunta especies de dos tramos dados de vegetación. De la misma manera, Merino entiende que la flora gallega guarda fuertes relaciones con la de los territorios limítrofes y vincula la presencia de especies propias de ambientes subalpinos al hecho de que las montañas de Galicia son el extremo más occidental de las montañas pirenaicas.

Para Merino, el "tramo del Pino marítimo" tendría una distribución ceñida a la costa gallega, siendo más estrecho en las comarcas norteñas de Lugo y A Coruña, y ampliándose progresivamente hacia el S. Gracias a la benignidad del clima en esta unidad, en ella se encontrarían más de la mitad de las especies vegetales de Galicia conocidas en esa época. El "tramo del Castaño" albergaría igualmente una gran cantidad de especies y se extendería por la mayor parte de la Galicia media de clima fresco. Por encima del anterior se encontraría el tramo del roble (Quercus robur), que ocuparía principalmente las áreas montañosas del interior de Lugo y Ourense, en cuyas cumbres más elevadas de Os Ancares, O Courel, Queixa y Trevinca se encontrarían, de manera discontínua, las escasas presencias del "tramo del enebro". En último lugar, cabría hablar de un área florística peculiar en el extremo SE de Galicia, de afinidad mediterránea en la que, a juicio de Merino, "el roble está sustituido por la corpulenta encina, los tojos desaparecen y en su lugar se desarrolla abundantemente la Genista hystrix a la que acompañan por dondequiera el Cistus ladaniferus, Quercus Toza, Campanula glomerata, Ferula sulcata, Dianthus Armeria, Dianthus Seguieri, Carex depauperata, Centaurea cyanus, Santolina rosmarinifolia, etc.".

Aunque esta visión del territorio gallego desde la perspectiva botánica no deja de tener un cierto carácter 


\begin{abstract}
Tramo del Pino marítimo
Adenocarpus lainzii, Anagallis parviflora, Apium nodiflorum, Asplenium billotii, Centaurea limbata, Centaurea nigra, Centaurea corcubionensis, Cirsium filipendulum, Cytisus striatus, Davallia canariensis, Euphorbia flavicoma subsp. occidentalis, Euphorbia segetalis, Festuca arundinacea, Genista berberidea, Genista triacanthos, Heracleum sphondylium, Leontodon tuberosus, Lepidophorum repandum, Quercus suber, Salix cinerea*, Salix fragilis, Silene portensis, Leontodon taraxacoides, Thymus caespititius, Ulex europaeus, Ulex micranthus

\begin{tabular}{l}
\hline Tramo del Castaño \\
\hline Allium victorialis, Angelica razulii, Arenaria erinacea, Arenaria grandiflora, Astrantia major, Betula pendula *, Chrysosplenium \\
oppositifolium, Cytisus multiflorus, Cytisus scoparius, Fraxinus angustifolia, Genista florida, Hieracium castellanum, Hieracium \\
murorum, Hieracium pilosella, Lavandula stoechas, Olea europaea, Ophrys apifera, Orchis mascula, Hymanthoglossum hyrcinum, \\
Ornithogalum pyrenaicum, Pimpinella villosa, Quercus pyrenaica, Ranunculus acris subsp. despectus, Rosa spp., Rubus spp., \\
Ruta montana, Saxifraga fragosoi, Selinum broteri, Stachys alpina, Thapsia villosa
\end{tabular}

Tramo del Roble

Acer pseudoplatanus, Acinos alpinos subsp. pyrenaeus, Aconitum vulparia subsp. neapolitanum, Actaea spicata, Adenostyles alliariae, Aphanes microcarpa, Anthericum liliago, Antirhinum meonanthum, Arabis alpina, Cardamine amara, Cardamine impatiens, Carex asturica, Cicerbita plumieri, Corylus avellana, Crepis albida, Deschampsia hispanica subsp. gallaecica, Dianthus langeanus, Epilobium angustifolium, Epilobium montanum, Erinus alpinus, Euphorbia hyberna, Fagus sylvatica, Galium odoratum, Genista micrantha, Geum rivale, Geum sylvaticum, Heracleum sphondylium subsp. granatense, Pritzelago alpina subsp. auerswaldii, Ilex aquifolium, Koeleria crassipes, Mycelis muralis, Laserptium latifolium, Lilium martagon, Luzula lactea, Luzula sylvatica subsp. henriquesii, Matthiola fruticulosa, Meconopsis cambrica, Milium effusum, Odontides hispanica, Orchis albida, Poa chaixii, Polygonatum verticillatum, Potentilla asturica, Ranunculus aconitifolius ${ }^{*}$, Rosa villosa, Rumex longifolius, Sagina saginoides, Saxifraga hirsuta, Sorbus aucuparia, Thymus pulegioides, Trollius europaeus, Vaccinium myrtillus, Valeriana pyrenaica, Veronica montana, Viola bubanii
\end{abstract}

Tramo del Enebro

Alchemilla saxatilis, Cryptogramma crispa, Antennaria dioica, Armedia duriaei, Campanula herminii, Chaerophyllum temulum, Conopodium pyrenaeum, Euphrasia minima, Festuca eskia, Festuca indigesta, Festuca paniculata subsp. spadicea, Genista florida, Genista obtusiramea, Herniaria latifolia, Hieracium glaucinum, Teesdaliopsis conferta, Juncus trifidus, Linaria supina, Lotus pedunculatus, Luzula caespitosa, Luzula nutans, Meum athamanticum, Pedicularis comosa, Phleum alpinum, Phyteuma hemisphaericum, Phyteuma orbiculare*, Pyrola minor, Plantago alpina, Pulsatilla alpina, Pyretrum pallidum, Silene ciliata, Trifolium alpinum, Tulipa australis, Valeriana montana, Veratrum album

Tabla 3.- Grupos de especies diagnósticas de los cuatro "tramos de vegetación" definidos por Merino (1906-1909) para Galicia. Se han substituído las denominaciones originales por las consideradas correctas actualmente siguiendo el criterio de Romero (2008) y se han marcado con un asterisco $\left(^{*}\right)$ las especies consideradas ajenas a la flora autóctona de Galicia

simplista, pervivió hasta bien entrado el siglo pasado de la mano de geógrafos y naturalistas, como Luís Iglesias (1962), y todavía encuentra reflejo en obras divulgativas u orientadas a la docencia en los niveles básicos de enseñanza, niveles en los que han tenido poco calado los avances experimentados en el ámbito geobotánico.

Con bastante posterioridad al trabajo comentado, ya en la segunda mitad del siglo XX, Bellot (1968) publica una descripción geobotánica de Galicia, tomando como referencia criterios geográficos utilizados por diversos autores precedentes, que serviría, a la postre, como base para su trabajo sobre la cubierta vegetal de la Península Ibérica (Bellot 1978). A partir de aquí, el proceso de elaboración de la cartografía corológica de Galicia ha seguido básicamente, como en la mayor parte de los territorios españoles, las propuestas de Rivas-Martínez y su equipo de colaboradores. Asturias, Cataluña, País Vasco y Navarra constituyen excepciones a esta tendencia, ya que sus Administraciones Autonómicas han financiado la elaboración desde el inicio de los años 90 de documentos técnicos propios en los que basan sus trabajos sobre caracterización de la cubierta vegetal y división ambiental territorial.

El primer esbozo cartográfico de sectorización corológica del territorio gallego, que en realidad no es más que una adaptación a una escala algo más detallada del mapa peninsular publicado por Rivas-Martínez en 1979 (cf. Figura 16), apareció publicado en una obra de Fraga \& Reinoso (1981), autores que establecen dos zonas, "litoral" e "interior", incluidas dentro de la "Provincia Atlántica" (Región Eurosiberiana) y una zona "meridional", identificable con la parte gallega de la Provincia Carpetano-Ibérico-Leonesa (Región Mediterránea), que englobaría su cuadrante suroriental (Figura 26).

Iniciada la década de los ' 80 , con motivo de la publicación de un estudio de la vegetación de la alta montaña cantábrica, Rivas-Martínez et al. (1984) dan a conocer una delimitación detallada de los subsectores corológicos en que dividen el área noroccidental ibérica comprendida entre Santander, Valladolid y la desembocadura del Río Limia en Portugal. En este mapa, se ciñe la extensión de los territorios mediterráneos de Galicia a las cuencas de Ourense y Monforte, el Cañón del Sil y los valles bajos de sus tributarios Xares y Bibei, las montañas de Trevinca y las tierras interiores de A Gudiña, Verín, A Limia y Larouco (Figura 27).

Años después, Izco (1987) realiza una propuesta de delimitación de unidades corológicas de Galicia en base a la distribución de las series de vegetación reconocidas en ese momento en el territorio gallego (Figura 28). Dicha 


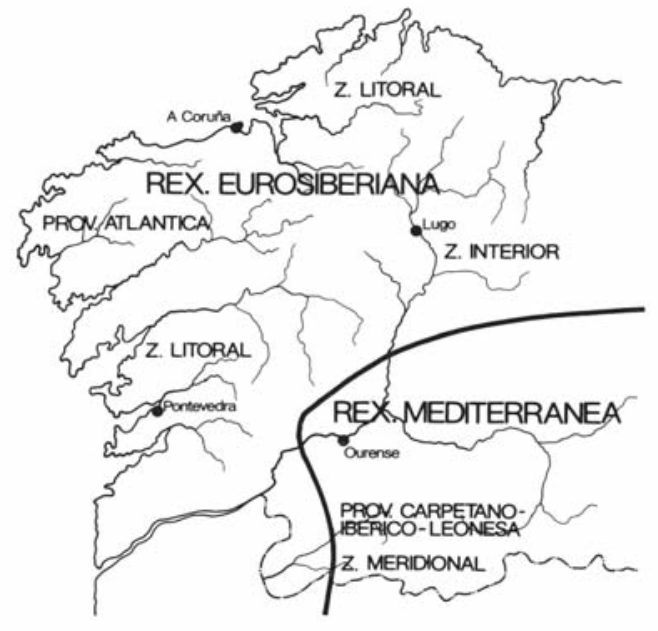

Figura 26.- Sectorización biogeográfica de Galicia propuesta por Fraga \& Reinoso (1981)

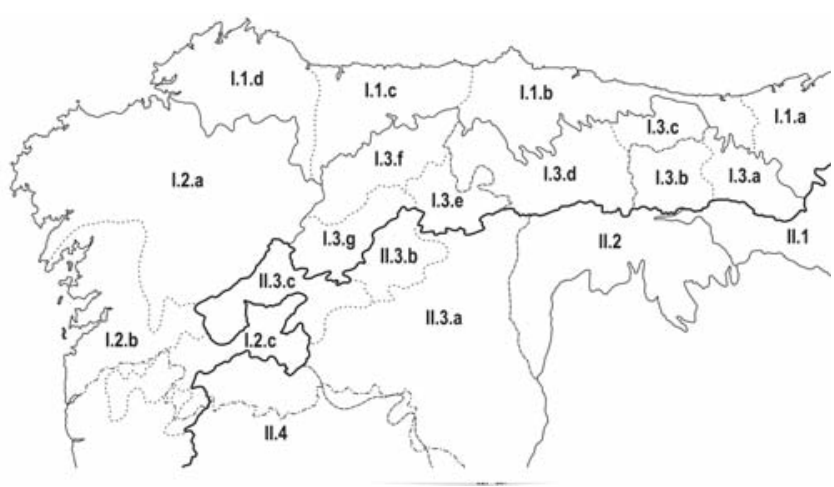

Figura 27.- Sectorización biogeográfica del NW Ibérico según Rivas-Martínez et al. (1984). I.1.a: subsector SantanderinoVizcaíno; I.1.b: subsector Ovetense; I.1.c: subsector Norastúrico; I.1.d: subsector Galaico septentrional; I.2.a: subsector Compostelano-Lucense; I.2.b: subsector Miñense; I.2.c: subsectorJuresiano-Queixense; 1.3.a: subsector Altocampurriano; I.3.b: subsector Altocarrionés; 1.3.c: subsector Picoeuropeano; 1.3.d: subsector Ubiñense; 1.3.e: subsector Laciano; 1.3.f: subsector Ibiano-Narceense; 1.3.g: subsector Ancarense; II.1: Sector Castellano-Cantábrico; II.2: Sector Leonés; II.3.a: Subsector Maragato-Sanabriense; II.3.b: subsector Berciano; II.3.c: subsector Orensano; II.4: sector Lusitano-Duriense (subsector Trasosmontano)

publicación constituye la culminación de su colaboración con Rivas-Martínez en la confección del Mapa de Series de Vegetación Potencial de España E. 1:400.000, publicado en el mismo año que el anterior, y ha sido utilizado en gran número de trabajos sobre flora y vegetación de Galicia hasta épocas recientes (cf. Rodríguez Guitián \& Guitián Rivera 1993, Giménez de Azcárate 1993a, 1993b; Ortiz \& Rodríguez-Oubiña 1993, etc.), así como en la redacción del Plan Forestal de Galicia (XUNTA 1992). Con respecto a esta propuesta corológica, se mantiene prácticamente la delimitación de las áreas mediterráneas en Galicia realizada por Rivas-Martínez et al. (1984), hecho que contrasta con lo expresado por este mismo autor en un trabajo anterior en el que se afirmaba que las áreas claramente mediterráneas, identificables por el dominio de los encinares, se ceñirían exclusivamente en Galicia a los territorios de la cuenca del Río Sil situados por debajo de los $400 / 450 \mathrm{~m}$ de altitud (cf. Izco et al. 1985).

A pesar de la precisión en la delimitación de unidades de la que hace gala la propuesta comentada, ésta se ha visto remodelada en mayor o menor medida, tanto por su propio autor como por otros posteriores, obteniendo las propuestas resultantes una repercusión variable en trabajos geobotánicos y forestales. En un buen número de casos las modificaciones realizadas afectan a los límites eurosiberiano-mediterráneos, en ocasiones para ampliar las áreas mediterráneas o retocar sus límites (cf. Silva-Pando \& Rigueiro Rodríguez 1992, Izco \& Sánchez 1995)(Figura 29), pero sobre todo para proponer su reducción a través de la incorporación de diferentes áreas a la Región Eurosiberiana, como en el caso de la Terra de Lemos (Romero Buján 1993, Amigo \& Romero 1994, Izco 1989, 1996, 2001) o las cuencas de Ourense (cf. Rodríguez Guitián \& Ramil Rego 1995, Rodríguez Guitián et al. 2003, Pulgar et al. 2004) y A Limia (Pulgar Sañudo 1999, 2003, 2004a, 2004b; Pulgar et al. 2004).

En otros casos, las nuevas aportaciones se centran en la redelimitación de las fronteras entre unidades de orden inferior (sectores, subsectores). Entre éstas cabe señalar la independización del Subsector Compostelano en los territorios coruñeses situados al $\mathrm{N}$ del Río Tambre, realizada por Izco (1989) y mantenida posteriormente, aunque con límites fluctuantes, en trabajos como los de Ortiz \& Rodríguez-Oubiña (1993), Izco \& Sánchez (1995), Izco (2001), etc. (Figuras 29 y 30).

Desde inicios del presente siglo, Rivas-Martínez ha impulsado una nueva revisión de las unidades biogeográficas de la Península Ibérica utilizando como unidades de orden inferior los "distritos", en detrimento de los "subsectores". Una primera aproximación cartográfica de dicha revisión utilizando sectores biogeográficos ha visto la luz hace unos años (Rivas-Martínez et al. 2002)(Figura 31), esperándose la inmediata publicación de mapas más detallados para la totalidad del territorio español con base en la división distrital (cf. Rivas-Martínez 2007).

Como adelanto de la versión definitiva, Vázquez \& Díaz González (2005) han publicado una delimitación geográfica de distritos en la Cornisa Cantábrica. Dicha cartografía, en lo que al territorio de Galicia se refiere, presenta un carácter rupturista con respecto a las delimitaciones mantenidas a lo largo de los años ' 80 y '90 del pasado siglo y principios del presente, ya que elimina prácticamente la existencia de áreas mediterráneas en este territorio, crea nuevas unidades y redefine los límites de muchas de las preexistentes (Figura 32).

\section{Integración de los estudios paleoambientales y los efectos de la actividad humana en los estudios corológicos.}

Además de criterios florísticos y vegetacionales, la delimitación de unidades fitogeográficas debe integrar otros tipos de fuentes de información, entre las que destacan el 

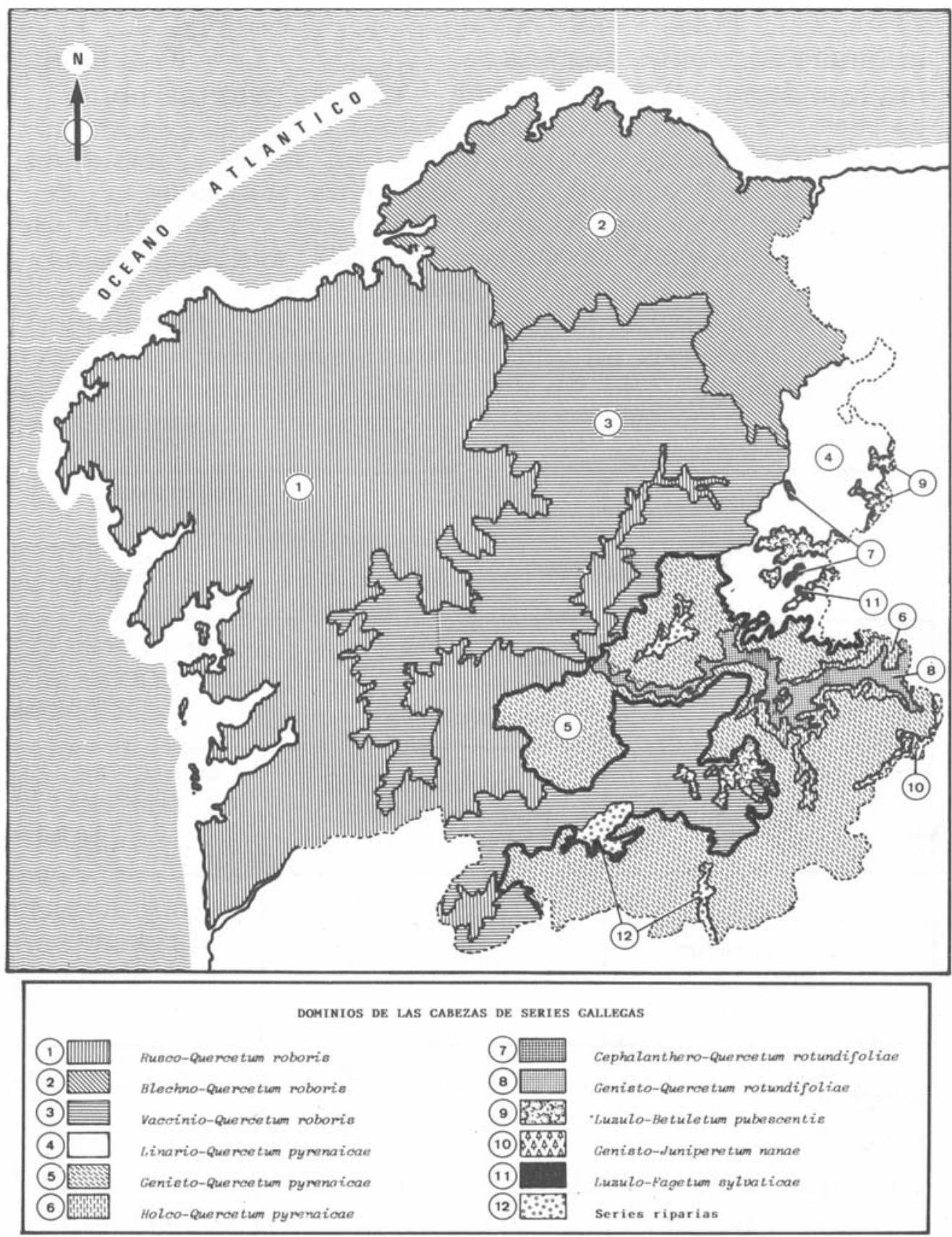

Figura 28.- Sectorización biogeográfica de Galicia en base a la distribución de las cabezas de serie de vegetación existentes, según IZCO (1987)

conocimiento del efecto de las actividades humanas en la configuración de la cubierta vegetal y la influencia de los cambios climáticos acontecidos en el pasado sobre la distribución de los ecosistemas y, consecuentemente, de la flora. Con respecto a este último ámbito científico, las aportaciones realizadas en los últimos 15 años por diversos autores en el campo de la dinámica paleoambiental de los territorios del NW Ibérico (Ramil Rego 1992; Muñoz Sobrino et al. 1997, 2001; Ramil-Rego et al. 1998a, 1998b, 2002; Muñoz Sobrino 2001, Gómez-Orellana 2002) vienen a indicar que el conjunto florístico de origen mediterráneo ha tenido una representatividad geográfica muy restringida en estos territorios a pesar de la existencia de fluctuaciones climáticas de gran entidad a lo largo de los últimos 100.000 años. En lo tocante al actual territorio gallego, ocupó principalmente las áreas situadas a menor altitud, en coherencia con las preferencias termófilas de la mayor parte de esta flora, pudiendo calificarse de anecdótica su participación en la constitución del paisaje de este área geográfica.

Por otra parte, se ha atribuído la condición de "elemento mediterráneo" a un extenso conjunto florístico orófilo distribuido por la mayoría de los macizos montañosos silíceos ibéricos, cuyos representantes más conocidos quizás sean diversos géneros de leguminosas retamoides y vulnerantes y gramíneas. El origen de esta flora parece guardar más bien relación con un proceso de especiación 


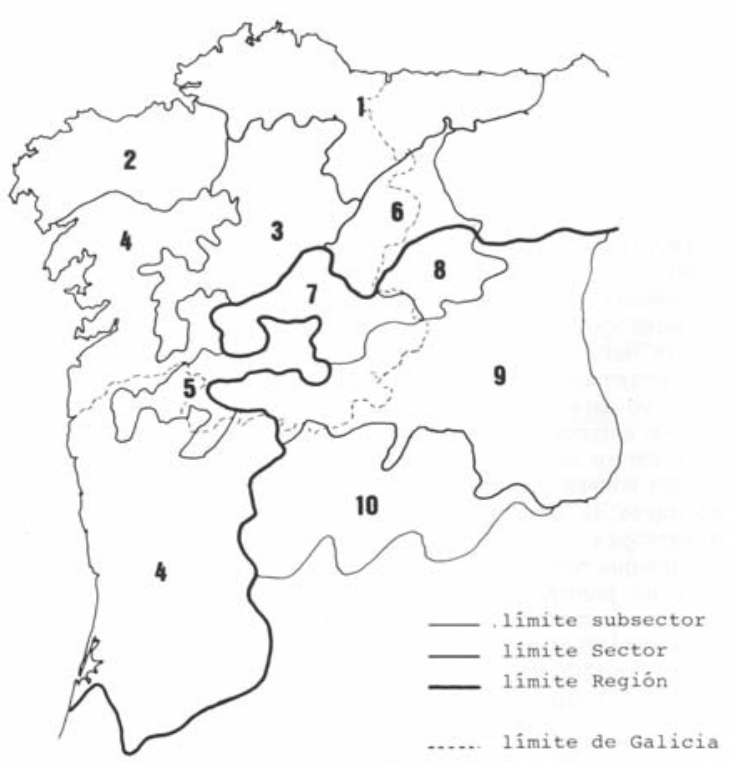

Figura 29.- Propuesta de sectorización corológica de Galicia y áreas limítrofes de IZCO \& SÁNCHEZ (1995). 1: subsector Galaico-Asturiano septentrional; 2: subsector Compostelano; 3 : subsector Lucense; 4: subsector Miñense; 5: subsector XuresianoQueixense; 6: subsector Naviano-Ancarense; 7: subsector Orensano-Valdeorrés; 8: subsector Berciano; 9: subsector Maragato-Sanabriense; 10: subsector Tamogués

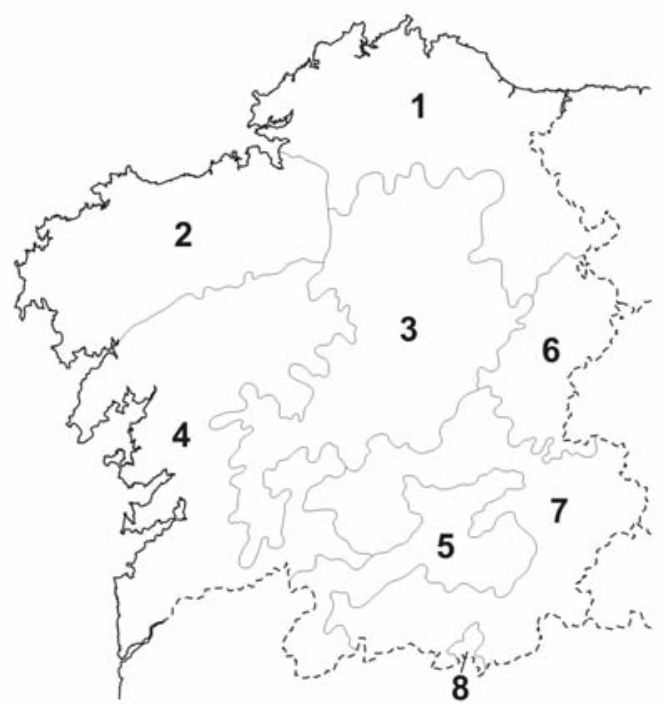

Figura 30.- Sectorización biogeográfica de Galicia según IZCO (2001). 1: subsector Galaico-Asturiano septentrional; 2: subsector Compostelano; 3: subsector Lucense; 4: subsector Miñense; 5 : subsector Xuresiano-Queixense; 6: subsector Naviano-Ancarense; 7: subsector Orensano-Sanabriense; 8: subsector Tamogués

en biotopos afectados de forma reiterada por climas fríos que como relictos de antiguas áreas de distribución continuas asociadas a climas mediterráneos que hubiesen sufrido una fragmentación reciente. Admitiendo este planteamiento, estas especies otorgan a los territorios por los que se distribuyen un rasgo corológico propio de "endemicidad", pero no de carácter mediterráneo.

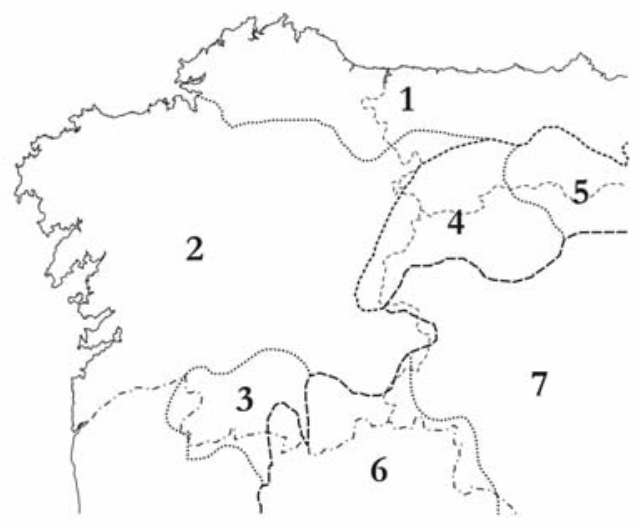

Figura 31.- Límites biogeográficos de Galicia y territorios limítrofes propuestos por Rivas-Martínez et al. (2002). 1: Sector GalaicoAsturiano; 2: Sector Galaico-Portugués; 3: Sector Juresiano; 4: Sector Laciano-Ancarense; 5: Sector Picoeuropeano-Ubiñense; 6 : Sector Lusitano-Duriense; 7: Sector Berciano-Sanabriense

En cuanto a la condición de mediterraneidad que se ha venido asignando a una parte del territorio meridional de Galicia, es interesante recalcar que en gran parte de dicha área escasean los bosques, es decir, la vegetación que se podría considerar en equilibrio con las condiciones climáticas imperantes. Cuando éstos se conservan, ocupan casi sin excepción lugares de difícil acceso y situaciones topo-edáficas poco representativas de las condiciones ecológicas mas extendidas en estas áreas. En los terrenos que no han sido repobladas con especies forestales introducidas o están ocupadas por cultivos, los matorrales de estas áreas están dominados principalmente por especies de los géneros Erica y Cytisus, constituyentes típicos de las "landas", tipo de formaciones arbustivas característico de los territorios atlánticos de Europa y extremo $\mathrm{N}$ de África que también se extiende por amplias áreas del interior ibérico en las que el clima presenta tendencia hacia la mediterraneidad, aunque se mantiene dentro del macrobioclima templado (Serra da Estrela, Sistema Central, Sistema ibérico, etc.).

Por todo ello, en el estado actual de los conocimientos sobre flora y vegetación de Galicia y sus fluctuaciones en épocas geológicas recientes, parece poco apropiado el mantenimiento de un esquema biogeográfico que propugne la existencia de extensas áreas claramente mediterráneas en este territorio ya que, si bien desde el punto de vista bioclimático podría admitirse un piso mesomediterráneo asociado a los niveles basales de las depresiones de Quiroga y Valdeorras, conectada ésta última con el Bajo Bierzo leonés (cf. Rodríguez Guitián \& Ramil-Rego 2007), el contingente florístico allí presente mantiene un elevado carácter transicional debido a la mezcla de los elementos existentes, como ya ha sido señalado en diversas ocasiones a lo largo de este trabajo.

Desde esta perspectiva, la vegetación mediterránea en Galicia encontraría acomodo en determinados enclaves en los que, por causas fundamentalmente meso 0 microtopográficas, las condiciones climáticas y edáficas favorecen la conformación de tipos de vegetación dominados por especies que caracteriza habitualmente las 


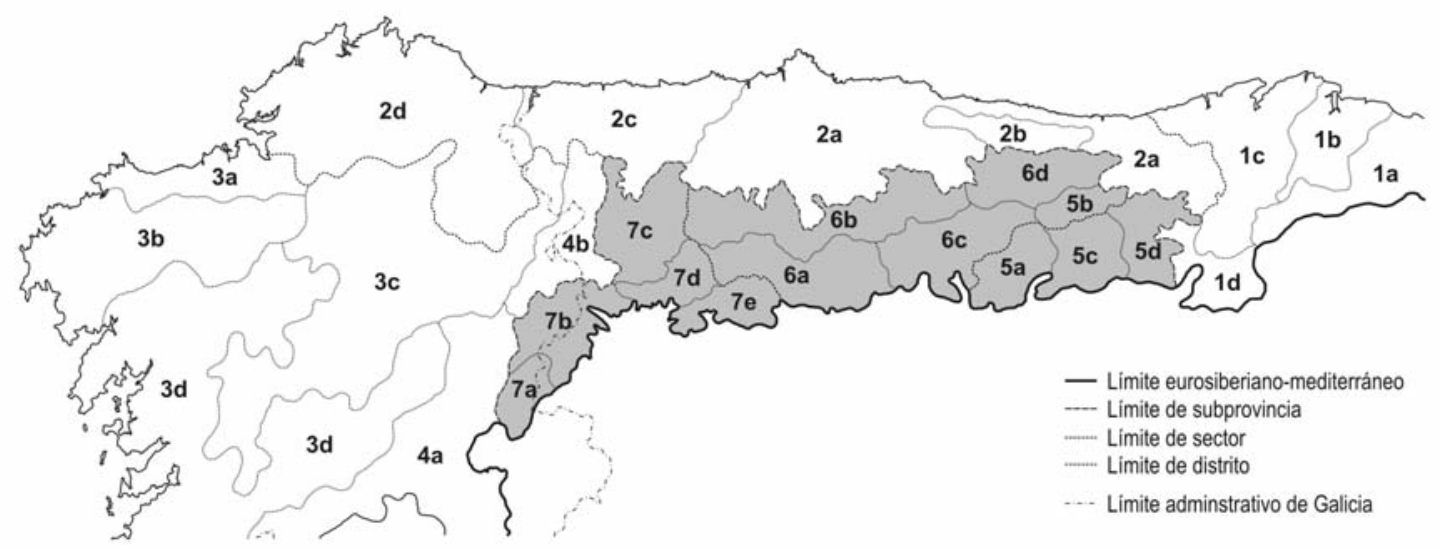

Figura 32.- Propuesta de sectorización corológica (unidades distritales) de Vázquez \& Díaz González (2005) para la Cornisa Cantábrica (solamente territorios eurosiberianos). En sombreado se ha resaltado la Subprovincia Orocantábrica

áreas centro-meridionales de la Península Ibérica frente a la mayoritaria, eurosiberiana, del entorno. A favor de esta interpretación juega la elevada proporción de flora eurosiberiana que se mantiene en territorios más allá del límite territorial de Galicia y del biogeográfico tradicionalmente admitido para la región Eurosiberiana, como las montañas zamorano-leonesas de Sanabria o las sierras del Teleno y la Culebra, y que llega en ocasiones a superar al de la flora estrictamente mediterránea (cf. Llamas García 1984; García López et al. 1992; García Río \& Navaro Andrés 1994). En este esquema, las áreas mediterráneas en Galicia se restringirían a localizaciones, preferentemente orientadas al S-SW del valle del Sil, como continuación de la cuenca del Bierzo, en consonancia con lo expresado por Izco et al. (1985). El resto de Galicia mostraría una flora y vegetación fundamentalmente eurosiberianas, aunque con una fuerte influencia termófila en las áreas costeras y tierras bajas del interior, encarnada en la presencia de estirpes de distribución esencialmente mediterránea occidental $\mathrm{o}$, incluso, noroccidentales u occidentales ibéricas, en las áreas situadas aguas abajo de la confluencia del Río Sil con el Miño, la cintura costera de las Rías Baixas y los valles interiores del cuadrante SE. Interpretación semejante podría aplicarse a otras áreas de la Cornisa Cantábrica en las que se evidencia este mismo fenómeno, como la Liébana en Cantabria o los valles internos de diversos ríos eukaldunes (cf. Berastegi et al. 1997, Loidi et al. 1997).

En todo caso, es preciso recordar que las divisiones territoriales netas no se dan en la naturaleza, de manera que entre medias de dos áreas de tendencias florísticas bien definidas suele existir un territorio ambiguo en el que se observa la coexistencia de taxones de vocación biogeográfica opuesta al amparo de enclaves ambientales favorables para sus respectivas supervivencias. A modo de ilustración de este fenómeno, sirva la presencia de especies calificadas como típicamente atlánticas, como Daboecia cantabrica, Lithodora prostrata, Pseudoarrhenatherum longifolium o Ulex europaeus, a lo largo del tramo gallego del Río Sil o, en sentido inverso, la de Genista hystrix, Dorycnium pentaphyllos o Lavandula stoechas subsp. sampaioana en el Baixo Miño, así como las de Daphne gnidium, Genista triacanthos y Osyris alba en la costa N de Lugo.

En el caso de Galicia, a la ambigüedad florística existente en diversas áreas de su cuadrante SE viene a unirse el predominio en su cubierta vegetal de bosques dominados por Quercus pyrenaica, especie que presenta una valencia ecológica extraordinariamente amplia. Su presencia en las áreas montañosas limítrofes entre Lugo y Ourense con León, Zamora y Norte de Portugal ha sido interpretada reiteradamente como indicadora de climas mediterráneos (figura 33), dejando en segundo plano su valor indicador frente a climas de tendencia continental, como el que se registra en las referidas montañas (cf. Rodríguez Guitián \& Ramil Rego 2007). Si se admite la identificación de gran parte de los bosques de Quercus pyrenaica con condiciones bioclimáticas de submediterraneidad, no sería hasta que las quercíneas perennifolias o los pinares y sabinares xerotermófilos se hacen frecuentes en el paisaje, ya en áreas meseteñas interiores, que nos encontraríamos de manera inequívoca dentro de territorios mediterráneos.

Por otra parte, a lo largo de los últimos 25 años se ha producido un considerable avance en el conocimiento de los cambios ecológicos acaecidos en los territorios del NW ibérico en los últimos 100.00 años como resultado de la integración de diversos tipos de técnicas (análisis polínicos, antracológicos y carpológicos, estudios arqueológicos, etc.). En las reconstrucciones obtenidas se establece que la actividad humana ha tenido, al menos en la segunda mitad del Holoceno (hace unos 5.000/4.500 años), un papel decisivo en la configuración del paisaje actual a través del empleo del fuego y de la eliminación de la cubierta vegetal preexistente para su aprovechamiento directo con finalidades diversas o el empleo del terreno sobre el que se asienta para otros usos (pastoreo, actividades agrícolas, aprovechamientos mineros, etc.).

Estos cambios han producido modificaciones en la distribución de muchas de las especies vegetales del NW Ibérico, de manera que la presencia o ausencia actual de determinados grupos de plantas es el resultado de la interacción de diversos factores en épocas históricas o 


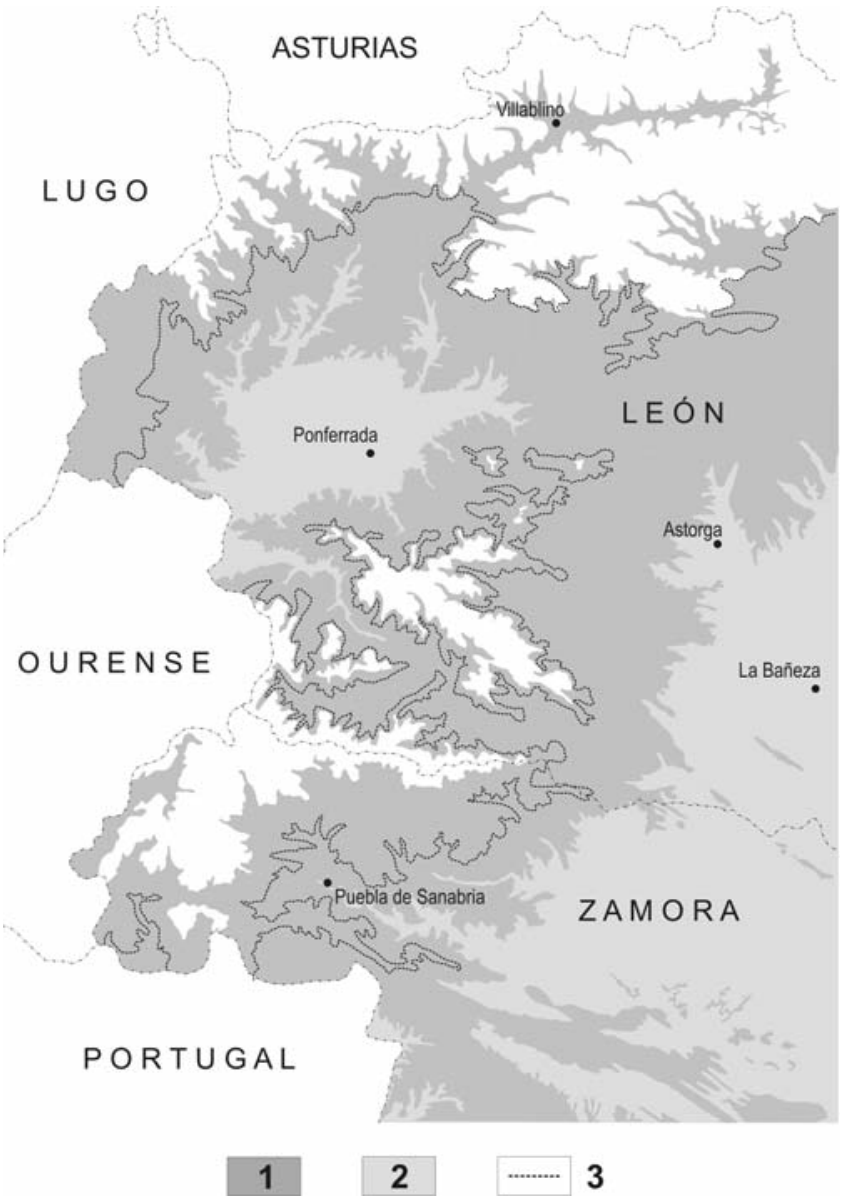

Figura 33.- Representación gráfica de la distribución de dominios de vegetación (1: melojares; 2 : encinares) próximos al límite entre los macroclimas templado submediterráneo (hacia arriba, la izquierda y el interior de las unidades delimitadas con trazo discontínuo) y mediterráneo pluviestacional existentes en el extremo NW de la Comunidad Autónoma de Castilla y León (adaptado de del Río 2005)

protohistóricas, entre los que no puede excluirse la influencia antrópica. De manera global, cabría considerar que el ser humano ha afectado a la distribución de los vegetales nativos de los diversos territorios mediante cuatro procesos:

Extinción regional por pérdida de núcleos poblacionales. Determinadas especies presentes en el NW ibérico hasta épocas recientes (unos pocos siglos) han debido desaparecer a consecuencia de la perturbación o destrucción de sus hábitats característicos generados o inducidos por actuaciones humanas. Sería para Galicia el caso de especies leñosas como el tilo (Tilia spp.) y el carpe (Carpinus betulus), extinguidas hace unos cientos de años, o del pino silvestre (Pinus sylvestris), visto vivo por Planellas en la primera mitad del siglo XIX en O Ocurel y cuya última población situada en las montañas galaico-minhotas (Xurés-Gerês) desapareció hace poco más de cincuenta años.

Extinción regional por mezcla de genotipos cultivados y silvestres. Algunas de las especies forestales más ampliamente difundidas hoy en día en el NW ibérico, entre las que destacan el castaño (Castanea sativa) y diversas especies del género Pinus (Pinus sylvestris, $P$. pinea, $P$. pinaster) estaban presentes en este territorio con anterioridad a la aparición regional de la agricultura. En el caso del castaño y los pinos pinaster y piñonero, existe constancia de su manejo y cultivo desde la Edad Media, llegando las variedades cultivadas y sus masas forestales a sustituir progresivamente a las poblaciones silvestres en numerosas áreas (cf. Guitián Rivera 1995). Así, desde finales del siglo XIX ya era imposible establecer la existencia de poblaciones silvestres de Pinus pinaster y Pinus pinea en el NW ibérico.

Reducción del área de distribución por extinción de poblaciones locales. Podría considerarse como una situación previa a la extinción regional, motivada por causas semejantes. Ejemplos de especies en las que se ha documentado una reducción de su área de distribución desde finales del siglo XVIII debido a la desaparición local de poblaciones y tras su expansión territorial registrada en la segunda mitad del Holoceno, serían el haya (Fagus sylvatica), la encina (Quercus ilex subsp. ballota), el almez (Celtis australis) o los olmos (UImus spp.). En algunos casos, la extinción local se debería a la sobreexplotación de las poblaciones existentes, como podría admitirse para las primeras de las especies citadas, pero en otros, su desaparición en gran parte del territorio parece haberse producido a consecuencia de la introducción accidental de agentes patógenos causantes de mortalidades elevadas, como ha ocurrido con el caso de los olmos (Ulmus glabra, U. minor).

Incremento del área de distribución. Incluiría un conjunto elevado de especies sinantrópicas que resultan favorecidas por prácticas como la quema del monte, la instauración de sistemas de cultivo, la tala de arbolado o el pastoreo intensivo. Dentro de este grupo cabe citar, para el caso de Galicia, tanto las especies segetales (asociadas a los cultivos) como ruderales (que prosperan a lo largo de caminos y otras vías de comunicación terrestre), junto con especies características de hábitats naturales que se vieron favorecidas indirectamente por la acción humana o tras el cese de la misma. En este último grupo se podrían encuadrar gran parte de las especies características de los matorrales gallegos, tolerantes a la radiación solar directa, como los toxos (Ulex spp.), las xestas (Cytisus spp.), los piornos (Genista florida), los brezos (Erica spp., Calluna vulgaris, Daboecia cantabrica) y diversas cistáceas (Halimium alyssoides, H. umbellatum, Cistus psilosepalus, C. salvifolius, etc.). En situación semejante se encontrarían algunas especies arbóreas de similar temperamento, cuya expansión se realizaría o bien a partir de núcleos de poblacionales naturales (Quercus pyrenaica) o de repoblaciones forestales (Pinus pinaster, Pinus pinea, Pinus radiata, Eucalyptus spp.).

Un fenómeno que aparece frecuentemente vinculado con los procesos comentados es la tendencia a la reducción de la variabilidad espacial que se observa en la vegetación como resultado del empleo secular del fuego. Su uso reiterado, unido en muchos casos a la existencia de fuertes limitaciones edafo-climáticas para el desarrollo de la 
vegetación, han favorecido la expansión de extensos matorrales dominados por un reducido número de especies (Erica australis, E. cinerea, E. umbellata, Pterospartum tridentatum, Halimium alyssoides) en amplias áreas de la montañas del interior de Lugo y de Ourense.

Estas consideraciones llevan a plantear que el estudio de la corología actual de las especies vegetales debe complementarse con el conocimiento sobre su dinámica reciente en los diferentes territorios considerados, especialmente dentro del lapso temporal en el que la actividad humana ha tenido un impacto mayor sobre la cubierta vegetal. La integración de ambas fuentes de información mejora apreciablemente la comprensión de las relaciones florísticas que se pueden establecer entre los diferentes territorios a la vez que puede explicar semejanzas cuyo origen radica precisamente en la homogeneización que dichos procesos antrópicos tienden a introducir en la cubierta vegetal. En este sentido, tienen especial valor como coroindicadoras aquellas especies que por sus requerimiento ecológicos se puedan haber visto escasamente influidas por la actividad humana. Aunque a primera vista pudiera parecer que la lista de plantas con estas características sea más o menos larga, en la práctica se reduce a especies propias de medios de carácter azonal, poco susceptibles de ser alterados, como ambientes rupícolas, principalmente grandes paredes rocosas 0 cantiles marinos en el caso de las áreas litorales, o ambientes acuáticos. Sin embargo, muchas de las especies propias de estos medios tienen áreas de distribución amplias debido a su carácter poco exigente o al estar adaptados a factores del medio limitantes para el resto de especies vegetales. De la misma manera, debe guardarse cierta cautela a la hora de interpretar el valor indicador de la distribución actual de especies sensibles a la deforestación, especialmente de las menos resistentes al empleo del fuego.

\section{Un nuevo modelo corológico para Galicia}

En los últimos 10 años se ha asistido a un importante incremento en la información disponible sobre la distribución de taxones y comunidades vegetales en el país gallego, lo que unido a los conocimientos adquiridos en este campo durante la realización de los trabajos conducentes a la redacción de la presente síntesis nos llevan a proponer una nueva división corológica de Galicia, enmarcada en líneas generales dentro de los postulados de la más reciente realizada por Rivas-Martínez (2007), pero sobre la que se introducen algunas modificaciones importantes (Tabla 2). Esta nueva sectorización parte de la base del reconocimiento de la ambigüedad florística y vegetacional de gran parte del territorio gallego, fruto de la condición submediterránea de su clima templado y de la tendencia a la continentalidad que se registra siguiendo un gradiente progresivo desde el NW hacia el SE, fenómeno bien caracterizado desde la publicación de trabajos como el de Carballeira et al. (1983) y matizado más recientemente por Rodríguez Guitián \& Ramil Rego (2007). Esta "indefinición" se ha reconocido también en numerosos estudios paleoambientales realizados dentro del contexto noroccidental ibérico, trabajos en los que se concluye, igualmente, que aunque minoritaria en términos paisajísticos, la flora termófila de amplia distribución el la región mediterránea ha estado presente desde hace más de 100.000 años en este territorio (Ramil-Rego 1992, RamilRego et al. 1998a, 1998b; Muñoz Sobrino 2001, Muñoz Sobrino et al. 1997, 2001, Gómez-Orellana 2002, GómezOrellana et al. 2007).

Consecuentemente, tanto por cuestiones bioclimáticas como botánicas y de dinámica paleoambiental, entendemos que se deben interpretar como pertenecientes a la region florística templada diversas áreas interiores de Galicia y territorios limítrofes que, en repetidas ocasiones, han sido incluidas en la Región Mediterránea (cf. Izco 1987, RivasMartínez 1987, Ortiz \& Rodríguez-Oubiña 1993, Pulgar Sañudo 1999). Este es el caso de las depresiones de Ourense, Monforte de Lemos y Pobra de Brollón, la depresión de A Limia, las tierras Altas de Riós y A Gudiña y las sierras del Macizo de Trevinca-Segundeira-Sanabria.

Dentro de este planteamiento, las cuencas media y baja del Río Sil concentran el mayor conjunto florístico de procedencia mediterránea existente en el extremo noroccidental ibérico, pero se hallan aisladas de las áreas mediterráneas próximas debido a la interposición del macizo montañoso Galaico-Duriense, que conecta las comarcas de Sanabria y las Omañas a través de las tierras altas de la Maragatería (Montes de León y Sierra del Teleno). De esta manera, aunque bioclimáticamente pueda admitirse la existencia de una pequeña área de características propiamente mediterráneas en Galicia (cf. Rodríguez Guitián \& Ramil-Rego 2007), la presencia en ella de un importante conjunto florístico eurosiberiano y el hecho de tratarse de un territorio aislado con respecto al resto del área mediterránea peninsular por barreras montañosas de macroclima templado, dificulta su interpretación clara como una unidad perteneciente a la Región Mediterránea, siendo más plausible su explicación como un caso extremo dentro del gradiente transicional eurosiberiano-mediterráneo anteriormente comentado y, en consecuencia, su inclusión dentro de la Región Eurosiberiana.

Por todo ello, proponemos la consideración del tramo gallego del Río Sil así como los tramos finales de sus principales tributarios (Casaio, Xares, Bibei, Lor) como las áreas eurosiberianas que muestran una mayor influencia mediterránea, esencialmente de carácter termófilo. Dichas áreas constituirían una unidad biogeográfica particular, que se prolonga a través de la parte baja de la cuenca del Bierzo, en la vecina provincia de León, que denominamos Sector Berciano-Valdeorrés. Consecuentemente, y a diferencia de lo considerado hasta el momento en las sucesivas delimitaciones corológicas que se vinieron comentando en las páginas anteriores, en la presente propuesta fitogeográfica se excluye la existencia de territorios asignables a la Región florística Mediterránea en Galicia, estableciéndose la jerarquía de unidades que se relacionan en la Tabla 2 y que aparecen delimitadas geográficamente en las Figuras 34 y 35.

Segun la tipología corológica aquí presentada, Galicia se incluye íntegramente en la Provincia Atlántica Europea, 


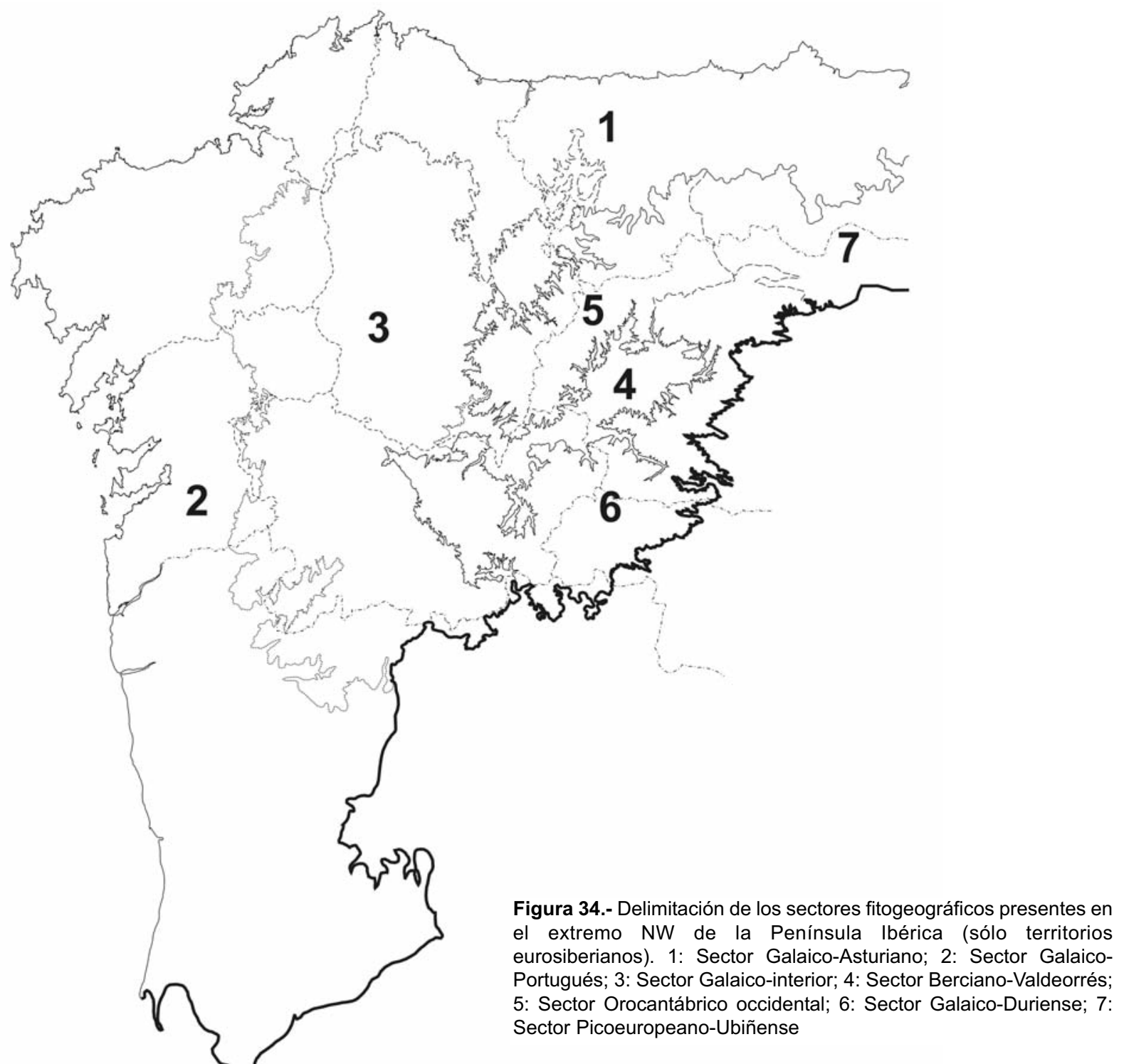

perteneciente a la Subregión Atlántica-Europea de la Región Eurosiberiana. Esta unidad se caracteriza florísticamente por contar en sus comunidades vegetales con la presencia de, entre otras muchas plantas vasculares, especies leñosas de amplia distribución en el continente europeo, como Acer pseudoplatanus, Betula pubescens, Daboecia cantabrica, Fagus sylvatica, Frangula alnus, Fraxinus excelsior, Hypericum androsaemum, Ilex aquifolium, Juniperus communis subsp. alpina, Lithodora prostrata, Prunus padus, Quercus petraea, Quercus robur, Rosa villosa, Salix alba, Salix caprea, Sorbus aucuparia, Ulex europaeus, Ulex minor, Ulmus glabra o Vaccinium myrtillus.

Dentro de esta unidad se distinguen, a nivel de subprovincia, las áreas Cántabro-Atlánticas, de fuerte influencia oceánica e inviernos poco rigurosos, caracterizadas por la presencia de taxónes como Arnica montana subsp. atlantica, Erica ciliaris, Erica erigena, Evonymus europaeus, Genista berberidea, Myrica gale,
Rosa pimpinellifolia, Rosa sempervirens, Salix repens, Smilax aspera, Suaeda vera, Tamarix gallica o Thymelaea coridifolia subsp. coridifolia, de las áreas interiores que forman parte del eje montañoso galaico-cantábrico, integradas en el extremo occidental de la Subprovincia Orocantábrica. Estas áreas montañosas se diferencian florísticamente por la ausencia de las especies antes citadas así como por la presencia de otras como Daphne laureola, Festuca elegans, Helianthemum apeninum subsp. cantabricum, Rhamnus cathartica, Thymelaea coridifolia subsp. dendrobryum o Vaccinium uliginosum.

A su vez, los territorios Cántabro-Atlánticos de Galicia están integrados por cuatro sectores, Galaico-Asturiano, GalaicoPortugués, Galaico-Interior y Berciano-Valdeorrés, mientras que dentro de las áreas orocantábricas se establece una división de rango semejante entre las montañas situadas al $\mathrm{N}$ del Río Sil, que conforman el Sector Orocantábrico occidental, y las situadas hacia S (Sector GalaicoDuriense). 


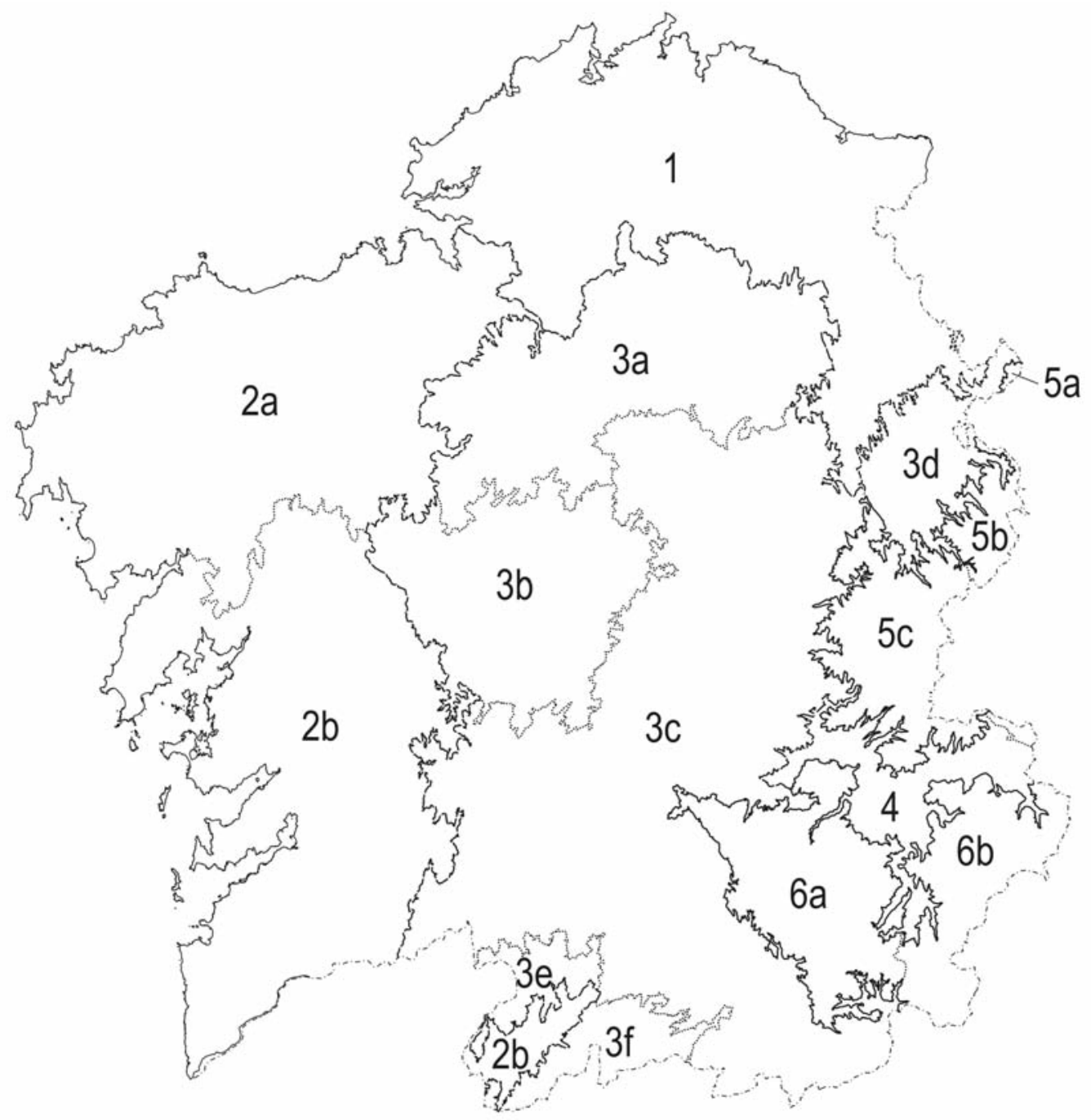

Figura 35.- Unidades fitogeográficas de Galicia (subsectores). 1: Cantábrico Occidental; 2a: Fisterrán; 2b: Rías Baixas; 3a: Chairego; 3b: Ulloa-Deza; 3c: Ourensano-Lugués; 3d: Naviego; 3e: Peneda-Leboreiro; 3f: Xuresiano; 4a: Valdeorrés; 4b: Berciano 5a: Altonarceense; 5b: Ancarés; 5c: Courelao; 6a: Queixense; 6b: Sanabrés

A grandes rasgos, las peculiaridades florísticas y vegetacionales que caracterizan actualmente a los diferentes territorios corológicos definidos responden a la interacción que en el pasado geológico reciente tuvieron tres factores ecológicos: el efecto dulcificador de los mares (tendencia oceánica o atlántica), el efecto de la distancia al mar y el incremento de altitud (tendencia continental) y la intensidad y duración de la sequía durante la época estival (tendencia mediterránea). De las unidades biogeográficas aquí consideradas, el subsector Cantábrico Occidental es el que presenta una mayor afinidad con el resto de territorios atlánticos europeos, mientras que el subsector BercianoValdeorrés concentra la mayor proporción de flora mediterránea. Por su parte, la flora y vegetación del Subsector Sanabrés responde a la mayor influencia de la continentalidad climática, al incluir tierras elevadas situadas en la parte más alejada de la costa del territorio gallego.

En las páginas siguientes se realiza una descripción geográfica y ambiental de cada una de las unidades de menor rango reconocidas (subsectores) en la clasificación biogeográfica hasta aquí esbozada. Para una mejor comprensión de los comentarios bioclimáticos, véase Rodríguez Guitián \& Ramil-Rego (2007).

\section{Subsector Cantábrico Occidental (1)}

Comprende las áreas litorales y sublitorales del $\mathrm{N}$ de Galicia, desde el Golfo Ártabro (Ría de Ares) hasta el límite con Asturias, englobando la totalidad de las cuencas de los ríos que drenan hacia el Mar Cantábrico y las de los que desembocan en el Golfo Ártabro hasta la Ría de Pontedeume. Hacia el interior rebasa las divisorias de aguas que limitan con la cuenca del Río Miño hasta el piedemonte de las Sierras Septentrionales de Galicia alcanzando cotas cuya altitud oscila de W a E entre los 550 y $700 \mathrm{~m}$ de altitud. Hacia el $\mathrm{E}$ se continúa por tierras asturianas hasta la caída de las sierras de Tineo y de los 


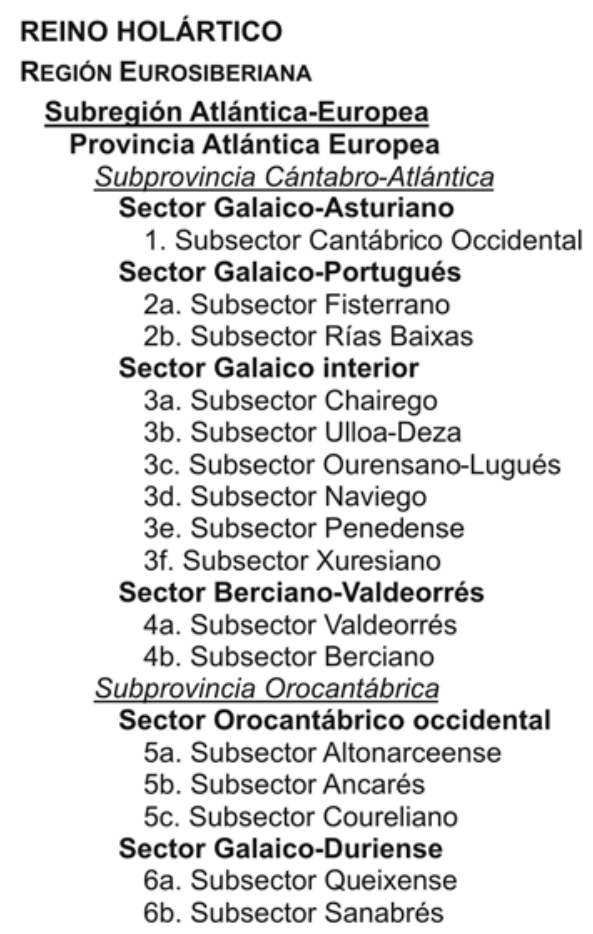

Tabla 4.- Jerarquía de las unidades biogeográficas presentes en Galicia

Vientos hacia el valle del río Narcea. El relieve de esta unidad se caracteriza en tierras gallegas por la sucesión de valles encajados separados por sierras que se disponen mayoritariamente perpendiculares a la costa y cuyas cotas culminantes se sitúan en las sierras de Xistral (Chao do Lamoso, $1.064 \mathrm{~m}$ ) y Penas Apañadas (1.203 m). Las escasas áreas de topografía aplanada que se encuentran están asociadas fundamentalmente a cubetas sedimentarias intramontañosas (Narón-Valdoviño, San Sadurniño, As Pontes, O Valadouro, Mondoñedo, Lourenzá) así como el borde septentrional de la Terra Chá, todas ellas originadas en diversos momentos de la Era Terciaria.

Los sustratos litológicos dominantes son de tipo metamórfico ácido, entre los que se intercalan diversos afloramientos de rocas graníticas, rocas metamórficas básicas y ultrabásicas (Complejo de Cabo Ortegal) y delgados estratos y lentejones de materiales carbonatados (calizas de Mondoñedo, Lourenzá y Riotorto). Los sedimentos cenozoicos no consolidados aparecen asociados a las áreas aplanadas, tanto en las interiores comentadas anteriormente como en las litorales ("rasa cantábrica", sistemas dunares y de humedales costeros). El perfil costero suele ser abrupto siendo general la existencia de acantilados más o menos desarrollados. Los sistemas de playas más extensos se conforman en la desembocadura de los principales ríos o como continuación hacia el mar de depresiones sublitorales o de las litologías más fácilmente erosionables por la acción del oleaje.

El clima de este territorio se caracteriza por su elevado grado de oceaneidad, debido a su situación litoral y a lo moderado de las cotas culminantes de la mayor parte de las sierras. Como característica distintiva con respecto al resto de Galicia, en el territorio Cantábrico occidental es donde se registra un mayor aporte pluviométrico durante la época estival, siendo prácticamente inexistente el período de sequía. Este hecho es resultado de la combinación de factores climáticos (elevada nubosidad y brumosidad que caracteriza los meses de verano en esta parte del país debido al predominio de vientos húmedos y frescos de componente N-NE) y edáficos (alta capacidad de retención de agua de los suelos derivada de su elevado contenido en materia orgánica).

En la actualidad, el paisaje vegetal de esta unidad se caracteriza por el predominio de áreas dedicadas a cultivos agrícolas y forrajeros en las partes llanas, los cultivos forestales de eucaliptos (sobre todo Eucalyptus globulus y E. nitens) y pinos (Pinus radiata, $P$. pinaster, $P$. sylvestris). La vegetación arbolada autóctona (fundamentalmente robledales dominados por Quercus robur y "soutos") se refugia en las cabeceras de los principales ríos y en sus tramos medios más abruptos siendo destacables por su importancia en el contexto gallego y NW ibérico, las masas presentes en la cuenca de los ríos Eo, Landro, Sor, Eume y Mandeo. Por lo general los niveles culminantes de las sierras se hayan desarboladas debido a la deforestación antrópica y en lugar de los bosques potenciales del territorio se encuentran, por lo general, matorrales de carácter mesohigrófilo en los que Erica mackaiana y Cytisus commutatus suelen ser especies frecuentes.

Una peculiaridad vegetacional de esta unidad biogeográfica, única en el contexto meridional europeo, la constituyen las turberas de cobertor activas que se conservan en los sectores culminantes de la Serra do Xistral y Montes do Buio (Lugo) y de la Serra da Capelada (A Coruña). En el plano estrictamente florístico, Centaurea borjae, Crepis novoana y Leucanthemum corunnense, son taxones que aparecen de forma exclusiva en esta unidad biogeográfica.

\section{Subsector Fisterrano (2a)}

Comprende los territorios costeros que se extienden entre la boca de la Ría de Betanzos y la parte meridional de la Ría de Noia, penetrando hacia el interior hasta el límite meridional de las cuencas baja y media del Río Tambre. Se trata de tierras con altitudes moderadas, pues raramente sobrepasan los 500 m (Cedeira 600 m, Monte Castelo 568 $\mathrm{m})$ que, ocasionalmente, cuentan con valles encajados, principalmente hacia el tramo final de los ríos más importantes (Mero, Anllóns, Xallas, Tambre).

El relieve costero se caracteriza por la intercalación de extensas playas de arena (Barrañán, Razo, Laxe, Traba, Trece, Carnota) e innumerables playas de cantos ("coídos") con acantilados, bajos en la parte oriental, mientras que en la "Costa da Morte" domina el litoral rocoso con acantilados de gran desarrollo vertical en algunos sectores. En el interior se observa una sucesión de áreas llanas de tendencia hidromorfa y pequeñas sierras en las que la alterabilidad de los materiales litológicos dominantes (esquistos biotíticos de Ordes, rocas gabroicas de Monte Castelo) y la presencia local de depósitos detríticos 
terciarios (Meirama, Ordes, Tordoia, etc.) favorece la formación de suelos profundos con potentes horizontes de alteración. Solamente en los enclaves graníticos situados hacia el W (montes de O Pindo y Serra do Corzán) se observa un menor desarrollo edáfico y la presencia de extensos afloramientos rocosos.

Estas tierras se hallan expuestas con frecuencia a los vientos húmedos de componente $\mathrm{W}$ y $\mathrm{N}$ durante la época estival, por lo que en ellas se manifiesta una cierta nubosidad durante la verano, si bien con menor recurrencia que en el caso del Subsector Cantábrico Occidental. Bioclimáticamente hablando, la cercanía al mar y el releve poco contrastado de esta unidad redundan en el predominio del bioclima de tipo hiperoceánico. El termotipo más representado es el mesotemplado inferior seguido del termotemplado. Como regla general, las áreas situadas por encima de los $450 \mathrm{~m}$ de altitud se encuentran ya dentro del termotipo mesotemplado superior. En cuanto al ombrotipo, se dan desde las variantes húmedas en las áreas costeras hasta las hiperhúmedas inferiores en las montañas de mayor elevación.

Las características del relieve y la elevada oceanidad del clima han favorecido desde épocas remotas el aprovechamiento intensivo de los recursos en las comarcas del Subsector Fisterrano, lo que explica la escasa representación que tienen hoy en día las masas de frondosas autóctonas (robledales, abedulares seriales, alisedas riparias y pantanosas, saucedas higrófilas) en esta unidad.

En la actualidad el paisaje se caracteriza fundamentalmente por el predominio de las áreas de producción agrícola y forrajera, seguidas de las repoblaciones con especies de rápido crecimiento (eucaliptos, pino marítimo, pino de Monterrey). La superficie de matorral tiende en los últimos años a ser sustituida por nuevas plantaciones, a menudo en situaciones edafo-climáticas poco favorables para las especies más ampliamente utilizadas, como los eucaliptos y el pino de Monterrey. A pesar de todo, en algunas comarcas de esta unidad se conservan importantes conjuntos de áreas higro-turbosas que se han desarrollado en alveolos y pequeños valles enclavados sobre litología granítica o al amparo de situaciones topográficas llanas o ligeramente inclinadas sobre sustratos más o menos impermeables, como se puede observar en el entorno de Carballo, Monte Castelo, Montes de Corzán, Serra de Pena Forcada o el margen septentrional del embalse de As Forcadas. Como acontece en el Subsector Cantábrico Occidental, el roble característico de los bosques más extendidos en esta unidad es Quercus robur, aunque localmente puede llegar a abundar el melojo (Quercus pyrenaica).

La originalidad biogeográfica de esta unidad se fundamenta en la presencia de algunos taxones endémicos, Centaurea ultraeii o C. corcubionensis, esta última compartida con el Subsector Rías Baixas, así como en el dominio de los brezales meso-higrófilos con Erica ciliaris en gran parte de las áreas forestales desarboladas, debido a la humedad edafo-climática existente.

\section{Subsector Rías Baixas (2b)}

Las Rías Baixas y sus cuencas fluviales tributarias conforman el núcleo geográfico sobre el que se extiende esta unidad en Galicia, al que hay que añadir el tramo inferior de la cuenca del Río Miño y el curso inferior del Río Limia, aguas abajo de la localidad ourensana de Muiños. Las cotas máximas $(800-1.1000 \mathrm{~m})$ se encuentran en las cumbres de las sierras que conforman la mitad meridional de la Dorsal Gallega. En conjunto, se trata de un área de relieve ondulado surcado por numerosas cadenas montañosas de baja altitud entre las que se intercalan pequeñas depresiones con orientación preferente N-S (A Maía, O Rosal, O Porriño, Val Miñor). Por otra parte y como es sabido, el perfil litoral de las Rías Baixas es sumamente recortado y está compuesto por la sucesión de áreas acantiladas y grandes playas en las partes más externas de las respectivas penínsulas, de costas bajas con pequeñas playas y calas en las partes intermedias y complejos de humedales marítimo-continentales (marismas, "esteiros" y "brañas") en las partes internas.

El contacto con el medio marino permite que las áreas cercanas al litoral presenten un bioclima hiperoceánico mientras que en las zonas interiores se registran oscilaciones termométricas anuales más acusadas, propias del bioclima oceánico, debido a los valores elevados de temperaturas medias mensuales que se registran durante el verano. El termotipo más extendido es el termotemplado, seguido del mesotemplado inferior, mientras que los ombrotipos son más variados, desde subhúmedos hasta húmedos superiores.

Los sustratos litológicos dominantes son de tipo granítico, aunque abundan las rocas metamórficas de tipo ácido y, rellenando el fondo de las cubetas anteriormente mencionadas, sedimentos de edad cenozoica. Con frecuencia, las áreas no aprovechadas agrícolamente presentan suelos poco profundos y arenosos sobre los que crecen principalmente masas arboladas procedentes de repoblación (pinares de pino marítimo y de Monterrey y eucaliptales) y matorrales de diverso tipo, principalmente "toxeiras" de Ulex europaeus, "xesteiras" y "uceiras", siendo muy escasas las representaciones de vegetación arbolada autóctona. En las áreas bajas en las que ésta subsiste pueden encontrarse robledales con alcornoque e incluso alcornocales, mientras que en las montañas interiores las masas de "carballo" pierden el caracter termófilo y tienden a presentar una cierta proporción de abedules, castaños y acebos.

A diferencia de lo que ocurre en las unidades anteriormente descritas, el maiz para grano, las patatas y el viñedo, son los principales tipos de cultivos tradicionales presentes en este subsector, a los que hay que añadir la producción moderna de hortalizas y planta de flor en invernadero.

Algunos taxones que caracterizan esta unidad biogeográfica en el territorio gallego son Genista ancistrocarpa, Myrtus communis y Ulex micranthus. 
Subsector Chairego (3a)

Esta unidad se extiende por la Terra Chá luguesa y las tierras altas de las cabeceras de los ríos Mandeo, Tambre y Ulla, englobando los conjuntos montañosos de las sierras de Cova da Serpe, Corno do Boi, Bocelo y Careón. El relieve de esta unidad oscila entre los 450 y poco más de $800 \mathrm{~m}$ de altitud, destacando la existencia de grandes superficies de topografía llana o ligeramente ondulada entre las que se intercalan pequeñas elevaciones. Aunque los sustratos litológicos son variados, en gran parte corresponden a depósitos detríticos de edad cenozoica, lo que unido a la topografía propensa al encharcamiento favorece la existencia de rasgos gleicos en los suelos y la formación de numerosos humedales de dimensiones muy variables (desde algunas decenas de $\mathrm{m}^{2}$ a más de una decena de ha).

El alejamiento del litoral y su emplazamiento en altitudes medias provoca un cierto efecto de continentalización climática que se refleja en un bioclima dominante de tipo oceánico. A su vez, el termotipo más extendido es el mesotemplado superior, restringiéndose el supratemplado inferior a las cotas situadas por encima de los $700 \mathrm{~m}$ de altitud. Los ombrotipos reconocidos son húmedos, comprendidos principalmente dentro del horizonte inferior.

La actividad humana ha conformado un paisaje en el que dominan las áreas de dedicación agrícola, principalmente como fuente de forraje para la amplia cabaña vacuna existente, así como la implantación de especies de crecimento rápido (principalmente eucaliptos en la parte occidental de esta unidad y de pinos en la oriental) sobre antiguas áreas cubiertas por matorrales. La escasa termicidad de este territorio y el carácter poco caluroso de sus veranos justifican la práctica ausencia de plantas termófilas autóctonas en este territorio a la vez que han dificultado el empleo de especies ornamentales de amplia presencia en otras áreas biogeográficas próximas. En los fondos de cubetas y valles amplios a menudo se conservan considerables extensiones de prados y matorrales higrófilos (las conocidas como "veigas "y "brañas") que, debido a sus dificultades de uso y acceso, todavía no han sido convertidos en praderas artificiales o plantaciones madereras. Conforme se produce el aumento de la altitud hacia el límite septentrional y oriental de esta unidad se incrementa progresivamente la proporción de las masas arboladas dominadas por frondosas autóctonas, principalmente "carballeiras" de Quercus robur y $Q$. pyrenaica y abedulares, que todavía cubren extensiones importantes en la Terra Chá luguesa.

Debido a la abundancia de humedales continentales, en esta unidad biogeográfica se concentran las principales poblaciones de algunas plantas vasculares raras (o ausentes), tanto en el contexto gallego como ibérico, de especies acuáticas o higrófilas, como es el caso de Eryngium viviparum, Luronium natans, Pilularia globulifera o Hydrocharis morsus-ranae. También es frecuente en este territorio la presencia de Erica vagans en los matorrales y el sotobosque de las formaciones arboladas autóctonas, especialmente de aquellas que se crecen en áreas propensas al encharcamiento. Por otra parte, asociadas a las Ilanuras de inundación del sistema fluvial Ladra-PargaTámoga se conservan extensos bosques de inundación dominados principalmente por alisos, abedules, robles y fresnos, en las que se encuentan algunas especies de pequeños árboles raros en el resto de Galicia, como el bonetero (Euonymus europaeus) o el viburno (Viburnum opulus).

\section{Subsector Ulloa-Deza (3b)}

Incluye las comarcas naturales de Ulloa y Deza, así como las áreas drenadas por los tributarios del Río Ulla por su margen derecho hasta la localidad de Ponte Ulla (Vedra, A Coruña). Este es un territorio relativamente alejado del mar que presenta una topografía dominada por la sucesión de pequeñas áreas llanas entre las que discurren numerosos ríos escasamente encajados, excepción hecha del Río Ulla, cuyo cauce experimenta una progresiva entalladura desde su área de cabecera hasta que abandona esta unidad y penetra en el Subsector Rías Baixas. Las cotas superiores de este subsector se sitúan alredor de los $800 \mathrm{~m}$ de altitud, mentras que el nivel de base no alcanza los $100 \mathrm{~m}$.

La existencia dentro de esta unidad de rocas silíceas básicas y ultrabásicas, sobre las que se forman suelos poco profundos y pedregosos pero con un contenido relativamente alto de nutrintes y elevados niveles de elementos tóxicos para muchas especies vegetales $(\mathrm{Cd}, \mathrm{Ni}$, $\mathrm{Zn}$ ) ha favorecido procesos de evolución por adaptación al medio que han desembocado en la formación de especies endémicas (edafoendemismos), entre las que destacan Santolina melidensis y Armeria merinoi, y comunidades vegetales muy particulares, como son los matorrales de Ulex europaeus y Erica scoparia.

Debido al efecto de protección orográfica que prestan las sierras que enmarcan esta unidad, se observa una cierta tendencia a la sequía estival (macroclima temperado submediterráneo) pareja a un descenso pluviométrico apreciable si se compara con las áreas costeras vecinas de las Rías Baixas. Su distanciamiento del mar incide en un incremento de la continentalidad (bioclima euoceánico). Anque el termotipo termotemplado está bien representado debido a la existencia de amplias superficies con altitudes inferiores a 300/350 m, gran parte de esta unidad se incluye dentro del termotipo mesotemplado inferior. Los ombrotipos más frecuentes son húmedos e hiperhúmedos inferiores.

Las condiciones mesológicas dominantes en esta unidad permitieron desde épocas remotas un aprovechamiento generalizado del entorno por parte de la población, de manera que el paisaje está dominado por cubiertas vegetales derivadas de los cultivos (tanto agrícolas como forestales) de especies introducidas y, principalmente en las cumbres de cordales y pequeñas serras, matorrales que ocupan antiguos terrenos de labor o han sido objeto de pastoreo extensivo. A pesar de ello, las áreas con relieve más abrupto todavía conservan importantes masas de arbolado autóctono, principalmente robledales con alcornoque, alcornocales, lauredales y bosques fluviales en las áreas termotempladas y robledales con castaño y 
abedulares en las áreas más elevadas. Las condiciones ecológicas de esta unidad favorecen la presencia abundante del melojo o "cerquiño" en los bosques, mientras que, frente al caso del Subsector Rías Baixas, aquí es frecuente encontrar la "xesta blanca" (Cytisus multiflorus), indicadora de cierto nivel de continentalidad y xericidad estival, en las formaciones de matorral.

\section{Subsector Ourensano-Lugués (3c)}

Esta unidad está constituída principalmente por una serie de cubetas sedimentarias interiores engarzadas mediante tramos fluviales encajados en los que se manifiesta una doble tendencia climática: una termicidad elevada, asociada a veranos luminosos y cálidos, y una continentalidad más acusada, como consecuencia de la existencia de inviernos relativamente rigurosos caracterizados por períodos prolongados de inversión térmica que provocan un incremento de la oscilación térmica anual frente a los territorios vecinos más septentrionales y occidentales, sobre todo en las principales depresiones.

Comprende las cuencas de Sarria, Monforte, Pobra do Brollón, Ourense, Maceda, A Limia y Verín, unidas a través del tramo medio del Río Miño, entre Portomarín y Ribadavia, y de las cuencas de los ríos Arnoia, Arenteiro, Avión y Támoga en su extremo $\mathrm{S}$. Este conjunto de depresiones y valles amplios se extiende entre los aproximadamente $100 \mathrm{~m}$ de O Ribeiro y los 600/650 m de A Limia, si bien la mayor parte de esta unidad se encuentra entre los 400 y $600 \mathrm{~m}$. En conjunto se trata de territorios retirados de la costa en los que se verifica un acentuamiento de las condiciones ambientales que se registran en los subsectores Chairego y Ulla-Deza por elevación tanto de la amplitud térmica anual como de las temperaturas durante la época estival. Consecuentemente, los termotipos más extendidos son el termotemplado y el mesotemplado inferior. Al mismo tiempo, la situación alejada de la costa y protegida de los vientos húmedos atlánticos por importantes alineamientos montañosos (Dorsal Galega, Sierras GalaicoMiñotas) produce una apreciable reducción de los aportes hídricos, especialmente durante el final de la primavera y el verano. Esto provoca que los ombrotipos más frecuentes se sitúen dentro del rango de los tipos subhúmedo superior y húmedo inferior.

La tipología litológica dominante de las cuencas interiores es la de los sedimentos cenozoicos, si bien tanto los materiales metamórficos silíceos como las rocas graníticas afloran en las áreas montañosas periféricas que delimitan esta unidad biogeográfica. Los suelos que la caracterizan tienen con frecuencia propiedades hidromorfas como resultado de la riqueza en elementos finos y la tendencia a acumular agua en sus horizontes inferiores debido al predominio de la topografía aplanada.

El paisaje de esta unidad corológica se caracteriza por el predominio de parcelas de dedicación agrícola, especialmente para la producción de forraje, así como la existencia de amplias áreas cubiertas por matorrales. La mayor parte de las masas arboladas autóctonas presentes dominadas por quercíneas ("carballeiras", "reboleiras") muestran huellas inequívocas de su utilización tradicional como fuente de leñas, siendo escasa la presencia de "soutos". Las masas procedentes de repoblación son en su mayor parte pinares ( $P$. pinaster, $P$. radiata) aunque abundan las choperas (Populus $\mathrm{x}$ canadensis) sobre los suelos con mayor disponibilidad hídrica. En las áreas con tendencia a la hidromorfía suelen conservarse pequeñas superficies cubiertas por matorrales y bosques higrófilos, siendo frecuente la presencia en estos ambientes de especies como Erica tetralix, Salix atrocinerea y Genista micrantha.

Fruto del contacto de esta unidad con territorios mediterráneos en su extremo $\mathrm{S}$, ya en tierras portuguesas de Chaves, en el Val de Verín se encuentran microenclaves edafo-xerófilos con especies de óptimo mediterráneo $(Q$. ballota, Cistus ladanifer, C. populifolius, Phillyrea angustifolia) rodeados de vegetación termófila rica en elementos endémicos del occidente ibérico, como Cistus psilosepalus, C. salvifolius, Ulex minor o Genista falcata.

\section{Subsector Naviego (3d)}

Esta unidad biogeográfica está asociada a las áreas de mayor termicidad del tramo gallego del Río Navia y su red de tributarios (entre los 225 y $700 \mathrm{~m}$ de altitud) y de la cabecera del Neira, hasta las proximidades de la localidad de Láncara. Se trata de una unidad de relieve anfractuoso caracterizado por la sucesión de sierras y valles encajados en la que escasean las áreas llanas, si se exceptúan los niveles de cumbres y pequeñas vegas asociadas a los principales cauces. Los sustratos son predominantemente de naturaleza metamórfica ácida (pizarras, esquistos, cuarcitas), aunque en algunas localidades aparecen roquedos carbonatados (Cruzul, Becerreá, Sixirei) y sedimentos cenozoicos (Val de Baralla). Los suelos, salvo en situaciones de rellanos a media ladera o en los fondos de valle, tienden a ser escasamente desarrollados y pedregosos, con un contenido bajo en nutrientes.

La situación abrigada de esta unidad con respecto a los vientos húmedos de componente $\mathrm{W}$ y $\mathrm{N}$ hace que se registren unos valores bajos de precipitación total anual, comprendidos entre 600 y 1000 mm. Simultáneamente, debido a su altitud media relativamente baja, se registra un elevado grado de termicidad, evidenciable fundamentalmente por las elevadas temperaturas estivales. Esto hace que en gran parte de esta área se registre un clima de carácter semicontinental, especialmente aguas abajo de la localidad de Navia de Suarna. Los termotipos más extendidos se incluyen dentro del piso mesotemplado aunque en el extremo $\mathrm{N}$ de esta unidad (Concello de Negueira de Muñiz, < $350 \mathrm{~m}$ ), se registran condiciones propias del termotemplado, como demuestra la existencia de abundante flora termófila (Cistus populifolus, Genista falcata, Lavandula stoechas subsp. sampaioana, Osyris alba, etc.), y de fragmentos de madroñales y alcornocales. Los ombrotipos pertenecen a las variantes subhúmedas y húmedas inferiores.

La cubierta vegetal actual se caracteriza por el predominio de diversos tipos de matorrales ("toxeiras", "xesteiras", 
"uceiras") y áreas arboladas dominadas por especies autóctonas ("carballeiras", "reboleiras", "soutos"); las áreas agrícolas se articulan fundamentalmente alrededor de pequeños huertos y prados de siega situados en los fondos de valle así como praderas polifitas destinadas a la producción de forraje en su mayor parte situadas sobre terrenos comunales situados en las áreas cumbreñas de las sierras. Las plantaciones forestales más ampliamente distribuidas son pinares de pino marítimo y de Monterrey, aunque en los últimos años se han implantado otras especies foráneas como eucaliptos y abeto Douglas en las áreas más abrigadas.

La presencia en esta unidad de taxones como Quercus ilex subsp. ballota, Rumex induratus, Silene scabriflora subsp. megacalicina, proporciona una suficiente individualidad corológica de esta unidad frente a las galaico-portuguesas con las que contacta, mientras que la de Quercus suber y el resto de plantas termófilas arriba indicadas lo hace frente a los subsectores Cantábrico Occidental, Altonarceense, Ancarés y Coureliano.

\section{Subsector Peneda-Leboreiro (3e)}

Está constituído por las partes culminantes (>700-1.416 m) de las sierras de Peneda (Portugal) y las montañas de Leboreiro, Basteira, Serra das Molas y Montes do Quinxo (límite ourensano-portugués). Las litologías dominantes son de tipo granítico o metamórfico ácido (esquistos, neises) a partir de las que se forman, por lo general, suelos de textura suelta y de escasa profundidad, existiendo amplias superficies dominadas por afloramientos rocosos en los sectores culminantes de las sierras. Se trata de un área montañosa fuertemente afectada por el glaciarismo pleistoceno, que ha modelado amplios valles y cumbres de aspecto redondeado. Esta área montañosa constituye una importante barrera montañosa frente a los vientos húmedos de procedencia atlántica, por lo que en ella se registra un elevado aporte pluviométrico anual, con frecuencia superior a $2.000 \mathrm{~mm}$, pero fuertemente concentrado durante el otoño e invierno. Los termotipos presentes corresponden a los horizontes inferior y superior del piso supratemplado, principalmente el primero de ellos, mientras que los ombrotipos varían desde el hiperhúmedo inferior al ultrahiperhúmedo.

La cubierta vegetal actual de esta unidad se caracteriza por el predominio de las superficies de monte raso cubiertas por diversos tipos de matorrales ("toxeiras", "xesteiras", "uceiras", "piornais", etc.). Intercaladas con las anteriores se encuentran las áreas agrícolas (huertos y parcelas dedicadas a la producción de forraje) y áreas arboladas, principalmente dominadas por Quercus robur y, en menor medida $Q$. pyrenaica, este último más frecuente cuanto más hacia el $\mathrm{S}$ y en las vertientes soleadas de sotavento. Las plantaciones forestales recientes que predominan son los pinares (Pinus radiata, $P$. sylvestris).

Desde el punto de vista corológico, la peculiaridad de esta unidad se debe a la presencia en estas montañas de taxones como Eryngium durieui subsp. juressianum, Thymelaea broteriana, Armeria humilis, etc.
Subsector Xuresiano (3f)

Comprende el conjunto montañoso situado al sur del valle medio del Río Limia, que lo separa de las montañas de la unidad fitogeográfica anterior. En Galicia está constituido por las áreas situadas por encima de los $800 \mathrm{~m}$ de altitud de las sierras de Santa Eufemia, Xurés, Pisco y Larouco (Ourense), continuándose hacia el $S$ por territorios portugueses a través de las áreas que conforman la cabecera del Río Cávado y la vertiente meridional de las sierras da Cabreira, das Torrinheiras, das Melcas, do Barroso y de Leiranco. Como en el caso de las montañas de Peneda-Leboreiro, las altas cumbres de estas montañas (Alto da Sobreira $1.542 \mathrm{~m}$ ) obligan a los vientos atlánticos a descargar gran parte de su contenido en humedad en forma de lluvia o nieve. Por su situación relativamente alejada de la costa y la escasa nubosidad estival que presentan, estas tierras están sometidas a un bioclima de tipo oceánico. Los termotipos dominantes son supratemplados, aunque la presencia puntual de especies de óptimo orotemplado, como Juniperus communis subsp. alpina o Genista obtusiramea, sugiere la existencia de dicho termotipo en los sectores culminantes de la Serra do Xurés, si bien no es posible afirmar su existencia debido a la carencia de estaciones meteorológicas. Los ombrotipos registrados se encuadran en los tipos húmedo superior a ultrahiperhúmedo.

El uso del fuego y el pastoreo de ganado caprino desde épocas inmemoriales han provocado la desaparición de la mayor parte de los bosques originales de este territorio, principalmente dominados por Quercus robur hacia el extremo occidental y gradualmente más ricos en Quercus pyrenaica, hasta llegar a ser claramente dominante, hacia el oriente. En lugares especialmente umbrosos y poco favorables para la incidencia de incendios dentro del termotipo supratemplado superior se conservan pequeños bosques de abedul, a veces con presencia de tejo. La mayor parte del paisaje se halla cubierto de formaciones de matorral (brezales de diversos tipos, xesteiras y, más raramente, piornales), aunque en numerosos lugares alcanzan una relevancia especial los afloramientos rocosos graníticos, como ocurre en la Serra de Santa Eufemia y en la Serra do Xurés.

Desde el punto de vista florístico, esta unidad se diferencia claramente de las de su entorno, además de por la presencia de las especies orófilas anteriormente comentadas, por albergar algunas plantas de distribución restringida que, en algún caso, son compartidas con la unidad de Peneda-Leboreiro, como Eryngium durieui subsp. juressianum, Thymelaea broteriana, Armeria humilis o Iris boissieri.

\section{Subsector Valdeorrés (4a)}

La delimitación de esta unidad está asociada íntimamente a la morfología de la cuenca baja del Río Sil y sus principales tributarios en Galicia (Casaio, Xares, Bibei, Quiroga, Lor), ya que comprende exlusivamente las vertientes que conforman el Cañon del Sil y las depresiones de Quiroga y Valdeorras, 
entre los 260 e 600/800 m de altitud. El límite oriental de esta unidad se establece en el piedemonte ourensano de las sierras de Enciña da Lastra y de Pena do Coto (Rubiá) y el occidental en el tramo de la Ribeira Sacra comprendido entre Doade (Lugo) y Castro Caldelas (Ourense). Debido a su especial configuración geomorfológica, esta unidad se caracteriza por ser un territorio dominado por laderas de fuerte inclinación, situación de la que se exceptúan los fondos de las cuencas sedimentarias antes mencionadas. Los sustratos litológicos más frecuentes son de naturaleza granítica, encontrándose en las depresiones de Quiroga y A Rúa-O Barco potentes depósitos de sedimentos arcillolimosos cenozoicos. En estas condiciones se forman suelos poco profundos y arenosos, con abundante pedregosidad, en el primer caso o más potentes y con un mayor contenido en arcillas, en el segundo.

Bioclimáticamente hablando, existen condiciones de mediterraneidad en los niveles altitudinales inferiores de esta unidad $(<450 / 600 \mathrm{~m})$ (termotipo mesomediterráneo superior) mientras que por encima y hasta el límite con las unidades biogeográficas vecinas, se hace dominante el termotipo mesotemplado superior. El relieve de este subsector favorece los fenómenos de inversión térmica durante los períodos invernales de tiempo estable, lo que unido a las elevadas temperaturas medias estivales hace que en algunas localidades se alcancen valores de amplitud térmica anual propios de bioclimas semicontinentales, semejantes a los registrados en el Alto Bibei. Los ombrotipos presentes son las variantes inferior y superior del tipo subhúmedo, consecuencia fundamentalmente de un reducido aporte pluviométrico estival y de las elevadas temperaturas medias que se registran durante este período.

El paisaje de esta unidad está fuertemente condicionado por la estructura tectónica y la naturaleza litológica, de manera que sobre los afloramientos rocosos se encuentran restos de encinares y matorrales (espinales, madroñales, tomillares) mientras que en las áreas poco inclinadas y en las vegas asentadas sobre sedimentos se concentran la mayor parte de las parcelas de cultivo y viñedos, así como fragmentos de bosques (melojares, alcornocales "xesteiras", "toxeiras", brezales) principalmente de naturaleza silicícola. En el tramo final del Río Sil la actividad humana modificó intensamente el paisaje de las laderas soleadas mediante las construcción de bancales para el cultivo del viñedo, mientras que en las vertientes umbrosas predominan las áreas cubiertas por "soutos" y restos de vegetación climatófila ("reboleiras", abedulares, etc.) así como diversos tipos de matorrales ("xesteiras", "piornais", "uceiras", "toxeiras", espinales, jarales, etc.).

Debido a las especiales condiciones mesoclimáticas de esta unidad y, sobre todo, en las vertientes orientadas hacia el SSW, en ella se concentra un elevado número de especies termófilas de distribución mediterránea occidental e iberoatlántica que lo singularizan con respecto a las unidades subsectoriales con las que contacta. Es el caso de Acer monspessulanum, Cistus ladanifer, Cistus populifolius, Genista hystrix, Phillyrea angustifolia, Lonicera etrusca, Pistacia therebintus, etc. Estas especies se comparten con la siguiente unidad subsectorial, con la que conforma el Sector Berciano-Valdeorrés.
Subsector Berciano (4b)

Esta unidad fitogeográfica es la de menor extensión representada en el territorio gallego, pues se ciñe a las áreas montañosas a través de las que se establece el límite administrativo entre el municipio de Rubiá (Ourense) y la comarca leonesa de El Bierzo, área a través de la que se extiende hasta los niveles inferiores $(700-800 \mathrm{~m})$ de las montañas que rodean la Hoya del Bierzo (sierras de $\mathrm{O}$ Courel, Ancares, Gistredo y Cabrera y Montes de León y Aquilianos). Desde el punto de vista geomorfológico destacan los potentes estratos calcáreos que conforman la Serra da Enciña da Lastra, sector de relieve marcadamente abrupto en el que abundan los afloramientos y paredes rocosas. Aunque existen pequeños estratos de materiales pizarrosos intercalados, la resistencia a la alteración de los materiales calcáreos predominantes no permite la formación de suelos profundos aunque, en general, presentan un elevado contenido en nutrientes.

Desde el punto de vista bioclimático, este territorio es muy semejante al Subsector Valdeorrés, si bien es en esta unidad donde se alcanzan los mínimos valores pluviométricos de toda Galicia (Pumares: $595 \mathrm{~mm}$ ). El piso bioclimático característico de este subsector es el mesomediterráneo superior

El paisaje de esta unidad está principalmente condicionado, como ya se ha comentado, por el aspecto agreste que proporcionan los afloramientos calizos, junto a la persistencia de extensas manchas de encinares, madroñales y matorrales de cistáceas ("estevais"). La irregularidad del terreno ha obligado a los habitantes locales a aprovechar pequeñas parcelas en las pequeñas vegas y depresiones cársticas para la producción agrícola, siendo también destacable la parte del territorio dedicada al cultivo del castaño.

A pesar de su reducida extensión, esta unidad es un área de elevada originalidad botánica, ya que en ella se encuentran un gran número de taxones vegetales que están ausentes del resto del territorio gallego, bien por tratarse de plantas calcícolas o bien por sus preferencias bioclimáticas termófilas. Tal es el caso, entre otras, de Aegilops triuncialis, Aethieonema saxatile subsp. ovalifolium, Armeria rothmaleri, Bifora testiculata, Biserrula pelecinus, Buglossoides purpureocaerulea, etc., hasta totalizar más de 50 (cf. Giménez de Azcárate \& Amigo Vázquez 1996). La personalidad biogeográfica de esta unidad se sustenta, además, en la presencia de algunos taxones rupícolas endémicos de ella, como Petrocoptis grandiflora o $P$. glaucifolia, esta última exclusiva de la parte leonesa de este subsector.

\section{Subsector Altonarceense (5a)}

Se trata de un pequeño territorio delimitado entorno a los sectores culminantes de las sierras de Gallardo y de Vilar, en el límite oriental del municipio de Negueira de Muñiz (Lugo) con el Principado de Asturias. Se extiende entre los 800 y 1.286 m (Pico do Busbeirón) sobre vertientes 
abruptas de elevada inclinación, dentro de los termotipos supratemplado inferior y superior y se asienta sobre roquedos de naturaleza pizarrosa y cuarcítica a partir de los que se forman suelos poco profundos y pobres en nutrientes. Los ombrotipos representados son el húmedo superior y el hiperhúmedo inferior. El bioclima, debido al alejamiento de la costa, es de tipo oceánico semihiperoceánico.

El paisaje de esta unidad en general, y de su parte gallega en particular, se ha forjado mediante el empleo secular del fuego para favorecer el pastoreo en detrimento de las masas arboladas, que se han visto relegadas a las vertientes más abruptas y alejadas de los núcleos habitados, donde pueden encontrarse pequeños robledales y abedulares situados al pié de cantiles rocosos y en valles angostos. No obstante, hacia oriente, en la cuenca alta del Río Narcea, las montañas de esta unidad incrementan considerablemente su altitud, lo que unido a su relieve todavía más agreste, han dificultado las actividades deforestadoras y han permitido que los bosques se conserven con mayor pujanza. En todo caso, las formaciones vegetales dominantes son matorrales dominados son brezales de Erica australis y Erica arborea, escobonales de Cytisus multiflorus y piornales de Genista florida. La ausencia de elementos termófilos (Ruscus aculeatus, Quercus suber, Cistus psilosepalus, Arbutus unedo, Genista falcata, Osyris alba, etc.) diferencia esta unidad de las vecinas galaico-portuguesas y galaicoasturianas, mientras que la presencia del endemismo orófilo Ranunculus parnassifolius subsp. muniellensis permite su individualización frente a las áreas picoeuropeanoubiñenses y ancaresas.

\section{Subsector Ancarés (5b)}

Engloba la parte lucense de las montañas de Os Ancares, cuyas características bioclimáticas y cubierta vegetal guardan gran parecido con diversos valles que, hacia oriente, forman parte de las cabeceras de los ríos Sil, Íbias y Narcea, dentro de las provincias de León y Oviedo. En esta unidad predominan las litologías metamórficas, entre las que se intercalan estratos carbonatados de poco espesor y algunos plutones graníticos. El relieve se caracteriza por la fuerte impronta glaciar que se observa en numerosos valles y la intensa incisión fluvial presente por debajo de los 900-1.000 m.

El bioclima está condicionado por su alejamiento costero y los elevados niveles altitudinales que se alcanzan, próximos a los $2.000 \mathrm{~m}$, lo que le confiere un cierto carácter continental (bioclima oceánico con tendencia a semicontinental). Dentro del intervalo altitudinal comprendido en esta unidad en Galicia (800-1.935 m) se encuentran representados principalmente los termotipos supratemplado inferior $(800-1.300 \mathrm{~m})$, supratemplado superior $(1.300-1.700 \mathrm{~m}$ ) y orotemplado $(>1.700 \mathrm{~m})$, si bien en lugares abrigados se registran condiciones propias del mesotemplado superior. Los ombrotipos identificados son el húmedo superior y el hiperhúmedo inferior.

Los suelos son, por lo general, pobres en nutrientes y sustentan una vegetación adaptada a esta condición. En este área biogeográfica se conservan algunos de los mejores y más extensos bosques de Galicia, en los que dominan robledales albares, melojares y abedulares, aunque también están presentes otros, como hayedos, bosques mixtos, avellanedas, acebales, etc. En los ríos escasean las alisedas, restringidas a las áreas más bajas, siendo dominantes las fresnedas riparias. Las áreas desarboladas están cubiertas por extensos matorrales de Erica australis, piornales de Genista florida y Genista obtusiramea, "xesteiras" de Cytisus multiflorus y, en áreas sobre suelos húmedos, tojales con Ulex gallii. Asociadas a los antiguos valles glaciares y las cubetas de sobreexcavación existentes en las cabeceras de los valles se mantienen importantes áreas turbosas.

En áreas cubiertas desde tiempos remotos por brezales se han realizado extensas repoblaciones forestales desde mediados del pasado siglo siguiendo, principalmente, los principales cordales de las sierras. En estos emplazamientos, la especie más utilizada ha sido Pinus sylvestris, si bien los resultados obtenidos en cuanto a productividad son, en general, deficientes. En los últimos años se ha diversificado el espectro de especies empleadas, realizándose plantaciones con roble americano (Quercus rubra), pino de Monterrey (Pinus radiata) y pino de Oregón (Pseudotsuga menziesii).

Algunas especies vegetales tienen en esta unidad biogeográfica sus únicas poblaciones o las más numerosas dentro de Galicia. Tal es el caso del arándano de montaña (Vaccinium uliginosum) o el enebro rastrero o "xenebreira" (Juniperus communis subsp. nana).

\section{Subsector Coureliano (5c)}

Esta unidad engloba las montañas de la Cordillera Cantábrica situadas hacia el S y W del Alto do Portelo (Lugo-León), comprendiendo el conjunto montañoso configurado por los Montes do Cebreiro y las sierras de Airibio, Trapa, Courel, Montouto y dos Cabalos, así como el extremo septentrional de la Serra de Enciña da Lastra, en el sureste de Lugo y noreste de Ourense. Se prolonga en tierras leonesas por la cabecera de los valles de los ríos Valcárce, Barjas y Selmo, hasta cotas situadas entre los 700-800 m de altitud.

Se trata de un área de fuerte carácter montañoso asentada sobre materiales predominantemente silíceos de origen metamórfico, pero en la que alcanzan especial relevancia, a diferencia del resto de Galicia, los estratos de rocas carbonatadas paleozoicas presentes (calizas, dolomías), que se disponen siguiendo alineamientos paralelos en sentido NW-SE. Su situación a considerable distancia del área costera le confiere al clima rasgos de continentalidad, aunque menos acusada que en el caso del subsector Ancarés debido a las menores altitudes alcanzadas (bioclima oceánico). Precisamente el factor altitudinal impide que está representado el termotipo orotemplado, repartiéndose estos territorios entre los tipos mesotemplado superior y supratemplado. Los ombrotipos identificados son el húmedo superior y el hiperhúmedo inferior. 
Aunque en estas montañas se aprecia la impronta de procesos glaciares en las cabeceras de los principales ríos, el paisaje está caracterizado morfológicamente por el fuente encajamiento de la red fluvial y la elevada inclinación de las vertientes, que han restringido grandemente la actividad humana intensiva en esta unidad, permitiendo la conservación de algunas masas arboladas autóctonas de gran interés ecológico. No obstante, la cubierta vegetal está dominada por diversos tipos de matorrales ("xesteiras", "piornales", "uceiras"), entre las que se intercalan repoblaciones forestales, fundamentalmente de Pinus sylvestris, castañares o "soutos" y áreas cultivadas en el entorno de las aldeas. Por lo general, los angostos fondos de valle han sido aprovechados tradicionalmente a través de la creación de prados de siega para la obtención de forraje (heno).

La variedad litológica que caracteriza a este subsector es responsable de la existencia de bruscos cambios en la vegetación debidos a los innumerables contactos existentes entre rocas silíceas (principalmente pizarras y esquistos) y rocas carbonatadas. Aunque en estos últimos casos los suelos presentan una mayor fertilidad y $\mathrm{pH}$ elevados, a menudo son muy poco profundos y pedregosos, lo que ha dificultado su aprovechamiento intensivo, a la vez que han servido de biotopo para el asentamiento de comunidades vegetales particulares. Precisamente, la flora que se localiza en estos afloramientos calizos dota a esta unidad de una peculiaridad biogeográfica muy marcada, pues gracias a ello se pueden encontrar en Galicia algunas especies como Campanula adsurgens, Inula montana, Rhamnus cathartica, $R$. legionensis, Santolina rosmarinifolia, etc., muchas de las cuales también están presentes en los afloramientos carbonatados del subsector BercianoValdeorrés. Aunque en menor medida, también la presencia de flora orófila en ambientes silíceos más elevados contribuye a individualizar estos territorios de los galaicointeriores y berciano-valdeorreses. Plantas como Genista obtusiramea, Saxifraga hirsuta, Sorbus aria, Sorbus aucuparia, Juniperus communis subsp. nana, Adenostyes hybrida o Valeriana pyrenaica pueden ser utilizadas con este carácter discriminante.

\section{Subsector Queixense (6a)}

Comprende las sierras y valles que conforman el denominado Macizo de Queixa o Manzaneda, también conocido como Macizo Central Ourensano, que se extienden entre los 700 y los $1.781 \mathrm{~m}$ de altitud, así como las tierras altas situadas entre A Mezquita, el Val de Verín y el límite con Portugal. Se trata de tierras interiores situadas a altitudes elevadas en las que se registra una oscilación térmica anual acusada que redunda en un bioclima de naturaleza oceánica, aunque con mayor continentalidad en su mitad oriental. Los termotipos son variables, desde el mesotemplado superior $(700-1.000 \mathrm{~m})$ hasta el orotemplado (> $1.700 \mathrm{~m})$, pasando por el supratemplado inferior $(1.000-1.300)$ y supratemplado superior $(1.300-$ $1.700 \mathrm{~m}$ ). Los ombrotipos oscilan entre el húmedo inferior y el ultrahiperhúmedo.
El relieve de esta unidad se caracteriza por la sucesión de niveles aplanados situados a diferentes altitudes entre los que se ha encajado la red fluvial de los principales rios que la recorren (Návea, Conso, Támega, Arnoia). La acción de los glaciares cuaternarios es responsable de la morfología que caracteriza las principales cumbres de estas sierras en las que son frecuentes elementos típicos de este modelado como circos, umbrales rocosos, morrenas, etc. Los tipos litológicos dominantes son las rocas graníticas y las metamórficas ácidas que, en general, originan suelos pobres en nutrientes y con un escaso desarrollo en las vertientes inclinadas y algo más profundos en las áreas llanas en las que, en algunos casos, se desarrollan suelos higroturbosos, especialmente en las áreas sometidas a una mayor pluviosidad.

La cubierta vegetal actual se caracteriza por el predominio de las superficies ocupadas por matorrales (xesteiras, toxeiras, uceiras, piornales) entre las que se intercalan áreas arboladas, principalmente "soutos" y, en menor medida, masas dominadas por Quercus robur y $Q$. pyrenaica, en las proximidades de los núcleos habitados. Otros enclaves en los que subsisten bosques autóctonos son las áreas de cabecera de los principales ríos, en donde se pueden encontrar bosques dominados por Betula pubescens, acebales y robledales con Quercus petraea y $Q$. $x$ rosacea. Los espacios agrícolas se componen fundamentalmente de huertos y parcelas de producción de patatas y maiz y de prados de siega en los fondos de valle. Las repoblaciones forestales más frecuentes se han realizado con Pinus sylvestris sobre antiguas áreas cubiertas por matorrales dominados por ericáceas.

Como se comentó con anterioridad, el efecto de la continentalidad climática favorece la presencia de algunos endemismos orófilos ibéricos, como Dianthus langeanus, Echinospartum ibericum, Genista obtusiramea o Campanula herminii, así como la de taxones endémicos de las montañas galaico-zamorano-leonesas (Festuca graniticola).

\section{Subsector Sanabrés (6b)}

Comprende las áreas montañosas del SE de Ourense que forman parte del Macizo de Trevinca-Sanabria. Se trata de una unidad que guarda una gran similitud con la anteriormente descrita, tanto en los aspectos bioclimáticos como en su relieve y litología. No obstante se observa un mayor efecto de la continentalidad climática, ya que se encuentra situada más al interior, así como la ausencia del termotipo mesotemplado y el predominio del supratemplado, mientras que el orotemplado alcanza aquí sus representaciones más extensas dentro del territorio gallego. En función de los valores bioclimáticos obtenidos en las estaciones del entorno, se estima que las cumbres situadas por encima de los $2.100 \mathrm{~m}$ podrían estar incluidas dentro del termotipo criorotemperado. Los ombrotipos presentes pertenecen a los tipos húmedos e hiperhúmedos.

Los sustratos dominantes son de tipo metamórfico ácido y granítico, aunque en las áreas situadas por encima de los $1.400 \mathrm{~m}$ de altitud son frecuentes los sedimentos cenozoicos, en su mayor parte derivados de la actividad 
glaciar desarrollada en estas montañas durante el Pleistoceno. Como en otras unidades descritas, los suelos derivados de los sustratos comentados son pobres en nutrientes y con escasa potencia, salvo en posiciones topográficas llanas en donde tienden a aparecer suelos más desarrollados 0 , si existe un exceso hídrico, se produce la formación de suelos de naturaleza turbosa.

El paisaje actual se caracteriza por el mosaico de matorrales ("xesteiras", "piornales", "uceiras"), fragmentos de masas arboladas autóctonas (abedulares, acebales, robledales, melojares), plantaciones forestales (Pinus sylvestris) y parcelas agrícolas dentro del piso supratemplado inferior, el dominio de formaciones arbustivas en el supratemplado superior y la intercalación de formaciones herbáceas (pastizales pioneros, cervunales, comunidades turfófilas), arbustivas y afloramientos rocosos en el orotemplado. Los bosques propios de este territorio se encuentran muy afectados por la actividad humana. Dentro de ellos se pueden reconocer principalmente "reboleiras", "carballeiras" de Quercus x rosacea, abedulares orófilos y alisedas y saucedas riparias. La abundancia de relieves aplanados y pequeñas cubetas, resultado de la actividad glaciar cuaternaria, unida a la elevada pluviometria que registran estas montañas, favorecen la existencia de una amplia representación de hábitats acuáticos (lagunas y charcas temporales) y de turberas.

La situación interior y la elevada altitud de estas montañas son factores que justifican la presencia en esta unidad de especies orófilas endémicas, algunas compartidas con otros subsectores del occidente orocantábrico, entre las que destacan por tener su área de distribución centrada en estas montañas Genista sanabrensis o Ranunculus parnassifolius subsp. cabrerensis.

Agradecimientos Los autores agradecen a Carlos Real la traducción del resúmen al inglés.

\section{Bibliografía}

Amigo, J. \& Romero, M.I. (1994): Vegetación atlántica bajo clima mediterráneo: un caso en el noroeste ibérico. Phytocoenologia, 22(4): 583-603.

Bellot, F. (1968): La vegetación de Galicia. Anal. Inst. A. J. Cavanilles XXIV: 3-306.

Bellot, F. (1978): El tapiz vegetal de la Península Ibérica. H. Blume Ediciones. Madrid. $421 \mathrm{pp}$.

Berastegi, A., Darquistade, A. \& García-Mijangos, I. (1997): Biogeografía de la España centro-septentrional. Itinera Geobot. 10: 149-182.

Braun-Blanquet, J. (1923): L'origine et le dévélopcment des flores dans le Massif Central de France. Aperçu sur les migrations des flores dans Europe sudoccidentale. Paris. Zurich: 1-282.

del Río González, S. (2005): El cambio climático y su influencia en la vegetación de Castilla y León (España). Itinera Geobot. (nueva Serie) 16. 533 pp.

Dupont, P. (1962): La flore atlantique europeenne.
Introduction a l'étude du secteur ibéro-atlantique. Documents pour les cartes des productions végétales. Série Europe-Atlantique. Vol. I. Faculté des Scientes. Toulouse. $414 \mathrm{pp}$.

Fraga, M.I. \& Reinoso, J. (1981): 4.2.2. A Vexetación. En: A. Pérez Alberti (Dir.): Xeografía de Galicia. Tomo I: O Medio: 128-158. Ed. Sálvora. Sada. A Coruña.

Frey, W. \& Lösch, R. (2004): Lehrbuch der Geobotanik. Pflanze und Vegetation in Raum und Zeit. 2. Auflage. Spektrum Akademischer Verlag. München.

García López, P., Luzurica, P., Rey Quiroga, P. \& Roa Medina, A. (1992): Informe botánico del Parque Natural del Lago de Sanabria y sus alrededores. Monografías de la Red de Espacios Naturales de Castilla y León. Dirección General del Medio Natural. Junta de Castilla y León. Valladolid. 143 $\mathrm{pp}$.

García Río, R. \& Navaro Andrés, F. (1994): Flora y vegetación cormofíticas de las comarcas zamoranas del Pan, Tera y Carballeda. Stvdia Botanica 12: 23-202.

Giménez de Azcárate, J. (1993a): Estudio fitosociológico de la vegetación de los afloramientos calizos de Galicia. Tesis Doctoral inéd. Facultade de Bioloxía. Universiade Santiago de Compostela. 310 pp.

Giménez de Azcárate, J. (1993b): La vegetación de la montaña caliza del oriente gallego. En: A. Pérez Alberti, L. Guitián Rivera \& P. Ramil Rego (Eds.): La evolución del paisaje en las montañas del entorno de los Caminos Jacobeos: 133-152. Consellería de Relacións Institucionais e Portavoz do Goberno. Xunta de Galicia. Santiago de Compostela.

Giménez de Azcárate Cornide \& Amigo Vázquez, J. (1996): Inventario da Flora vascular de afloramientos calíos de Galicia (Pteridophyta e Spermatophyta). Cadernos da Área de Ciencias Biolóxicas. Inventarios XII. Publicacións do Seminario de Estudos Galegos. Ediciós do Castro. Sada. A Coruña. 181 pp.

Gómez-Orellana, L. (2002): El último ciclo glaciarInterglaciar en el Litoral del NW Ibérico: dinámica climática y paisajística. Tesis Doctoral inédita. Escola Politécnica Superior de Lugo. Universidade de Santiago de Compostela. 356 pp.

Gómez-Orellana, L., Ramil-Rego, P. \& Muñoz Sobrino, C. (2007): The Würm in NW Iberia, a pollen record from Area Longa (Galicia). Quaternary Research, 67(3): 438-452

Guitián Rivera, L. (1995): Origen y evolución de la cubierta forestal de Galicia. Tese de Doutoramento inédita. Facultade de Xeografia e Historia. Universidade de Santiago de Compostela. $474 \mathrm{pp}$.

Huguet del Villar, E. (1927): Geobotánica. Sección XII. Ciencias Naturales, n 199-200. Colección Labor, Biblioteca de Iniciación Cultural. Ed. Labor. Barcelona. 339 pp.

Iglesias Iglesias, L. (1962): Xeografía fito-zoolóxica. En: R. Otero Pedrayo (Dir.): Historia de Galicia. Vol.I: IntroducciónPrimeira Parte: 247-254. 
Izco Sevillano, J. (1992): La vocación forestal de Galicia. En: Especies frondosas en la repoblación de Galicia: 45-73. Academia Galega de Ciencias. Servicio de Publicacións. Diputación Provincial de Lugo. Lugo.

Izco, J. (1987): Galicia. En: M. Peinado Lorca \& S. RivasMartínez (Eds.): La vegetación de España: 383-418. Colección Aula Abierta $n^{\circ} 3$. Servicio de Publicaciones. Universidad de Alcalá. Madrid.

Izco, J. (1989): El Río Miño: barrera y camino en la migración de las plantas. En: Conferencias sobre el Río Miño: 85-97. Caixa Ourense. Editorial Evergráficas. León.

Izco, J. (1996): Fitoxeografía: orixe e distribución da flora galega. En: F. Rodríguez Iglesias (Ed.): Proyecto Galicia. Tomo XVII: 204-227. Hércules Ediciones. A Coruña.

Izco, J. (2001): La flora y la vegetación. En: A. Precedo Ledo \& Sancho Comíns (Dir.): Atlas de Galicia. Tomo I: Medio Natural: 219-257. Sociedade para o Desenvolvemento Comarcal de Galicia.

Izco, J. \& Sánchez, J.M. (1995): Revisión crítica del listado de flora endémica gallega. Bot. Macaronesica 21: 75-84.

Izco, J. Amigo, J. \& Guitián, J. (1985): El papel de la topografía en la transición Eurosiberiano-Mediterranea en el extremo noroeste ibérico. Colloques Phytosociologiques, 13: $344-359$.

Loidi Arregui J., Biurrun Galarraga, I. \& Herrera Gallástegui, M. (1997a): La vegetación del centro-norte de España. Itinera Geobot., 9, 161-618.

Lacoste, A. \& Salanon, R. (1973): Biogeografía. Oikos-Tau s.a. Ediciones. Barcelona. 271 pp.

Llamas García, F. (1984): Flora y vegetación de la Maragatería (León). Institución Fray Bernardino de Sahagún. C.S.I.C. Excma. Diputación Provincial de León. León. 273 pp.

Mayer, H. (1984): Wälder Europas. Gustav Fischer Verlag. Stuttgart.

Merino, B. (1905-1909): Flora descriptiva é ilustrada de Galicia. Tomos I, II y III. Tipografía Galaica. Santiago de Compostela.

Meusel, H., Jäger, E. \& Weinert, E. (1965): Vergleichende Chorologie der Zentraleuropäischen Flora. Gustav Fischer Verlag. Jena.

Moreno Sáiz, J.C. \& Sáinz de Ollero, H. (1992): Atlas corológico de las monocotiledóneas endémicas de la Península Ibérica e Islas Baleares. Colección Técnica. I.C.O.N.A. Ministerio de Agricultura, Pesca y Alimentación. Madrid. $354 \mathrm{pp}$.

Muñoz Sobrino, C. (2001): Cambio climático y dinámica del paisaje en las montañas del noroeste de la Península Ibérica. Tesis Doctoral inédita. Escola Politécnica Superior de Lugo. Universidade de Santiago de Compostela. 311 pp.

Muñoz Sobrino, C., Ramil Rego, P., \& Rodríguez Guitián, M.A. (1997): Upland vegetation in the north-west Iberian peninsula after the last glaciation: forest history and deforestation dynamics. Vegetation History and Archaeobotany, 6: 215-233.

Muñoz Sobrino, C., Ramil-Rego, P. \& Rodríguez Guitián, M.A. (2001): Vegetation in the mountains of nothwest Iberia during the last glacial-interglacial transition. Vegetation History and Archaeobotany, 10: 7-21.

Ortiz, S. \& Rodríguez-Oubiña, J. (1993): Synopsis of the rupicolous vegetation of Galicia (North-western Iberian Peninsula). Folia Geobot. Phytotax. Praha, 28: 15-49.

Ozenda, P. (1994): Végétation du Continent Européen. Delachaux \& Niestlé, S.A. Lausanne-Paris. 270 pp.

Pérez Alberti, P. (1982): Climatoloxía. En: A. Pérez Alberti (Dir.): Xeografía de Galicia. Tomo I: O Medio: 71-98. Ed. Sálvora. A Coruña.

Planellas Giralt, J. (1852): Ensayo de una flora fanerogámica gallega. Ampliada con indicaciones acerca los usos médicos de las especies que se describen. Imprenta y litografía de D. Juán Rey Romero. Santiago de Compostela. $452 \mathrm{pp}$.

Polunin, O. \& Walters, M. (1989): Guía de la Vegetación de Europa. Ed. Omega. Barcelona. 236 pp.

Pulgar Sañudo, Í. (1999): La vegetación de la Baixa Limia y sierras del entorno. Tesis doctoral inédita. Facultade de Farmacia. Universidade de Santiago de Compostela. 275 pp.

Pulgar Sañudo, Í. (2003): Guía da flora do Parque Natural Baixa Limia-Serra do Xurés. $1^{a}$ Edición. Consellería de Medio Ambiente. Xunta de Galicia. Santiago de Compostela. 70 pp.

Pulgar Sañudo, Í. (2004a): Guía da flora do Parque Natural Baixa Limia-Serra do Xurés. $2^{a}$ Edición. Consellería de Medio Ambiente. Xunta de Galicia. Santiago de Compostela. 92 pp.

Pulgar Sañudo, Í. (2004b): Guía da flora do Parque Natural Montes de Invernadeiro. Consellería de Medio Ambiente. Xunta de Galicia. Santiago de Compostela. 84 pp.

Pulgar Sañudo, Í., Amigo Vázquez, J. \& Giménez de Azcárate, J. (2007): Guía da flora do Parque Natural Fragas do Eume. Consellería de Medio Ambiente e Desenvolvemento Sostible. Xunta de Galicia. Santiago de Compostela. 108 pp.

Ramil-Rego, P. (1992) La vegetación cuaternaria de las Sierras Septentrionales de Lugo a través del análisis polínico. Tese de Doutoramento inédita. Universidade de Santiago. 356 pp.

Ramil-Rego, P., Muñoz-Sobrino, C., Rodríguez Guitián, M.A. \& Gómez-Orellana, L. (1998a): Differences in the vegetation of the North Iberian Peninsula during the last 16,000 years. Plant Ecology , 138: 41-62.

Ramil-Rego, P., Rodríguez Guitián, M.A. \& Muñoz-Sobrino, C. (1998b): Sclerophyllous vegetation dynamics in the north of the Iberian peninsula during the last 16.000 years. Global Ecology and Biogeography Letters, 7: 335-351. 
Ramil Rego, P.; Muñoz Sobrino, C. \& Gómez Orellana, L. (2002): Historia do Ecosistema Terrestre. En: F. Rodríquez Iglesias, (Ed.): Galicia. Natureza. Tomo XLIII: 475-512. Hércules de Ediciones, S.A. A Coruña.

Rivas-Martínez, S. (1973): Avance sobre una síntesis corológica de la Península lbérica, Baleares y Canarias. Anal. Inst. Bot. Cavanilles 30: 69-89.

Rivas-Martínez, S., Arnáiz, C., Barreno, E. \& Crespo, A. (1977): Apuntes sobre las provincias corológicas de la Península Ibérica e Islas Canartias. Opuscula Botanica Pharmaciae Complutensis 1: 1-48.

Rivas-Martínez, S. (1979): Brezales y jarales de Europa occidental (Revisión fitosociológica de las clases CallunoUlicetea y Cisto-Lavanduletea). Lazaroa 1: 5-119.

Rivas-Martínez, S. (1982): Series de vegetación de la Región Eurosibeirana de la Península Ibérica. Lazaroa 4: 155-166.

Rivas-Martínez, S. (1985): Biogeografía y Vegetación. Discurso de ingreso como Académico de Número. Real Academia de Ciencias Exactas, Físicas y Naturales. Madrid. $86 \mathrm{pp}$.

Rivas Martínez, S. (1987): Memoria del Mapa de Series de Vegetación de España. Serie Técnica nº 1: 9-208. I.C.O.N.A. Madrid.

Rivas-Martínez, S. (2001): Bioclimatic Map of Europe. Bioclimates. Servicio Cartográfico. Universidad de León. León.

Rivas-Martínez, S. (2007): Mapa de series, geoseries y geopermaseries de vegetación de España (Memoria del Mapa de Vegetación Potencial de España. Parte 1). Itinera Geobot. (Nueva Serie) 17. 436 pp.

Rivas-Martínez, S. \& Penas, A. (1996): Biogeographic Map of Europe. Servicio Cartográfico. Universidad de León.

Rivas-Martínez, S., Arnáiz, C., Barreno, E. \& Crespo, A . (1977): Apuntes sobre las provincias corológicas de la Península Ibérica. Op. Bot. Pharm. Comp. 1: 1-48.

Rivas Martínez S., Díaz González, T.E., Fernández Prieto, J.A., Loidi, J. \& Penas, A. (1984): La vegetación de la alta montaña cantábrica: los Picos de Europa. Ediciones Leonesas. León. 295 pp.

Rivas-Martínez, S., Díaz González, T.E., FernándezGonzález, F., Izco, J., Loidi, J., Lousâ, M. \& Penas, A. (2002): Addenda to the syntaxonomical checklist of 2001. Itinera Geobot., 15, 2 vol.
Rodríguez Guitián, M.A. \& Ramil Rego. P. (1995): Distribución de especies y Cartografía. En: C. Rodríguez Dacal: Árboles y arboledas de Galicia. Documentos Educativo-Culturales del Jardín Botánico-Artístico de Padrón, $n^{\circ} 1.32$ pp. Concello de Padrón.

Rodríguez Guitián, M.A., Real, C., Amigo, J. \& Romero, R. (2003): The Galician-Asturian beechwoods (Saxifrago spathularidis-Fagetum sylvaticae): description, ecology and differentiation from other Cantabrian woodland types. Acta Bot. Gallica, 200: 15-36.

Rodríguez Guitián, M.A. \& Ramil Rego. P. (2007): Revisión de las clasificaciones climáticas aplicadas al territorio gallego desde una perspectiva biogeográfica. Recursos Rurais 1(3): 31-53.

Romero Buján, M.I. (1993): La vegetación del valle del Río Cabe (Terra de Lemos, Lugo). Tesis Doctoral inédita. Facultade de Bioloxía. Universidade de Santiago de Compostela. 279 pp.

Romero Buján, M.I. (2008): Catálogo da Flora de Galicia. Monografías do IBADER, $\mathrm{n}^{\circ} 1.172 \mathrm{pp}$.

Sáinz Ollero, H. \& Hernández Bermejo, J.E. (1981): Síntesis corológica de las dicotiledónesa endémicas de la Península Ibérica e Islas Baleares. Monografías del I.N.I.A. $n^{\circ} 31$. Ministerio de Agricultura. Madrid. 111 pp.

Sáinz Ollero, H. \& Hernández Bermejo, J.E. (1985): Sectorización fitogeográfica de la Península Ibérica e Islas Baleares: la contribución de su endemoflora como criterio de semejanza. Candollea 40: 485-508.

Salvo Tierra, E. (1990): Guía de helechos de la Península Ibérica y Baleares. Ed. Pirámide, S.A. Madrid. 377 pp.

Silva-Pando, F.J. \& Rigueiro Rodríguez, A. (1992): Guía das árbores e bosques de Galicia. Ed. Galaxia. Vigo. 294 pp.

Takhtajan, A. (1988): Floristic regions of the World. University of California. $522 \mathrm{pp}$.

XUNTA (1992): Plan Forestal de Galicia. Dirección Xeral de Montes e Medio Ambiente Natural. Consellería de Agricultura, Gandería e Montes. Santiago de Compostela.

Vázquez, A. \& Díaz González, T.E. (2005): Parque Nacional de los Picos de Europa. Naturaleza y biodiversidad en tierra de lobos. Ed. Nobel. Oviedo. 174 pp. 